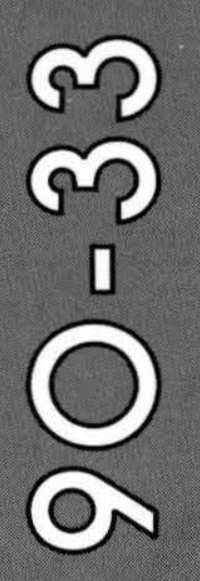

\title{
Highway Snow Control Research in Japan
}

Kazuhiko Itagaki 
For conversion of SI metric units to U.S./British customary units of measurement consult ASTM Standard E380, Metric Practice Guide, published by the American Society for Testing and Materials, 1916 Race St., Philadelphia, Pa. 19103.

\section{USING THIS REPORT}

More than 100 reports, preprints, and reviews pertinent to highway snow control have been collected and included in this report. All but a couple of the reports are in Japanese. Appendix A gives the detailed source information, compiled and arranged in the order the articles are discussed in the text. The in-text citations include a code number (for example, [D5]) that keys them to the information in Appendix A.

Appendix B contains an alphabetical list of applicable keywords.

Appendix $C$ includes English summaries of some of the reports; these are marked with an asterisk (*) both in citations in the main text and in Appendix A. These summaries have been edited for inclusion in this report.

Appendix D presents detailed information about various snow-removal equipment that has been and is currently in use in Japan. 


\section{Special Report 90-33}

\section{Highway Snow Control Research in Japan}

Kazuhiko Itagaki 


\section{PREFACE}

This report was prepared by Dr. Kazuhiko Itagaki, Research Physicist, Snow and Ice Branch, Research Division of the U.S. Army Cold Regions Research and Engineering Laboratory, Hanover, N. H.

The author thanks D. Minsk and B. N. Lord for their technical review of this report. Funding was provided under DA Project No. 4A161102AT24, Research in Snow, Ice, and Frozen Ground; Task SS, Staff Support; Work Unit 006, Physical Properties of Snow and Ice.

The contents of this report are not to be used for advertising or promotional purposes. Citation of brand names does not consititute an official endorsement or approval of the use of such commercial products. 


\section{CONTENTS}

(1)

Japanese snow-control research ..............................................................................................

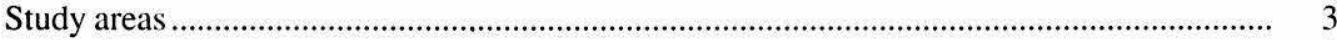

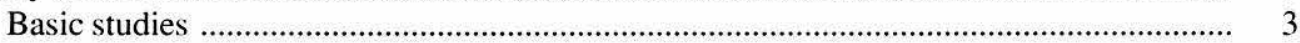

Snow-removal equipment ……………………….................................................... 5

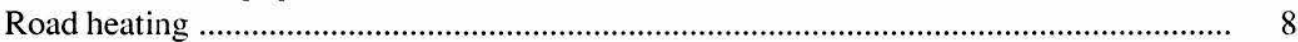

Chemicals and snow melters ........................................................................................ 11

Snow-protection facilities ....................................................................................... 12

Trafficability, friction, and adhesion ........................................................................ 15

Social and economic impact ..................................................................................... 15

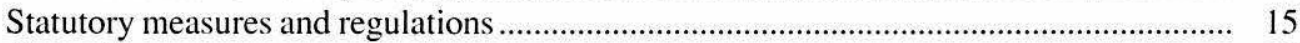

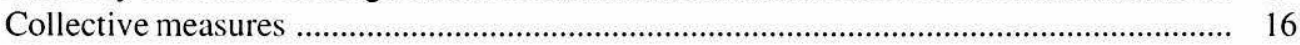

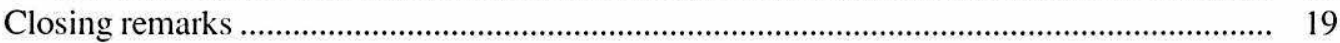

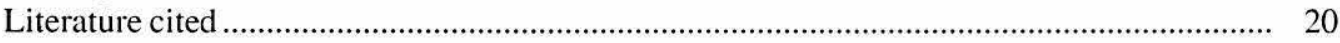

Appendix A: Detailed reference information ....................................................................... 25

Appendix B: List of keywords .................................................................................... 31

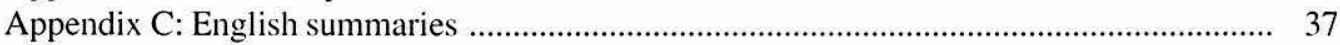

Appendix D: Snow-removal equipment specifications ……….......................................... 57

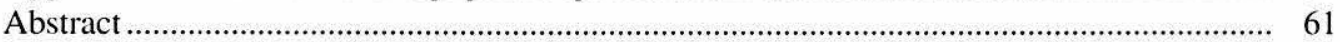

\section{ILLUSTRATIONS}

Figure

1. Scenes from the deep snow area of Japan ....................................................................... 2

2. Rotary snowblower augers ........................................................................................ 4

3. Avalanche impact facility at the Shinjo Branch of the National Research Center for Disaster Prevention ............................................................................................. 5

4. Reverse-action snowplow blade ............................................................................. 6

5. Cable cornice cutter ……………................................................................................. 6

6. Saw-type cornice cutter mounted on a rotary snowblower for single-pass operation.... 7

7. Wavy-groove cutter mounted to the rear of a motor grader .......................................... 7

8. Snowplow shutter attachment ......................................................................................... 8

9. Steel sled and hard rubber casters replace the slider....................................................... 8

10. Sliding MacLeigh wing to clear obstacles .................................................................... 9

11. Snow-plow fins ........................................................................................................... 9

12. Vertical-axis snow auger for two-stage rotary snowblower ........................................... 9

13. Over-sized garden soak hose is used as a temporary water spray snow melter ............. $\quad 10$

14. Snow discharge drains frequently have no cover ........................................................ $\quad 10$

15. Pneumatic snow conveyer being tested ................................................................. 11

16. Snow shelter protecting a highway .............................................................................. 12

17. Avalance shed system and avalanche fences protect the highway ............................... 13

18. The tips of the snow fence are bent toward the prevailing wind direction .................... 13

19. Test of the banana-peel-shaped snow fence ............................................................ 14

20. Snow fence designs ................................................................................................. 14

21. Infrared snow depth gauge ..................................................................................... 16

22. Electric road sign advising motorists of construction in the tunnel ahead .................... 17

23. Fliers advertising small snow melters .................................................................... 18

24. Noise barriers along the highway near Tokyo ............................................................ 19 


\title{
Highway Snow Control Research in Japan
}

\author{
KAZUHIKO ITAGAKI
}

\section{INTRODUCTION}

Although no larger in area than the state of California, Japan spans $22^{\circ}$ of latitude, from $24^{\circ}$ to $46^{\circ} \mathrm{N}$. This is almost the same as from Key West, Florida, to Maine's border with Canada. Winter snowfall is extensive, especially on the Japan Sea coast of Honshu Island, due to cold seasonal winds from Siberia that pick up moisture from the warm Japan Sea and dump it on north-facing mountainsides. More than $5 \mathrm{~m}(15 \mathrm{ft})$ of snow accumulation is often recorded in many highly populated areas.

Before the end of World War II, the railway was the only major mode of transportation. Most of the population living away from the railroads stocked up on necessary commodities before the snow season and simply stayed within their houses, not unlike the hibernation of animals. One of the most important wintertime chores was shoveling snow from roofs to keep houses from collapsing. Since there was no room to dispose of the snow, it was piled up around the houses and along the road. Deep eaves kept walkways clear, but people had to climb up to street level by cutting steps in the snow. Frequently, second-floor windows served as convenient exits to the street.

In one of the stories of Baron von Munchhausen (Abenteuer des Freiherrn von Munch hausen by August Burger), he was travelling in the Russian snow fields. He tied his horse to a stake sticking out of the snow and bivouacked. After spending a very warm night, he found his horse hanging from the tip of a church tower the next morning. With only a slight exaggeration of the time span and magnitude, such a story can reflect the real life of the people living in the coastal towns on the Japan Sea, as shown in Figure 1. Note that power and telephone lines are under the snow, and the people in Figures la and c are working on the roof, not on the ground.

Such deep snow and the narrow streets of the old towns cause particular problems in removing snow from roads and houses. Riverbeds are the only spaces available for snow disposal. Most other open fields are already committed in this small, densely populated country. Mechanical transportation of snow is slow and expensive. Large, heavy equipment cannot maneuver in tight spaces and, if the road allows only one-way traffic, little can be achieved by heavy equipment.

Fortunately, most of these areas are relatively warm (the coldest monthly mean temperature is usually above freezing) and warm, clear water is abundant. Dumping the snow in irrigation ditches, where water is plentiful and unnecessary in winter, is the most effective method of disposal. Another unique method was spraying warm groundwater on the road to melt the snow and keep road surfaces snow-free; it became the most popular method of snow removal until the groundwater level dropped due to overpumping. The most recent development in road snow removal is to use the warm groundwater to heat the road surface through a network of pipes and then return the used water to the ground. Attempts have also been made to store solar heat underground in summer to improve the heat supply. In addition, heat pipes are used to pump geothermal heat from underground.

Conditions on the northern island of Hokkaido are somewhat similar to those in New England, for the climate is colder and the roads are wider than in the old Honshu island towns, providing more space for snow disposal. More mechanized methods, similar to those used in the U.S., have been adopted there. A major problem in this area, however, is the loss of skilled snow-removal-equipment operators. Since the job is so physically demanding, the working life span of skilled operators is short. To alleviate such problems, computer-controlled automation has been introduced.

\section{JAPANESE SNOW-CONTROL RESEARCH}

The subjects covered by Japanese research into snow and ice control range from basic studies of snow mechanics, engineering design, and field-operating pro- 
cedures to regulations and discussions of the social impact of snow and control of accumulated snow on the ground, roads, roofs of residences and public buildings, and railroads. Some topics were included in this report because they are closely related to research on road snow removal.

In 1832, the feudal Lord Toshitsura Doi published sketches of 86 snow crystals. This is probably the first documented scientific study of snow in Japan. About 100 years later, Nakaya started his famous studies of snow crystals. Aside from these pure scientific works, many efforts have been made to ease the hardship caused by heavy snows. For instance, a snow discharge drain is one of the most effective methods for disposing of snow in warmer areas that have an abundant supply of water, but the inventor of the technique is unknown.

Extensive use of highway transportation began in Japan after World War II. As the volume of traffic increased, snow removal became more important. Initially, shoveling by hand and primitive snowplow were the main snow-removal forces. Around 1950 more powerful snow-removal equipment was introduced and studies of snow mechanics, including visco-elastic properties and impact fracture of snow began. Purely scientific studies of snow and ice have continued since then; most are published in Low-Temperature Science and Seppyo (Journal of the Japanese Society of Snow and Ice).

More engineering-oriented reports are scattered in a wide range of journals and internal reports; some of them are difficult to access or are unknown to outsiders. A considerable number of titles have been compiled in Research on Snow and Ice, edited and published by the Japanese Society of Snow and Ice. A glimpse into recent developments can be observed in the preprints of the annual meetings of the Japanese Society of Snow and Ice. Many of these are reviewed in this report. Recently, the journal Snow and Roads started publication. The most recent issue has been included in this review.

General descriptions of the fundamental properties of snow, planning of snow-removal operations and administration, as well as descriptions of equipment, procedures, regulations, and laws are given in the $\mathrm{New}$ Road Snow-Removal Handbook (Japan Const. Mech. Assn. 1981 [B1]). The history of the development of snow-removal equipment in Japan is given in detail in Evolution of Snow-Removal Equipment (Hokkaido Devt. Bureau 1982 [B2]). Both books were very useful in writing this report.

Efforts have been made to collect more publications, and this report will be supplemented if demand justifies further effort.

Most of the reports reviewed here are written completely in Japanese. Foreign names were written in
Japanese phonetic symbols (katakana) and usually no English spelling was given. To translate back into English, this author had to guess at the spelling, but was not able to confirm the spelling of a few names, so question marks have been placed by them.

\section{STUDY AREAS}

Japanese studies on snow and ice control on highways cover a wide range. They have been grouped into the following categories:

1. Basic studies

2. Snow-removal equipment

3. Road heating

4. Chemicals and snow melters

5. Snow-protection facilities

6. Trafficability, friction, and adhesion

7. Sociological and economic impact

8 . Statutory measures and regulations

9. Collective measures

\section{Basic studies}

Basic studies include the classification of snow on the road surface and the basics of highway design, mechanical snow removal, snowblower and snowplow design, and snow control. Some other areas, including model snowdrift studies, are included in the section on snow protection facilities.

The most fundamental studies are the classification of snow and ice on road surfaces (Kinosita and Akitaya $1969[\mathrm{~A} 1 \%]$, Kinosita et al. $1970[\mathrm{~A} 2 \%])$. Without a proper method of description, snow discussed in one report can be a totally different material in another. Although the classifications given in these reports are not complete, they do provide a decent starting point.

In snow mechanics studies, a wide range of effects of loading rates on fracture and flow behavior have been reported. Kinosita's studies on the breakdown of snow by impulsive force date back to 1955 [A3*], 1956 [A4*], and 1957 [A5\%]. He extended his study to deformation rates and types (1957b [A6*], 1958 [A7*], $1960 \mathrm{a}[\mathrm{A} 8 \%])$, the hardness of snow (1960b [A $9 *])$, and the penetration of a cone into snow (1965 [A 10\%]). Kinosita's studies provided the basis for further studies on the drag of a body moving through snow (Miyairi et al. $1966\left[\mathrm{~A} 11^{*}\right]$ ), plastic wave propagation (Sato and Wakahama 1976[A 12*]), the compaction properties of wet snow (Muro 1978 [A13*]), high-speed compression of snow (Sato and Wakahama 1980a [A14]), snow impact force (Kawada et al. 1980 [A15]), and the strength (Watanabe 1981 [A16]) and hardness (Izumi and Akitaya 1982 [A17]) of wet snow.

More engineering-oriented studies include theoretical studies of snow removal by a plow (Yosida 1974 

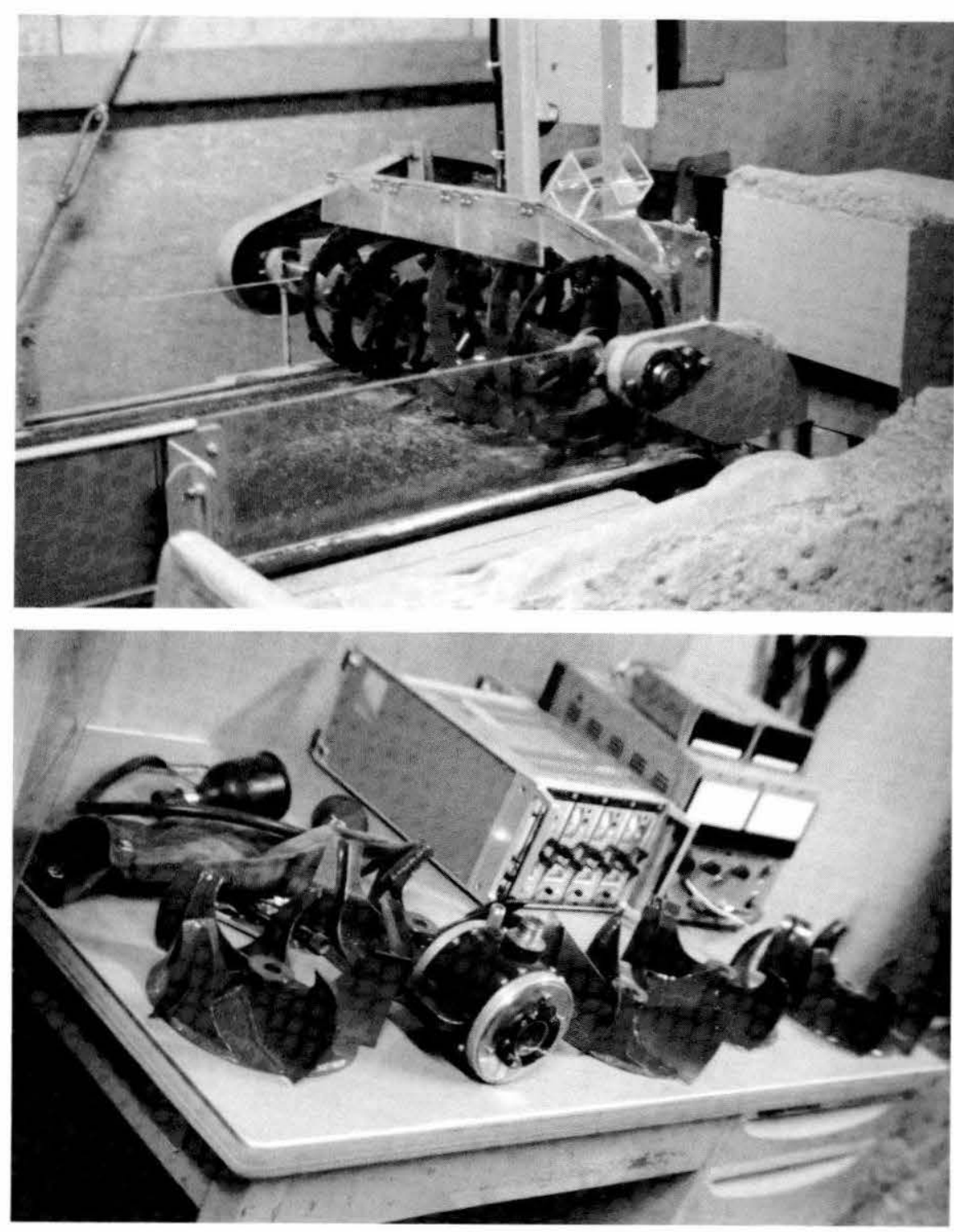

a. Model auger is used to study operation of a rotary snowblower.

\section{b. Various configurations of model rotors to be tested.}

Figure 2. Rotary snowblower augers.

[A18*], 1975 [A 19]) and shear strength and vane shear strength studies (Kuriyamaet al. 1981 [A20], Kuriyama 1982 [A21], and Igarashi 1982 [A22]). A series of studies that provide a design base for rotary snowblowers are by Shimoda and Sato (1969 [A23*]), Kuriyama and Shibuya on power requirements (1978 [A24*]), Kuriyama et al. (1980 [A25]) on snow cutting resistance, and Nohara et al. (1982 [A26]) and Kuriyama $(1984[A 27 *])$ on the shear strength of snow. The author observed tests using various configurations of model augers and blower blades, as shown in Figure 2, at the Construction Equipment Development and Maintenance Office of the Hokkaido Development Bureau. The test results are not yet available.
Other areas of basic study include the adhesive shear strength of ice to road surfaces (Takeuchi and Kamada 1973 [A28*]), rolling resistance on unpacked snow (Kuriyama 1980 [A29]), the velocity of crack propagation in ice (Sato and Wakahama 1980b [A30]), and the nature of compacted snow on road surfaces (Isobe et al. $1981[$ A31]).

Avalanches are one of the major causes of disaster in the hilly, deep-snow-covered areas of Japan. Many field measurements, observations, and statistical and theoretical analyses have been published, but only recently have experimental facilities been built to study avalanches. One is an outdoor facility with a glass-bottomed chute $1 \times 20 \mathrm{~m}$ inclined 30 degrees (Fig. 3[top]). 
Figure 3. Avalanche impact fa-

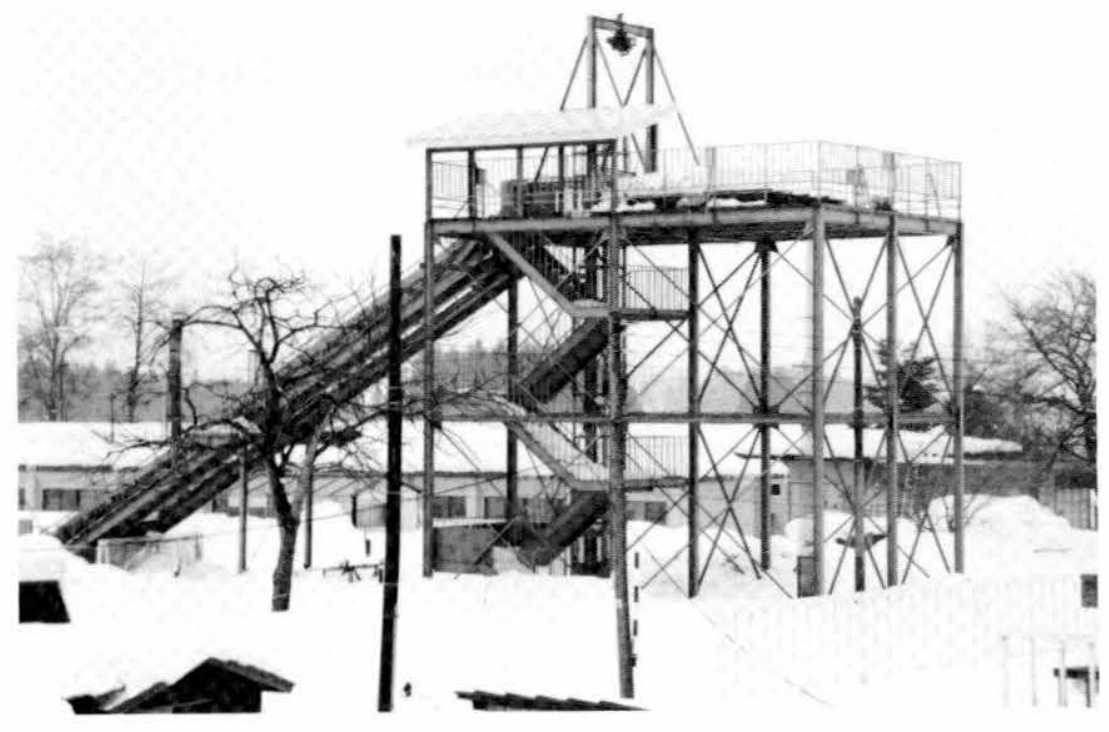
cility at the Shinjo Branch of the National Research Center for Disaster Prevention.

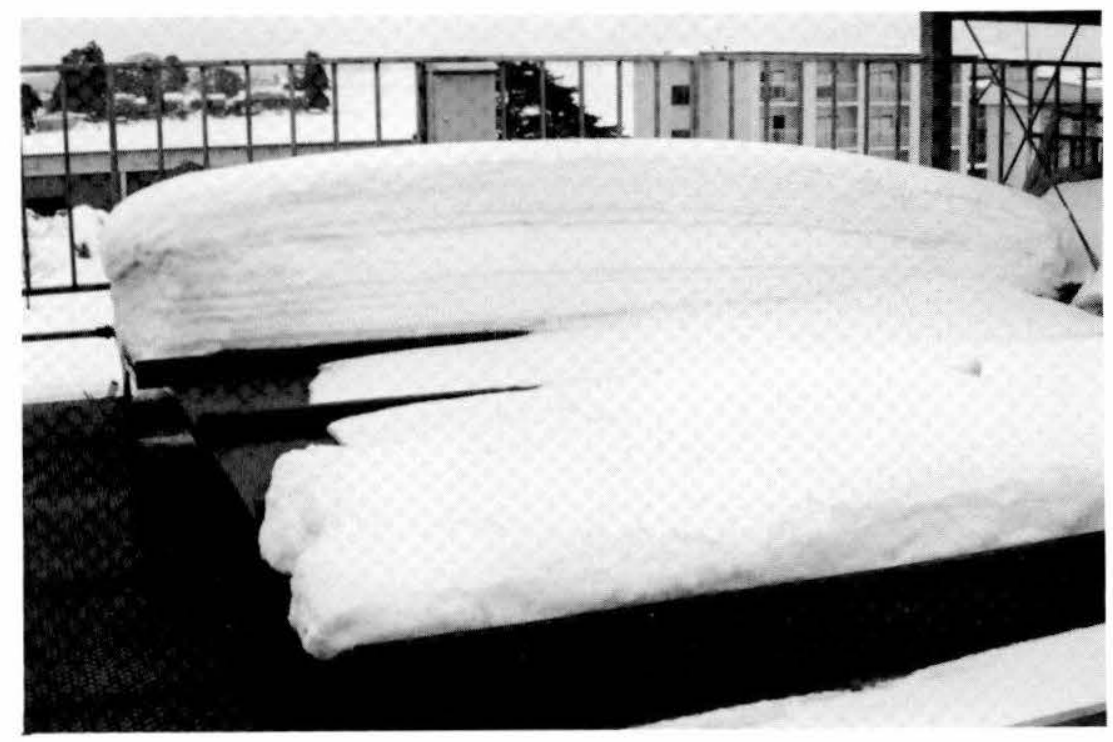

The snow accumulates naturally on a pallet (Fig. 3 [bottom]) and is then slid down the chute to collide with an instrumented pile or wall placed at the bottom. Another facility studies the physical processes of the two-phase flow of a snow-air mixture. Both facilities have started to produce results.

\section{Snow-removal equipment}

The basic snow-removal equipment that is used in Japan, such as snowplows and snowblowers, are generally similar to those in the U.S. The main fleet of 7-ton dump truck (27,000 lb GVW)-based snowplows and 10-ton dump truck (37,000 lb GVW)-based snowplows are used on open, wide rural highways. In Hokkaido, where the climate is colder and the roads are wider than on Honshu, more snowplows (displacement plows) are used than rotary snowblowers. On Honshu, where heavy wet snow dominates and the roads are generally narrower, greater use of rotary blowers is seen. Bulldozers, wheeled dozers, and motor graders are generally slow but they are suited to urban use and the narrow winding roads of Honshu. Specifications and operational procedures are detailed in the New Road Snow-Removal Handbook (Japan Const. Mech. Assn. 1981 [B1]). Part of the specifications are reproduced in Appendix D. Most of the following descriptions of the equipment (except where noted) are found in Evolution of SnowRemoval Equipment (Hokkaido Devt. Bureau 1982 [B2]).

A shortage of skilled operators has prompted introduction of computer-controlled equipment. The blade angle of snowplows and the power distribution in rotary snowblowers are the main areas of computer control. 


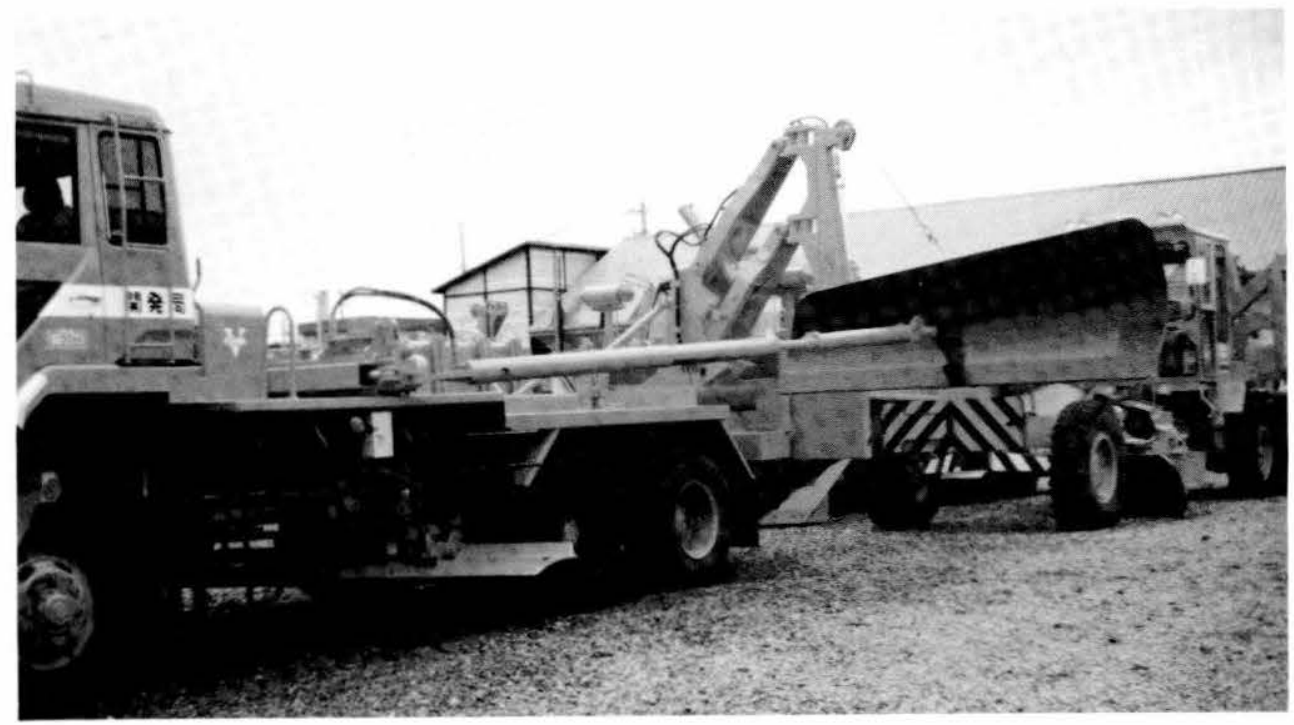

Figure 4. Reverse-action (MacLeigh) snowplow blade.

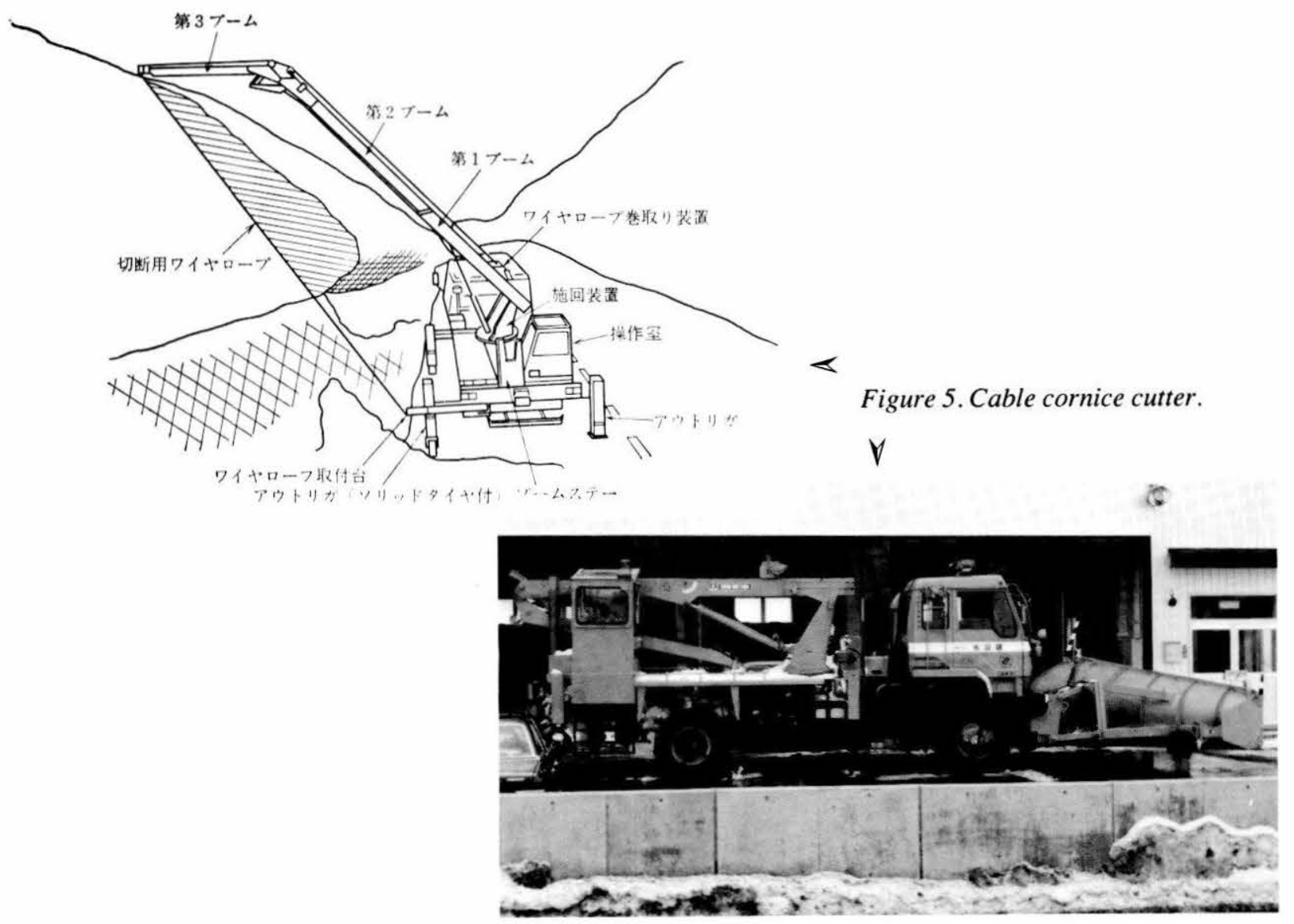

The operation speed and feed rate of rotary snowblowers is controlled by computer so operators just set the distance of throw and drive the equipment. An attempt to improve visibility for operators has led to the use of cab-over types of vehicles.

A variety of attachments or specially designed equipment to overcome problems associated with snow removal have been developed or are under development. For small-scale operations, for example, adapters to convert farm tractors into rotary snowblowers have been developed (Sakai et al. 1982 [B3]), and Nohara (1983 [B4]) examined their operational characteristics. Snow-removal operations in tight spots using rotary snowblowers are frequently encountered in the towns of 

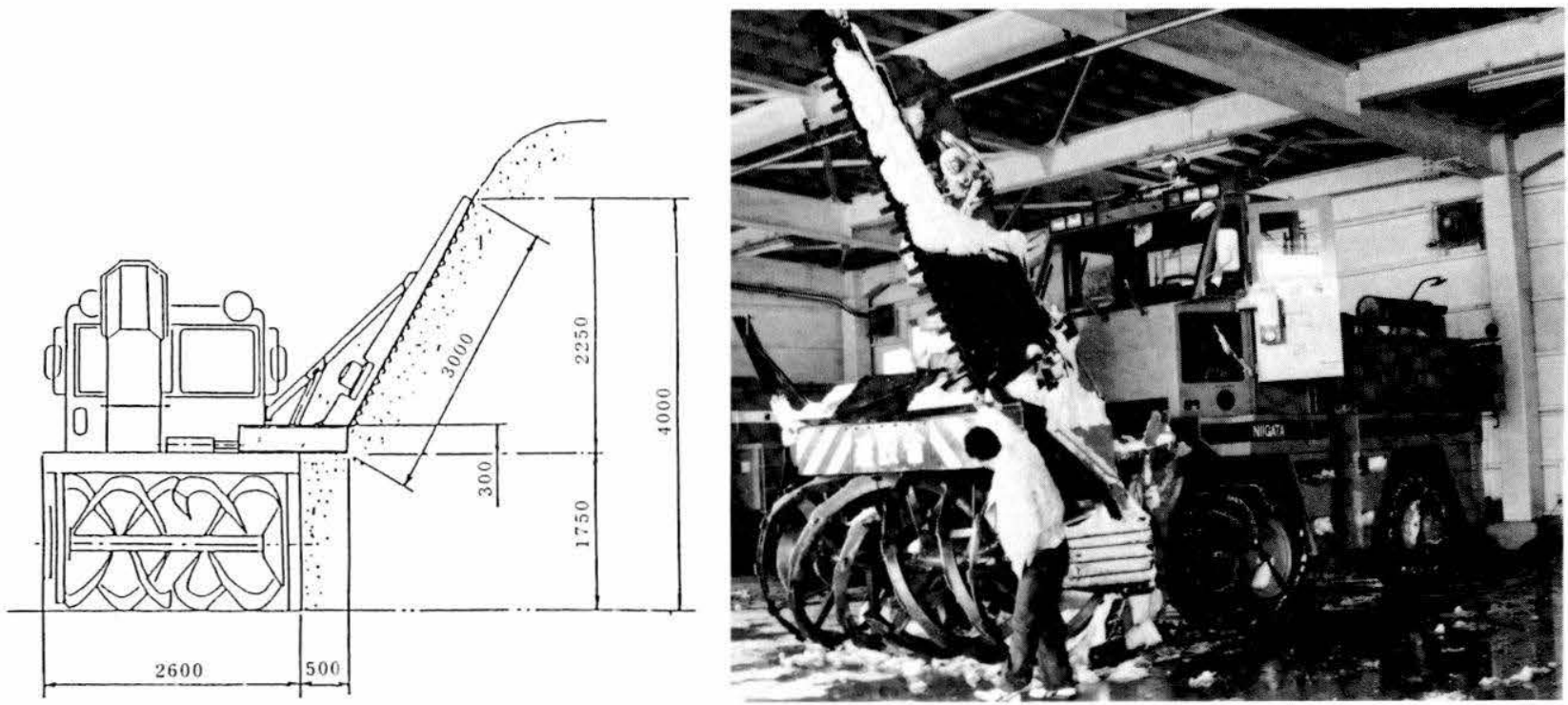

Figure 6. Saw-type cornice cutter mounted on a rotary snowblower for single-pass operation.

Honshu Island. Accurate control of the snow discharged from the blower is important to avoid damage from the thrown snow. To improve visibility of where the snow lands, an additional operator cab that can be raised or moved sideways was developed (Sakai and Takahashi 1983 [B5]). Another solution for snow removal from tight spots is a side-sliding rotary snowblower unit that was developed to reach areas that were difficult for fixed snowblowers (Haga 1984 [B6]).

Snow control along sidewalks draws a lot of attention since many people depend on public transportation in Japan and sidewalks are used to reach their final destinations. When a snowplow clears soft snow from sidewalks, the unplowed snow tends to fall back onto the sidewalk, reducing the passable width. To prevent this, a small attachment for mounting on a snowplow blade was developed (Tohoku Dist. Const. Bureau 1982 [B7]). A small wing is attached to the end of the blade and compresses the snow sideways to solidify it and prevent it from falling. Various equipments developed to remove snow from sidewalks are evaluated in Yorioka and Iwasaki (1983 [B8]).

In an area with very heavy snow accumulation, snowbanks quickly develop from snow-removal operations, and their control can be a big problem. In an attempt to cut snowbanks and remove fallen snow in one pass, a snowbank cutter attachment was developed (Inoue 1983 [B10]). It was mounted ahead of the snowblower so that fallen snow can be blown away in one pass. Due to repeated plowing in heavy snow accumulation areas, snowbanks grow rapidly and eventually there is no more room for a plow to push the snow into. Under such conditions, a snowplow with a side wing mounted in the reverse direction (Fig. 4) is used to plow the snow back onto the road, where it is removed by a rotary snowblower. In deeperopen cuts, the slope of the snowbank becomes too steep and a cornice is formed that becomes unstable after several plowings. Special equipment has been developed to cut the cornice with a taut wire or a saw (Fig. 5 and 6) (Hokkaido Devt. Bureau 1982 [B2], Iwamoto and Inoue 1985 [B11].

On heavily trafficked roads in urban areas, snow is frequently heavily compacted and very hard, reducing traction to a dangerous level. To restore traction, various equipments have been developed, including a vibrating comb-shaped cutter to make a wavy grooved pattern on the road snow surface (Sakai et al. 1982 [B9]) as shown in Figure 7.

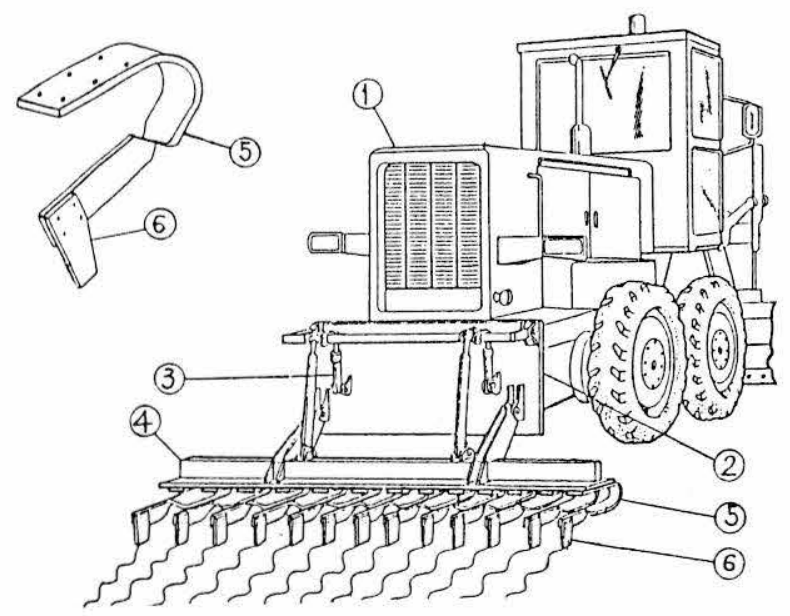

Figure 7. Wavy-groove cutter mounted to the rear of a motor grader. 


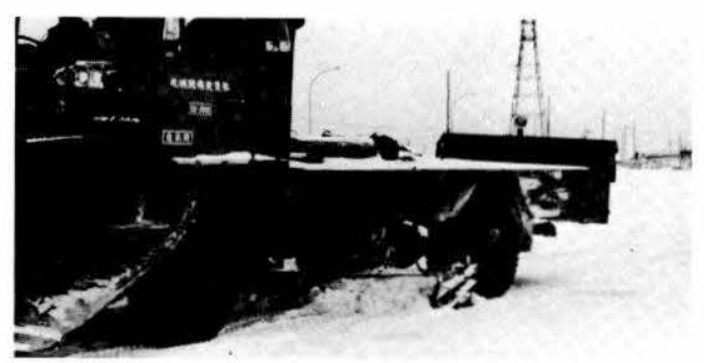

a. A movable shutter attachment designed for urban use keeps snow from spilling from the end of the blade.

Figure 8. Snowplow shutter attachment.

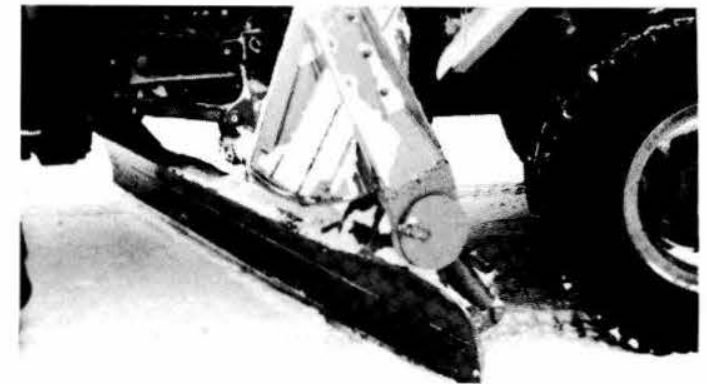

b. The shutter is raised for plowing large areas.

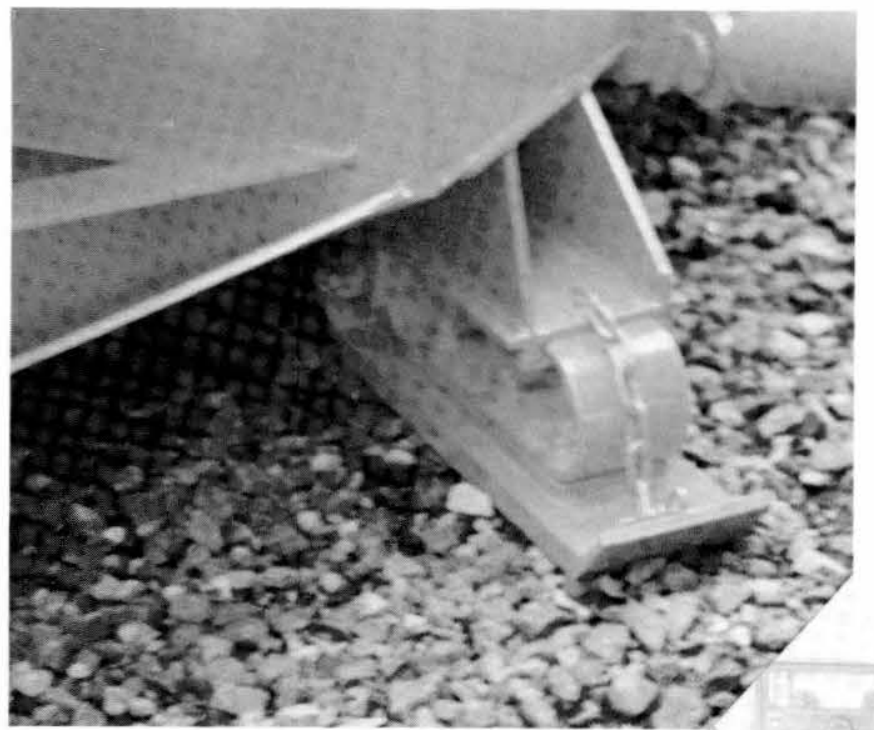

$<$

Figure 9. Steel sled and hard rubber casters replace the slider.

$\mathrm{V}$

Another urban snow-removal problem is that snow trapped near the edge of the plow blades leaves a ridge of snow when the plow crosses an intersection. A movable shutter was developed to keep the snow from dislodging from the plow (Fig. 8). Sometimes a rubber edge is used on the bottom of the snowplow blades to squeeze residual water from the pavement. To prevent damage to pavements, steel sleds and hard rubber casters are widely used (Fig. 9).

Some of the equipment under development included:

1. A retractable side wing to avoid obstacles along the roadside (Fig. 10).

2. A two-way side wing that can be converted from normal plowing to the reverse direction to plow snow from the snowbank onto the road.

3. Fins and heaters to prevent blown snow from accumulating on the rear window, rearview mirrors, signs, and lights of the snow-removal equipment. Two types of fins designed to blow snow from warning signs, shown in Figure 11, were tested.

\section{(1)}
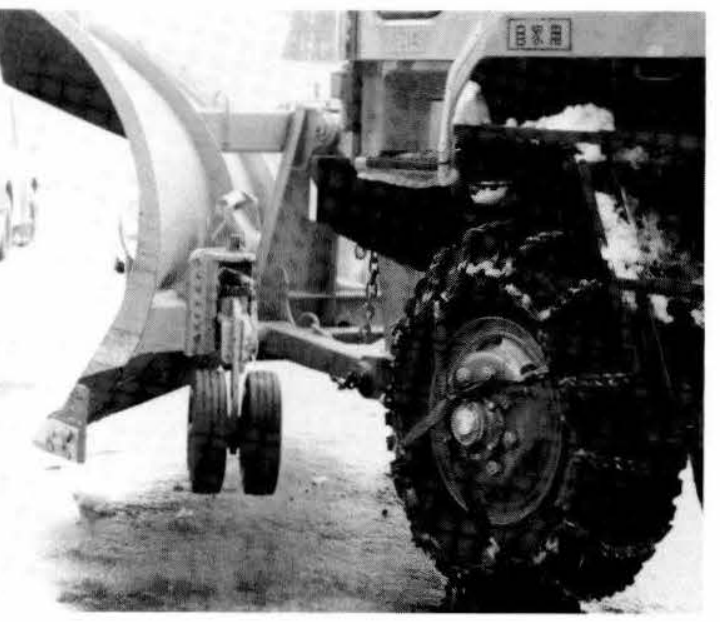

4. This author also observed a two-stage snowblower with augers that were mounted vertically (Fig. 12).

\section{Road heating}

Heating of roads by electricity or other high-quality energy sources became very restricted after the oil crisis of 1972 and now is used only where absolutely necessary, such as at tunnel entrances. However, development of lower-grade energy sources has gained more popularity. Most of the deep-snow areas in Japan enjoy 

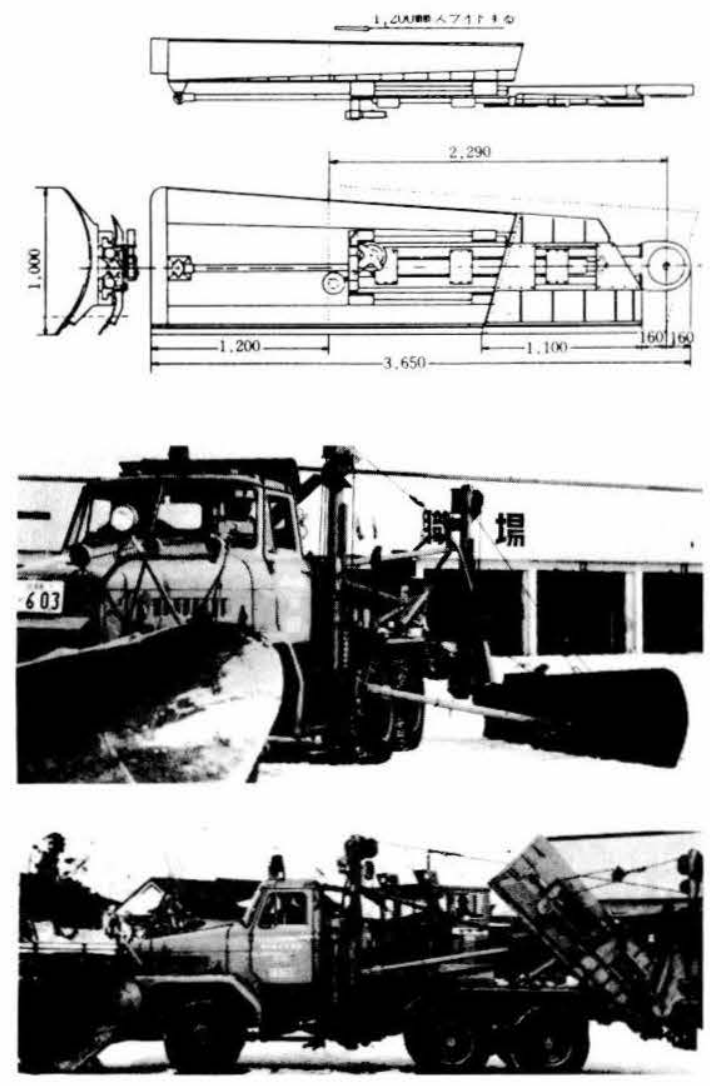

Figure 10. Sliding MacLeigh wing to clear obstacles.
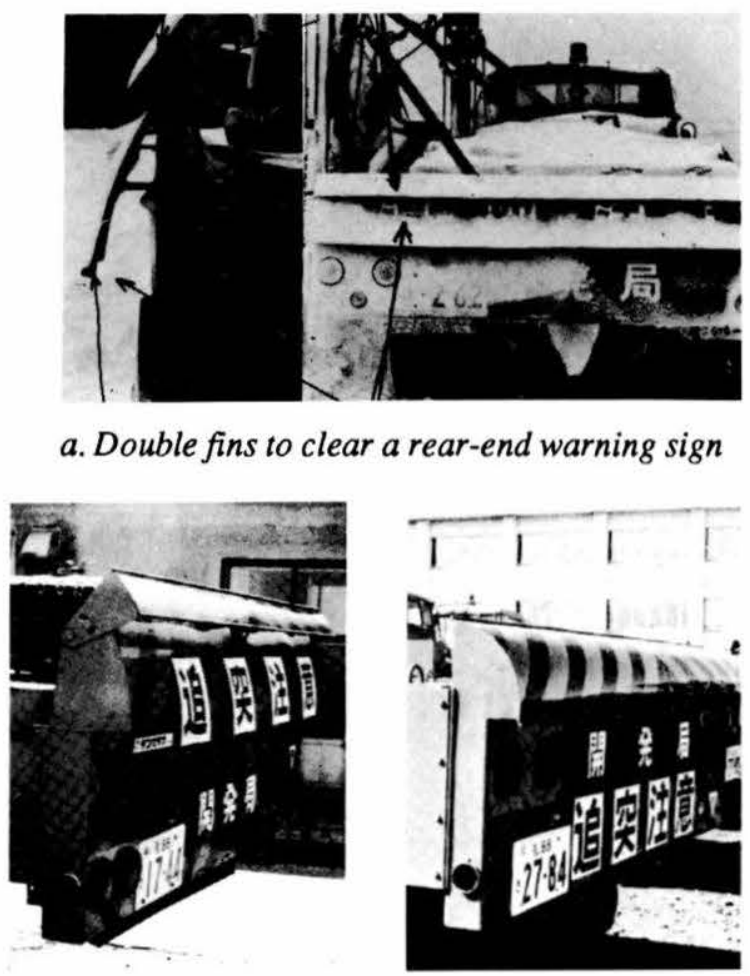

b. Single-fin design.

Figure 11. Snow-plow fins.

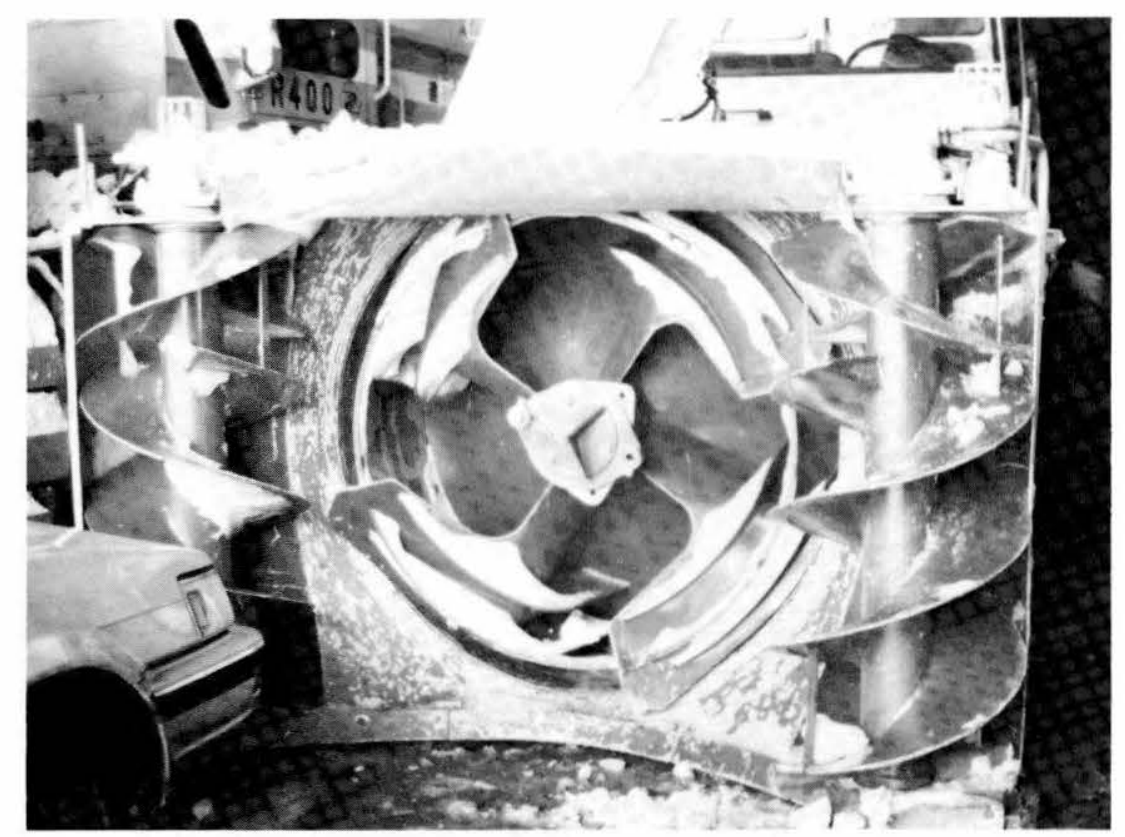

Figure 12. Vertical-axis snow auger for two-stage rotary snowblower. 


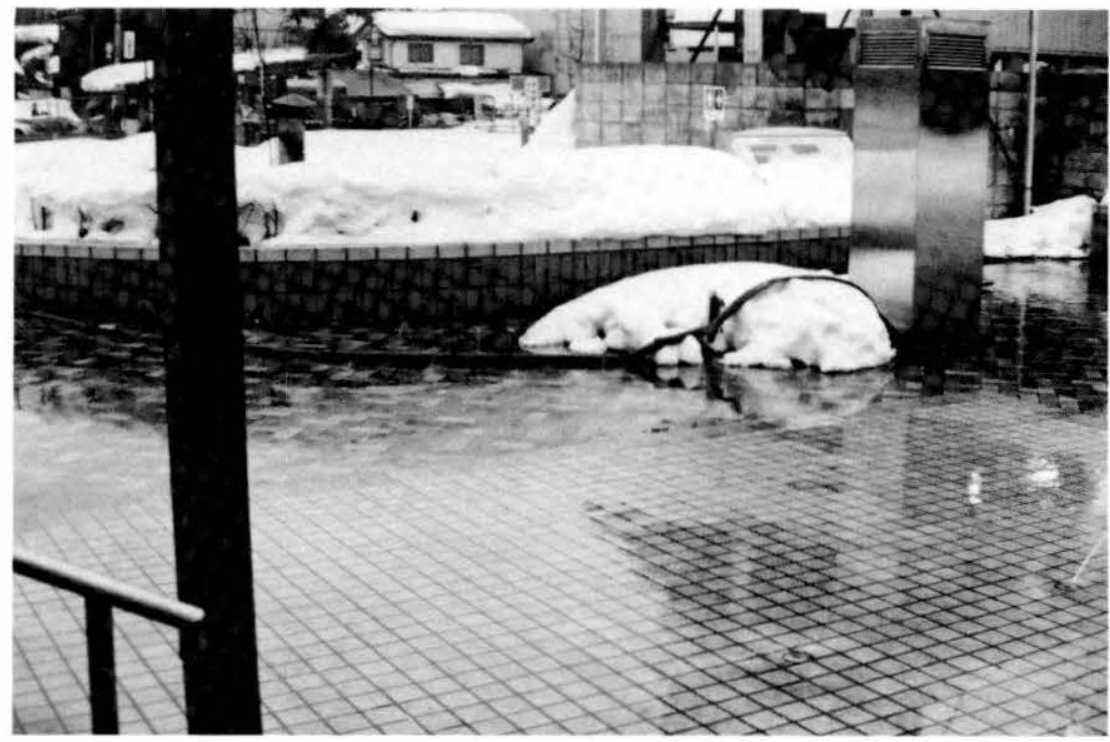

Figure 13. Over-sized garden soak hose is used as a temporary water-spray snow melter. an abundant supply of warm, clean water, which can be:

1. Sprayed on the road surface to melt fallen snow.

2. Used to heat the road surface via a network of pipes.

3. Used to transport snow in a snow discharge drain either to melt in water or as a two-phase flow of the snow and water mixture.

Method 3 is discussed later in this report under Collective Measures, Design. Method 1 was installed in the city of Nagaoka (Okuyama [B12]) since 1961, but overpumping lowered the groundwater level, even given Japan's generally abundant water supply. As a temporary measure, over-sized garden soak hoses are still in use (Fig. 13). Instead of spraying warm groundwater directly onto the road surface, method 2 uses a network of pipes buried a few inches below the road surface to warm it. The groundwater warms the pipes and is then pumped back into the ground. The groundwater level is little affected by this method, so it has become quite popular. Many reports on this subject appeared, including Akiba et al.(1981 [B13]), Ahiko et al.(1981 [B14]), Suzuki (1981 [B15]), Katsuragi et al. (1982 [B16]), Ahiko and Tobiyama (1982 [B17]), Anno(1982a [B18], 1982b [B 19]), the Road Maintenance Department of Yamagata Prefecture (1985 [B20]). Instead of using steel pipe, Nohara (1985 [B21]) experimented with nylon pipe and obtained good results. More refined methods of storing heat during the summertime (Anno 1981 [B22]), supplementing it with solar heat in the colder areas of Asahikawa (Horino et al. 1982 [B23]), or raising the circulating water temperature by heat pump (Sato 1982 [B24]) are under development.

Other approaches are to minimize the use of highgrade energy by automatic control (Oizumi 1982 [B25]) or to limit the use of water to melting roadside snow- banks and discharging it through drains (Murakuni 1982 [B26]). Anno (1985 [B27]) reported that when solar radiation is available, energy input can be reduced to $66 \mathrm{~W} / \mathrm{m}$ or less. Murakuni (1985 [B28]) discusses the use of electric heating at critical areas such as tunnel entrances and toll gates, and Goto (1974 [B29]) describes the snow melting system on the Joetsu bullet train track.

Heat pipes are another way of bringing out the heat

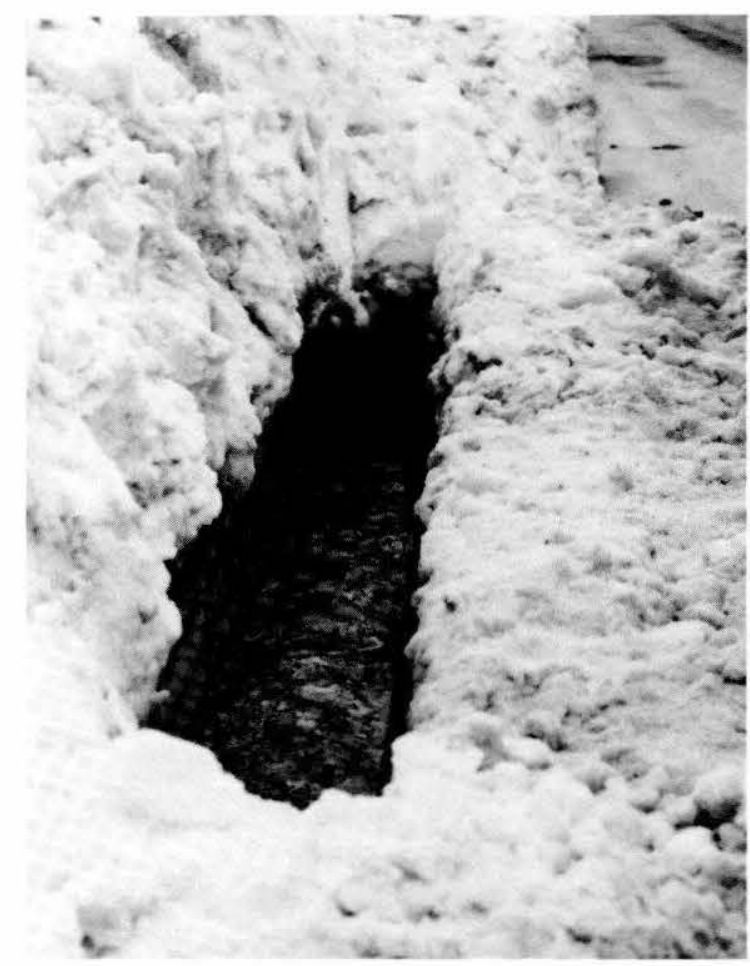

Figure 14. Snow discharge drains frequently have no cover. 


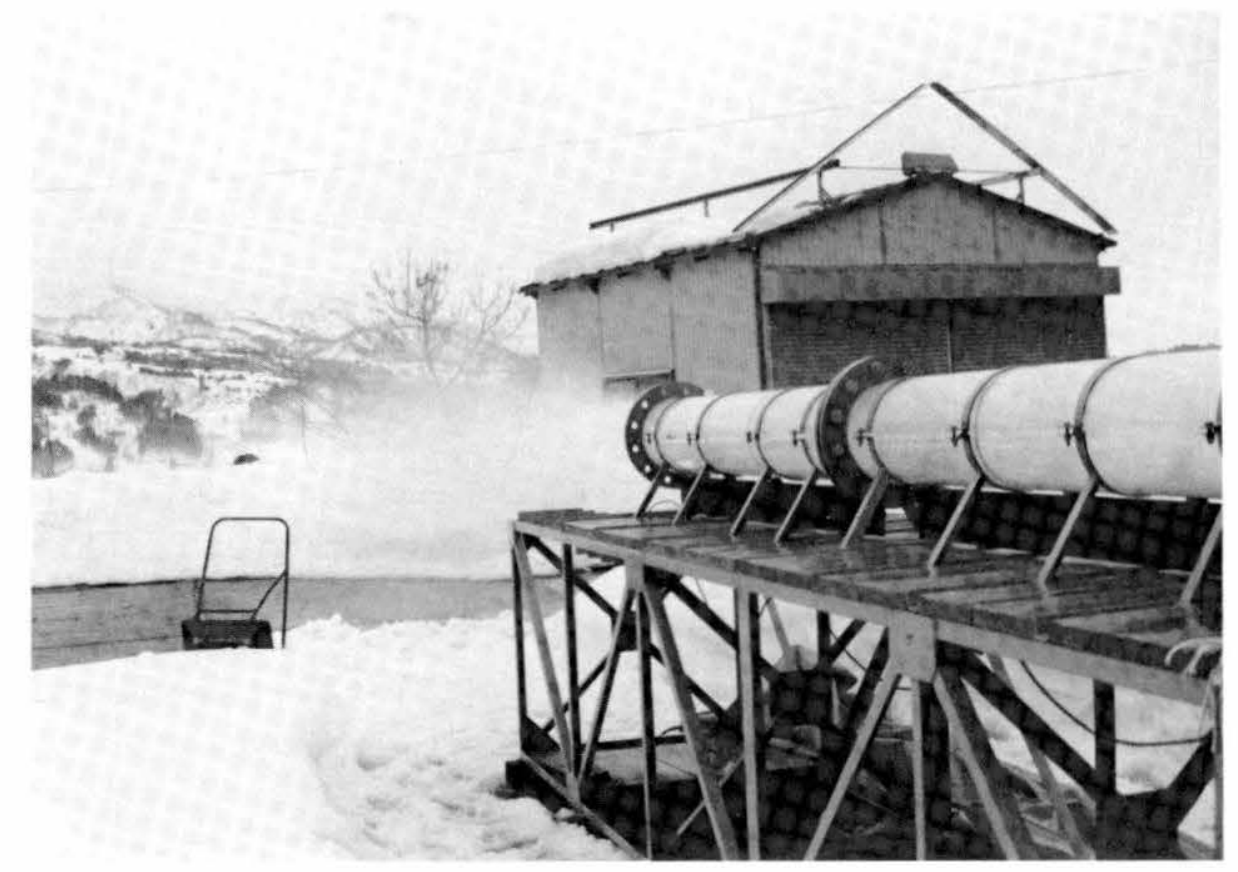

Figure 15. Pneumatic snow conveyer being tested.

stored underground. Shinojima et al. (1985 [B30]) attempted to reduce icicle formation on tunnel walls with heat pipes. The author noted that heat pipes $12 \mathrm{~m}$ long and positioned at intervals of about $0.3 \mathrm{~m}$ have been installed under Toyama city sidewalks. Many streets are provided with snow-discharge drains, as shown in Figure 14. The snow is dumped into the drain manually or by a small snowblower. Frequently, no cover is provided on these drains. In spite of the motorists' driving skill (notonly the famous kamikaze taxi, but many common drivers as well), one does hear occasionally that someone goes into the ditch. On the other hand, narrow streets without snow-discharge drains can pose serious problems.

Removing snow from very tight spaces by heavy truck is time-consuming and inefficient. Attempts have been made to convey snow in slush form. A series of basic studies by Shirakashi et al. (1982 [B31*]), Umemura et al. (1984a [B32*]), and others [B33*-B39*] addressed various problems including pressure loss of the snow-water mixture in straight pipes and elbows as well as mixing and separation methods. The development of the necessary equipment was discussed by Aizawa (1984 [B40]). Iwamoto and Isobe (1985 [B41]) reported on test results with a snow-slush conveyor system in which snow was made into slush and transferred through flexible hoses. Water and snow were separated at the other end and the water was sent back for reuse. By using a 1:0.4 ratio of water to snow, a 7.5$\mathrm{kW}$ pump could deliver about 45 tons of mixture (15 tons of snow) a distance of $300 \mathrm{~m}$ through $100-\mathrm{mm}$ flexible pipes. Another candidate for a fluid for conveying snow is air. Kobayashi and Kumagai (1988 [B44]) measured the pressure drop of snow in an air-pipe snow conveyer (Fig. 15) as a function of air speed and snow types. Depending on the snow type, clogging occurred below a certain critical air speed.

\section{Chemicals and snow melters}

The major reasons for spreading chemicals are:

1. To melt snow and ice directly on the road surface.

2. To prevent freezing of the water layer left on the road surface.

3. To form a weak layer between the snow and the road surface for easier snow removal.

4. To increase friction, in combination with sand or gravel, between tires and the road surface.

Of these applications, direct spreading requires large amounts of chemicals, which is uneconomical and causes many problems, including environmental degradation and rust formation on vehicles and structures. The major use of chemicals in Japan is to prevent the freezing of residual water. A snowplow blade with a rubber bottom can squeeze residual water from the pavement. For easier snow and ice removal from road surfaces, chemicals must be applied before the snowfall. Sand or gravel can clog drains, so these materials are applied only in emergencies. 
According to the New Road Snow-Removal Handbook (Japan Const. Mech. Assn. 1981 [B1]), the chemicals most widely used in Japan are calcium chloride $\left(\mathrm{CaCl}_{2} 2 \mathrm{H}_{2} \mathrm{O}\right)$, magnesium chloride $\left(\mathrm{MgCl}_{2} 6 \mathrm{H}_{2} \mathrm{O}\right)$, and sodium chloride $(\mathrm{NaCl})$. Occasionally urea $\left(\left(\mathrm{NH}_{2}\right)^{2}\right) \mathrm{CO}$ is used. These chemicals are selected based on their effectiveness in the particular locality and climate, their cost, ease of use, supply, and environmental impact.

The chemicals are either used as pellets or flakes applied directly to the road surface or they are sprayed as a solution. Deliquescent chemicals such as calcium chloride and magnesium chloride may be better stored and sprayed in solution form. This way deliquescence in storage or clogging of a chute during spreading can be avoided, though the effectiveness of the chemicals may be somewhat reduced. Sato et al. (1981 [C1]) discuss the loss of effectiveness of chemicals due to snowfall and traffic. According to this study, even on a dry road surface, $30 \mathrm{~g} / \mathrm{m}^{2}$ of the original concentration of $\mathrm{MgCl}_{2}$ was lost after about 200 car passages.

\section{Snow-protection facilities}

Unlike active snow control methods such as plow- ing, passive methods like snow sheds draw less attention. Still, a considerable amount of money has been spent to construct snow shelters and snow fences. In 1951 a special law for maintaining highway transportation in cold and deep-snow areas was enacted. Snow sheds, snow fences, avalanche shelters, and so forth were built, with $2 / 3$ of the funding coming from the central government. Figure 16 shows snow sheds observed during a visit to Japan. Extensive systems of sheds and fences were built to protect highways and railroads from avalanches (Fig. 17). Most reports on these snow protection facilities are internal reports and trade publications that are difficult to access, but a considerable amount of money has apparently been spent to build these facilities.

Recently, fences to control drifting snow have drawn considerable attention and several papers have been published on the subject. A wind tunnel model study by Anno [(1984a,b [D1, D2]) successfully reproduced realistic drifting snow patterns by using activated clay particles. Takeda et al. (1985 [D3]) tested a snow fence designed to divert the wind to the top and bottom of the vertical elements in a wind tunnel and found the snow

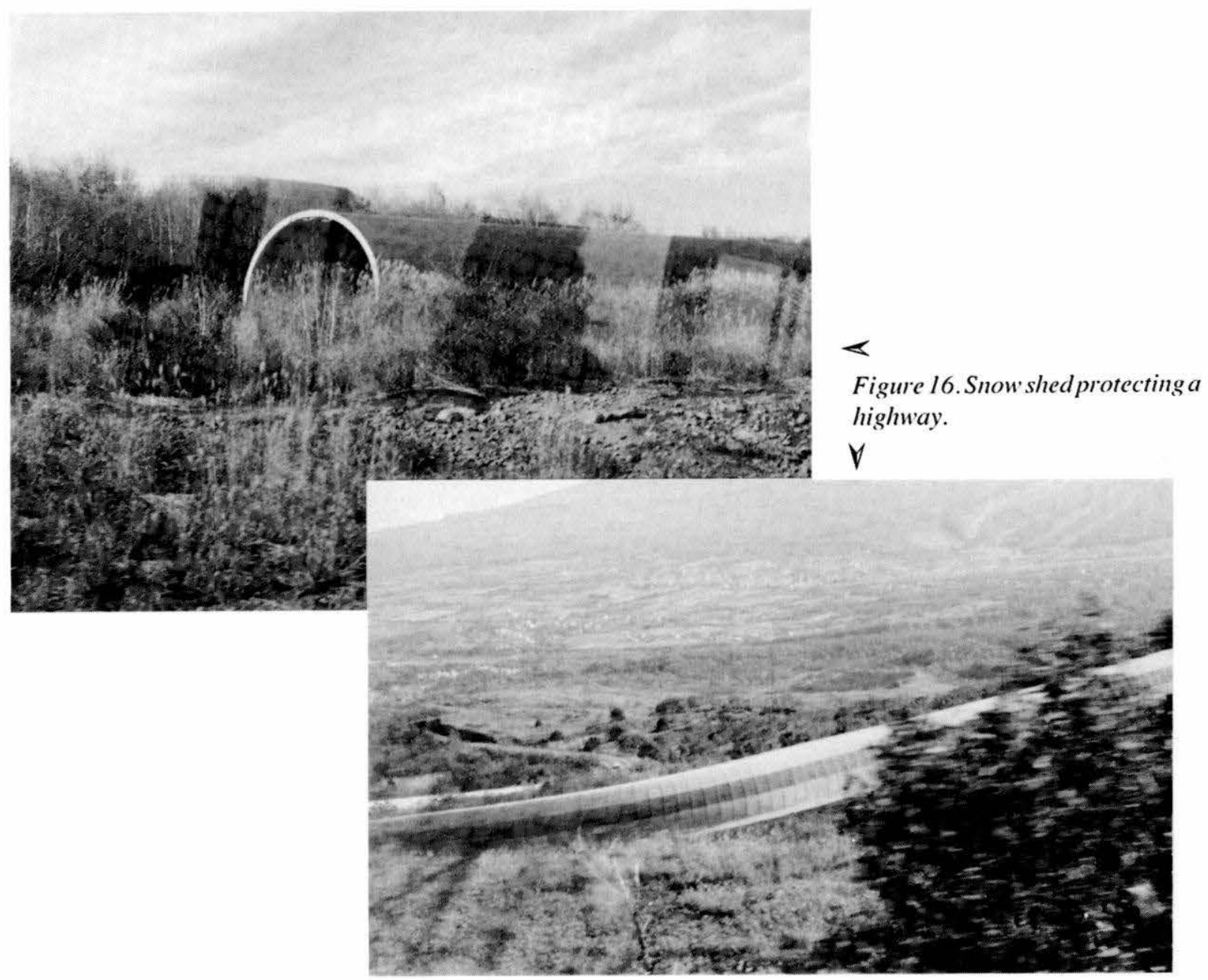




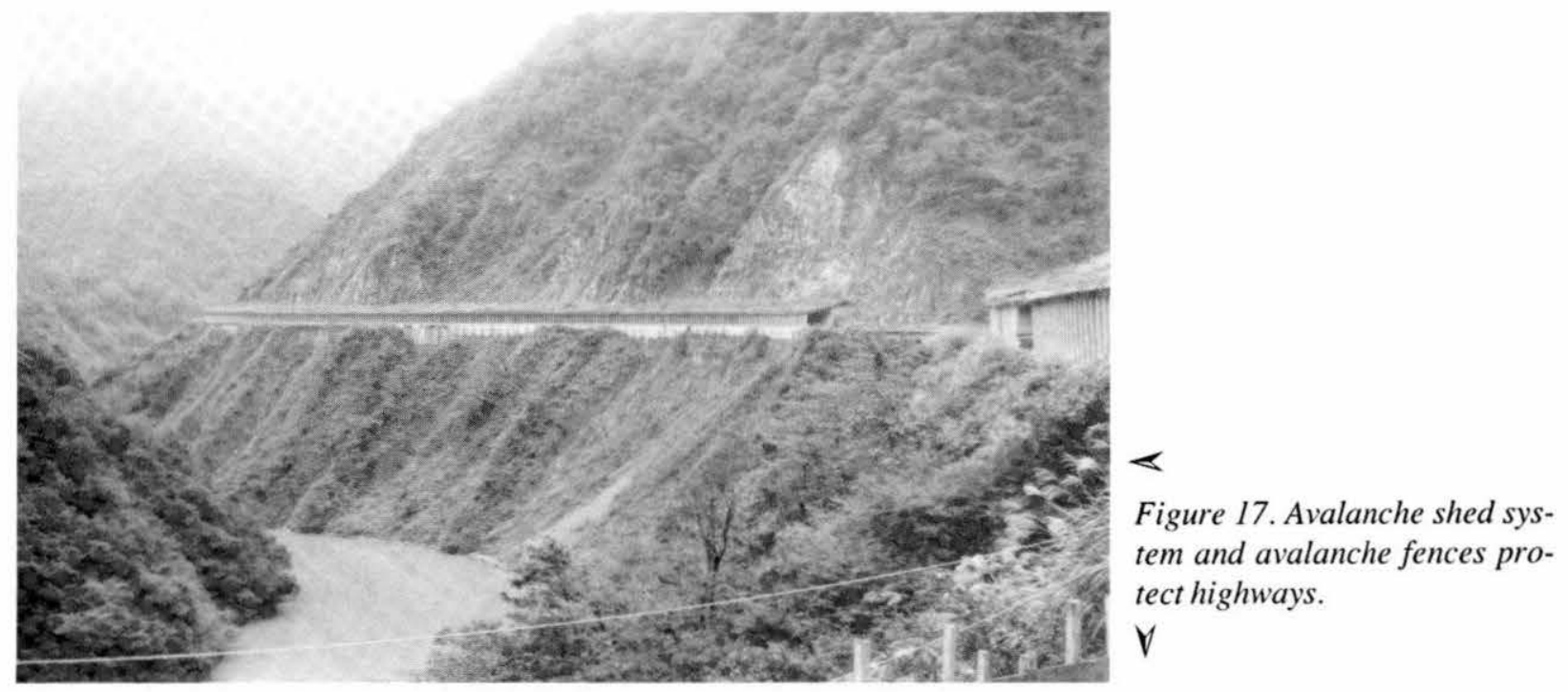

deposited in the upstream side was reduced by this design. Kaneda et al. (1982 [D4]) conducted field model tests of snow accumulation in the cut-out. In real-size field tests, Fukuzawa et al. (1982 [D5]) compared the height and bottom space effect on the distribution of snow on both the upwind and downwind sides. Naruse (1982 [D6]) measured wind speed and snow depth around the various heights of snow fences and found positive correlations. Various designs of snow fences, such as having the tips of the vertical elements bent toward the prevailing wind direction, as shown in Figure 18 (Kobayashi 1982 [D7]) or banana-peelshaped elements, as shown in Figure 19 (Takahashi et
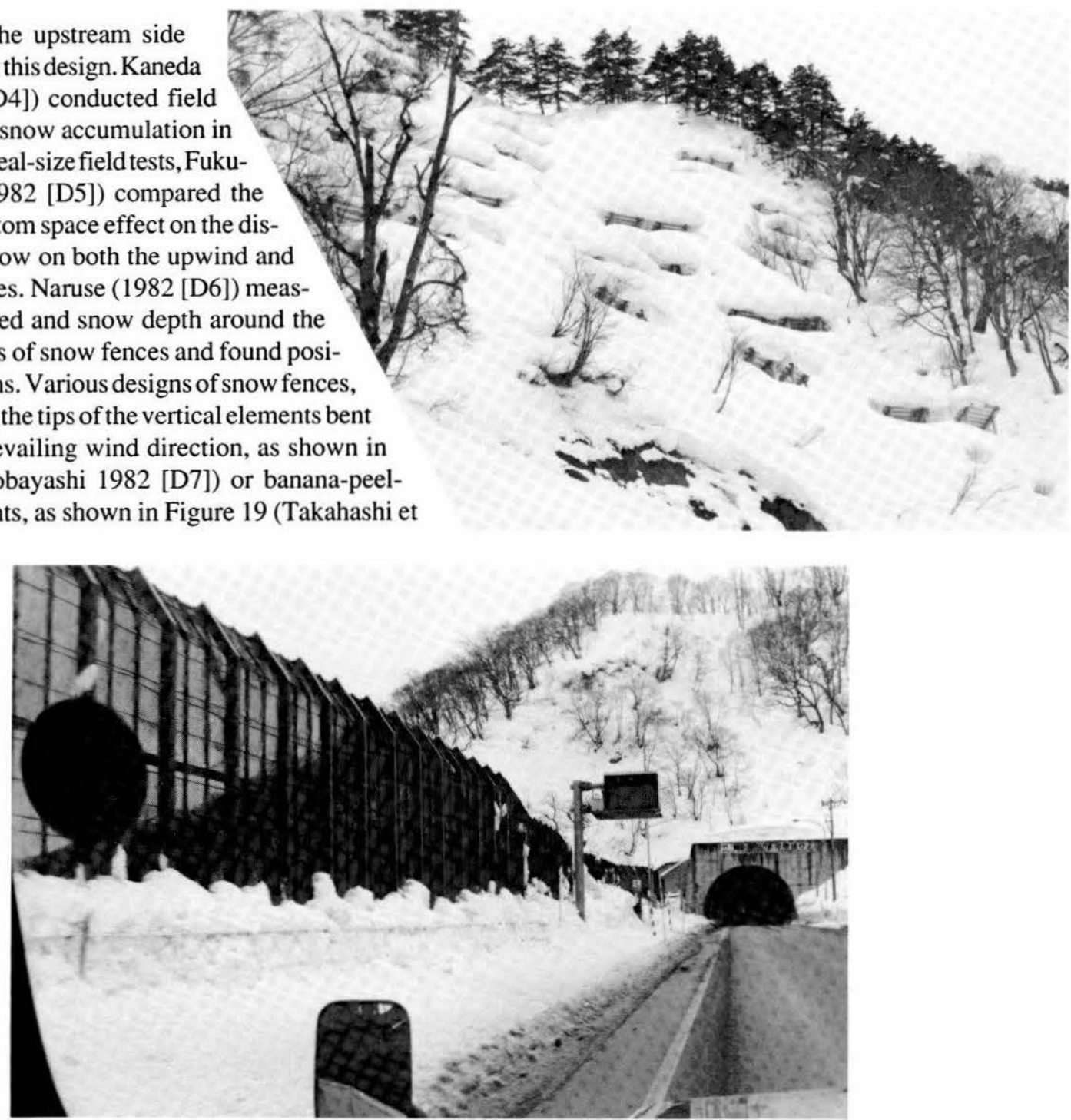

Figure 18. The tips of the snow fence are bent toward the prevailing wind direction. 


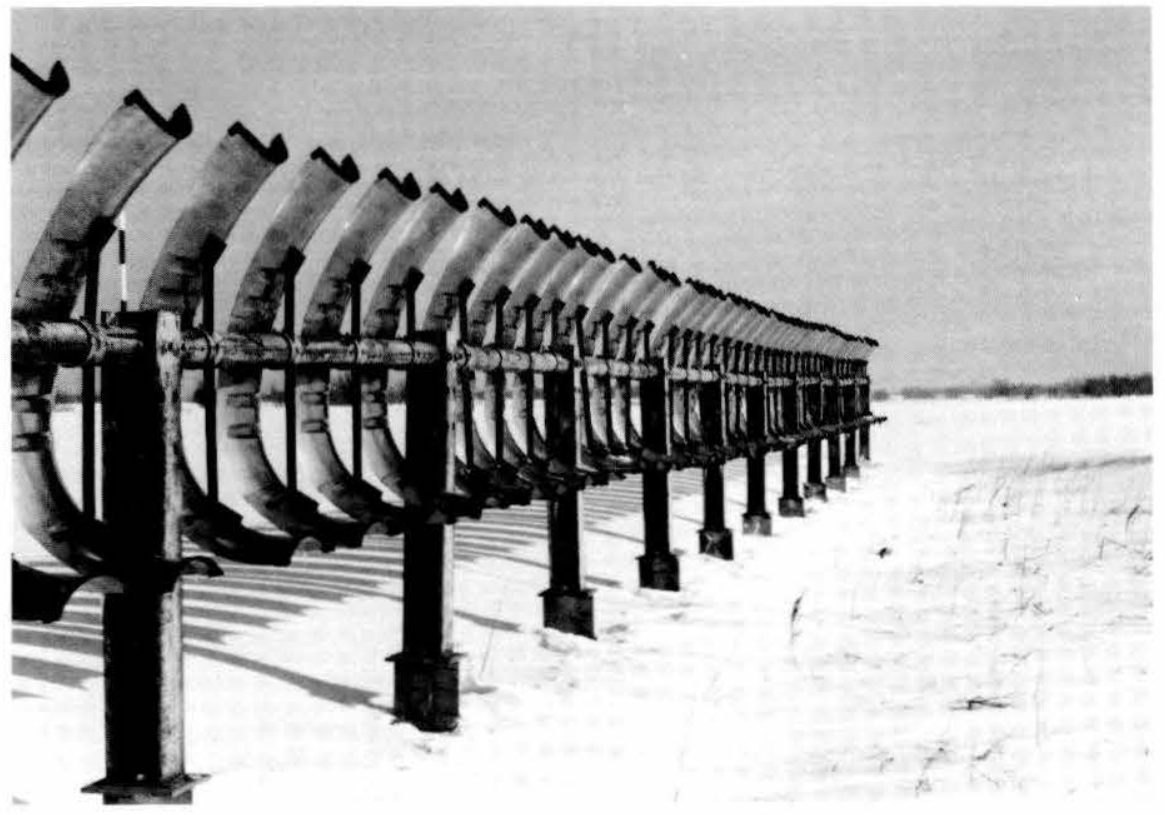

Figure 19. Test of the banana-peel-shaped snow fence.

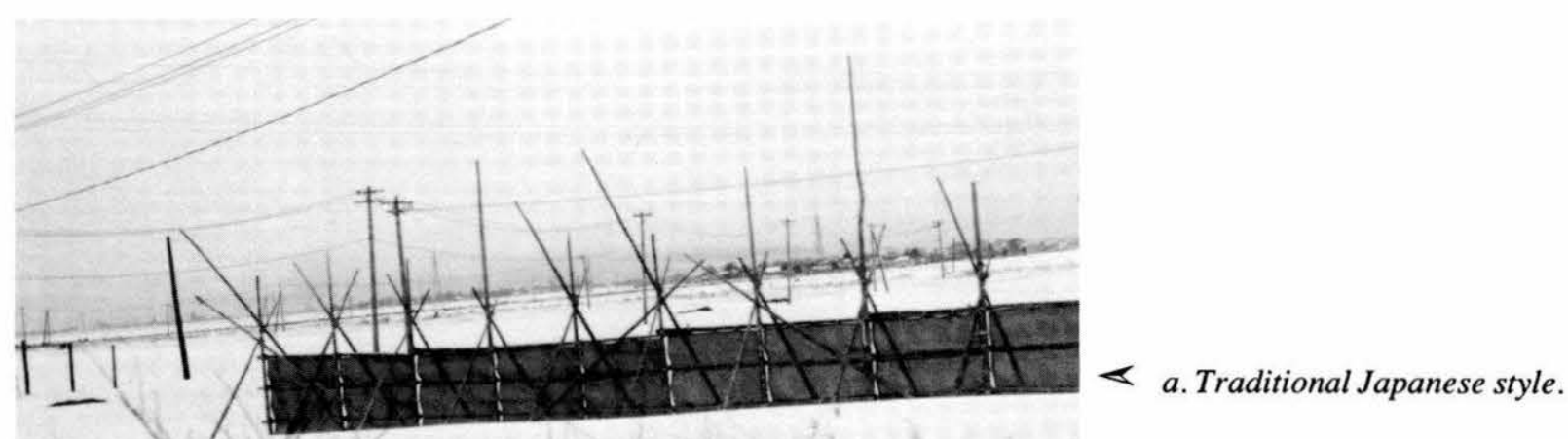

b. Modern design. $>$

Figure 20. Snow fence designs.

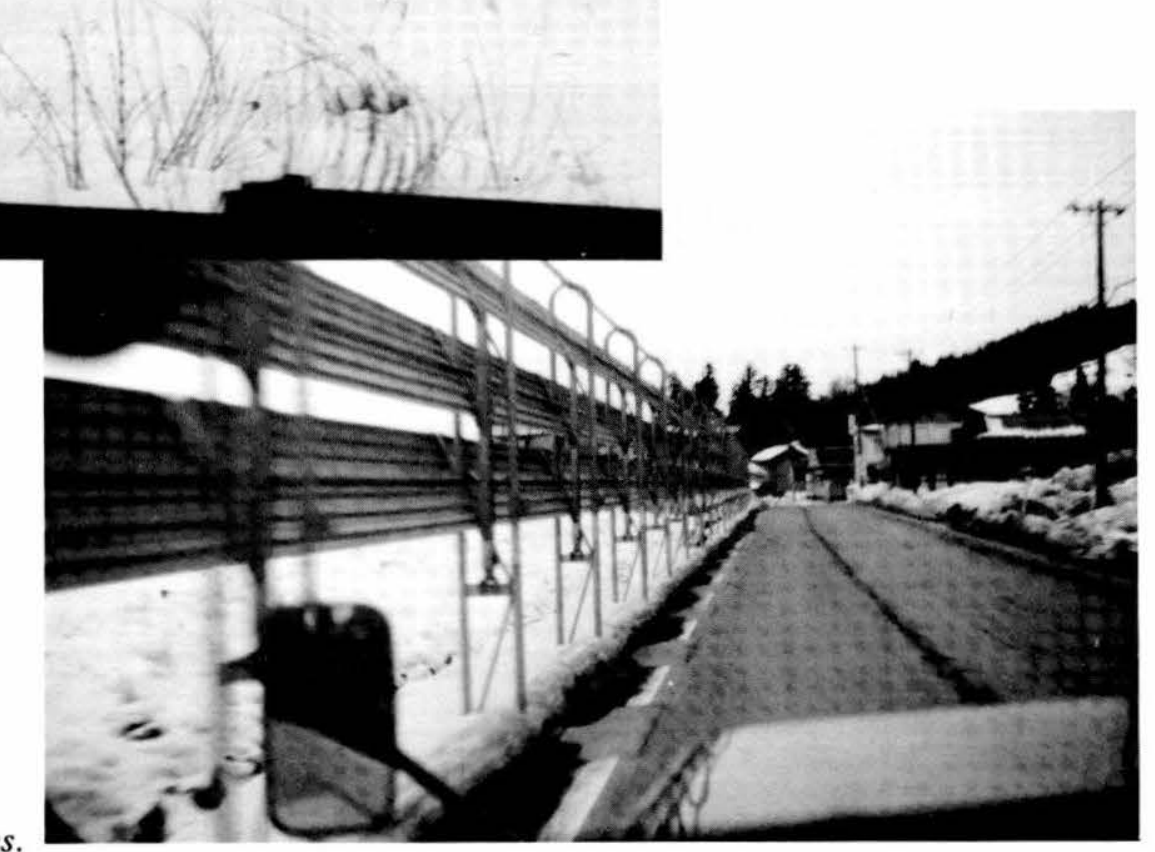


al. 1985 [D8]) have been tested. The latter design was effective up to $5 \mathrm{mleeward}$ of the fence when wind conditions were favorable, but had no effect when the wind was calm. This type of fence is commercially available.

In Japan, scaffoldings were traditionally built by tying logs together with straw rope. The same technique was adopted to make the framework of a snow fence (Fig. 20a) that supported a tarpaulin. It is a good contrast to the modern metal snow fence design (Fig. 20b).

Another way to control snow drift is to plant forests alongthehighways. Saito(1981 [D9]) discussed the selection of species and raising them in high-wind areas.

\section{Trafficability, friction, and adhesion}

Various factors hinder road travel under snowy conditions, including reduced visibility of the road surface and traffic signs, the increased roughness of the road surface, and reduced traction. Snow is the greatest single source of these road hazards. On the whole, the effect of snow is to reduce traffic. Nakatao (1985 [E1]) discussed traffic reduction due to snowfall intensity, accumulation, and days after the snowfall. Takeuchi (1982 [E2]) also discussed traffic control during snowstorms as a system.

Takeuchi and Fukuzawa (1985 [E3]) reported reduction in vehicle speeds due to reduced visibility. Snow also sticks to traffic signs, making them less visible. Attempts have been made to reduce snow accretion by Takeuchi (1978 [E4*]) and Shimomura et al. (1982 [E5]). Takeuchi and Nohara (1985 [E6]) introduced $30^{\circ}$ $\mathrm{V}$-shaped folded road signs. Since winds during snowstorms tend to prevail in one direction, at least half of the sign has little accretion, making this sign far more legible than a flat sign.

Road slipperiness is another source of difficulty encountered in highway travel due to snow. Although tire chains are the most effective way to gain sufficient traction on snow-covered road surfaces, various materials and designs give different starting tractions. Kaneda (1981 [E7]) measured starting traction with high-speed photography and reported that metal chains with diamond-shaped patterns gave the best traction after initial slippage. Kadoyama et al. (1985 [E8]) reported that test vehicle results indicated that studded tires gave consistent longitudinal traction, but that snow tires without studs are effective only on fresh snow; they are less effective on compacted snow. They also reported that average traction was linearly increased by the number of studs and the degree of stud protrusion. Shimomura and Sakai (1985 [E9]) reported that larger truck tires showed lower friction than small tires near $0^{\circ} \mathrm{C}$ using a testing machine.

Motorcycles are one of the most popular modes of transportation in Japan, but their use is limited on slippery, snow-covered roads. The stability of motorcycles on snow-covered roads was reported by Yokomori (1975 [E12*]).

As snow is plowed, the displaced snow accumulates along the roadside and gradually reduces the effective width of the road. Takamatsu and Toida (1970 [E10]) discussed the reduction of serviceable width due to snow accumulation. Nakamura (1981 [E11]) developed a simple method for measuring the passable width after snow-removal operations and reported the measured results of the passable width of the road.

\section{Social and economic impact}

Once residents in deep-snow-covered areas discovered the convenience of snow-cleared highways and started to rely on highway transportation, the impact of snowfall and its disruption of highway traffic became an important issue, seen even as a disaster. Nakatao (1981 [F1*]) introduced the concept of a "disaster index" to describethe labor required to get through a heavy snowstorm. He and Mizukoshi (1982 [F2*]) further derived an empirical relationship between this disaster index and the cost of snow control. Since the capacity to endure a snow-caused disaster is highly dependent on the area's snow-removal capacity, Sakurada and Goto (1982 [F3]) attempted to define snow endurance capacity as a reduction of city functioning due to snowfall and calculated the effects of given snowstorms on various cities. Watanabe et al. (1982 [F4]) investigated the amount of snow discharged from individual residences, the trafficable road width, and the effect of waterspraying systems as a function of snowfall.

Saito (1970 [F5]) analyzed the cost of various snowmelting techniques; the values he used were from before the oil crisis and are inapplicable today, but the trend and his approach are of some value. Ohshima (1978 [F6*]) further studied snow-melting methods after the oil crisis by combining excess heat from electric power plants and obtained favorable results.

Several attempts have been made to take advantage of snow rather than to deter its effects. Enjoyment and revenue from winter sports is one. One approach related to highway traffic is to build temporary parking spaces on fields that aren't used in winter. Takahashi (1969 [F7]) studied the feasibility of packed-snow parking lots.

\section{Statutory measures and regulations}

To alleviate the burden on residents in cold and deepsnow areas and on local industrial development, several interrelated special laws have been enacted since 1951. Under one of these laws, local governments in cold or deep-snow areas are entitled to receive $2 / 3$ of the cost of snow-control operations from the national treasury. 
This snow control includes not only snow-removal operations and equipment, but snow sheds, snow discharge drains, water spraying, and other snow-melting facilities as well.

As the turnpike developed, highway travel between warm snow-free areas and deep-snow areas has become more common. Drivers unaccustomed to driving on snow are tempted onto snowy roads. Under certain conditions, use of tire chains is mandatory and before entering a snowy area, special parking facilities along the highways are set aside for mounting tire chains.

Studded tires are widely used in snowy areas. Even snow-removal equipment relies on studded tires. The problem is that the studs cause road surface damage. To minimize the damage while retaining traction on icy surfaces, a new standard for tire studs was proposed (Yamanaka 1985 [G1]). The general trend is to eliminate studded tires altogether.

Tire chains and studded tires give rise to noise pollution. Shimoda et al. (1981 [G2*]) studied the noise spectrum of various tires with and without a snow layer and derived an empirical equation of the noise level.

\section{Collective measures}

Since the problems caused by snow cover a wide range and no single measure can solve all the problems, a wide range of administrative efforts have been made. To accomplish such objects collectively, a variety of approaches is necessary, including:

1. Data collection and transfer

2. Planning

3. Forecasting

4. Design

5. Operational and administrative approaches.

\section{Data collection and transfer}

Global data can be obtained from the network of meteorological observatories and satellites. To utilize such data under Japan's widely variable local conditions, a local-scale supplemental meteorological observation network has been established. Further data are accumulated from patrols. Regression analysis of these data has enabled the derivation of a regression equation of snowfall that is used for planning and forecasting.

In addition to conventional data collection instruments, several attempts have been made to automate the measurements and place the data into the information network. Of the various meteorological elements, detection of the snow surface was one of the most difficult to automate. Several attempts have been made. Kimura $(1973[\mathrm{H} 1 *])$ designed an instrument to measure snow depth automatically by measuring an infrared laser beam bounced back from the snow surface to a detector. Thirty-two of these instruments have been integrated into the data collection network (Fig. 21). Another difficult item for automatic measurement is detecting the beginning and end of a snowfall. Tsubata and Sorimachi $(1981[\mathrm{H} 2 *])$ used infrared ray scattering to detect snowfall.

Information is collected at the local control office and distributed to road maintenance officials. The general

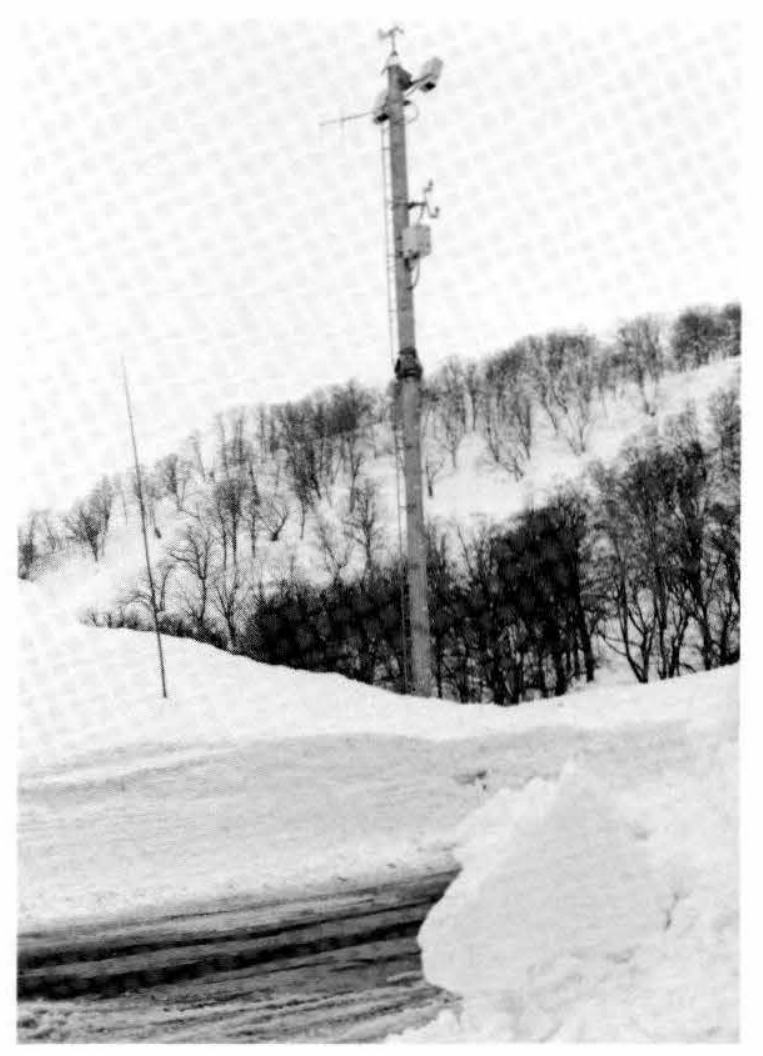

Figure 21. Infrared snow depth gauge. 


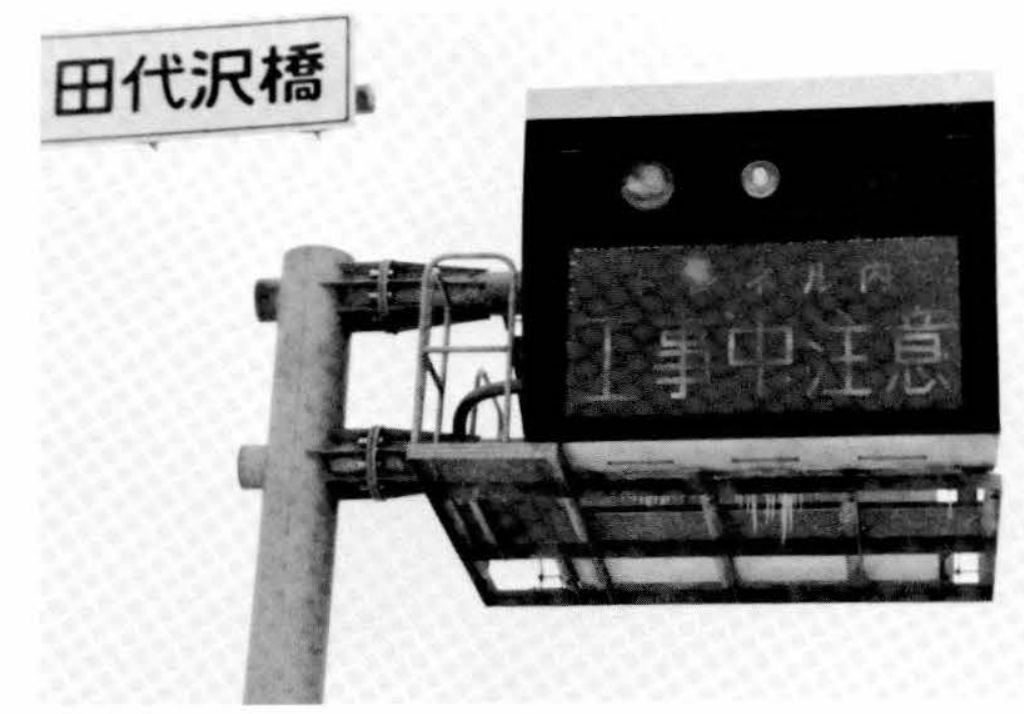

Figure 22. Electric road sign advising motorists of construction in the tunnel ahead.

public is also informed by roadside radio transmitters and roadside electric billboards (Fig. 22).

\section{Planning}

Efficient snow-removal operations begin with good planning. Maeda and Egawa (1982 [H3)] provide a way to estimate the amount of snow to be removed from an urban area. Such information is essential to planning effective snow-removal operations; however, good snow-removal paranning begins with good urban planning. Nakamata (1982 [H4]) discusses urban residential design in deep-snow areas.

\section{Forecasting snowfall and road-surface freezing}

To prepare snow-removal operations for an oncoming snowstorm, a reliable snowfall forecast is mandatory. For long-term forecasting, Ishihara (1971a [H5]) proposed a forecasting system for the Hokuriku region (Japan Sea coast of mid-Honshu Island), where the heaviest snows usually occur. Compared with the U.S., Japan's topography is very complicated; weather varies drastically in each locality, making forecasting very difficult. To forecast snow depth away from a meteorological observatory, Ishihara (1971b [H6]) performed statistical analyses and applied the results to estimation.

Systems for forecasting freezing conditions on road surfaces have also been developed (Inoue and Takada 1971 [H7]). Their system consisted of automatic meteorological stations (air and ground temperatures, dewpoint, radiation, wind direction and speed) located along the road every 5 to $15 \mathrm{~km}$, a data transmission system, and a central computer. Collected data were processed together with the synoptic data by using regression equations to forecast road surface temperatures. Efforts to forecast road icing conditions from synoptic data was continued by Takahashi and Shindo (1982 [H8]) and Tsuchiyama et al. (1985 [H9]). Takahashi and Shindo reported that the forecast was $85 \%$ quantitatively correct.

Together with the development of the laser snowdepth gauge (Kimura $1973[\mathrm{H1}$ *]), a network of snowfall and depth forecasting systems was developed (Japan Const. Mech. Assn. 1981 [B1]), and the data were transferred to local governments.

\section{Design}

Good overall design of a highway and its snowremoval system can make snow-removal operations easier and lower their cost. Ichihara (1971 [H10]) discussed the slope of a highway as a major factor of highway design in deep-snow areas, for reduced friction and resistance caused by snow can make uphill operation of motor vehicles in deep snow very difficult. Yamagami (1971 [H11]) discussed highway shoulders and the structure necessary to hold plowed snow. Proper shoulder design is not simply to leave room for plowed snow; it is also important to control snow drift and prevent cornice formation. The results of these studies were included in the New Road Snow-Removal Handbook (Japan Const. Mech. Assn. 1981 [B1]).

The median strips of a divided highway in a deepsnow area sometimes create peculiar snow-removal problems. After several snowstorms and repeated plow- 


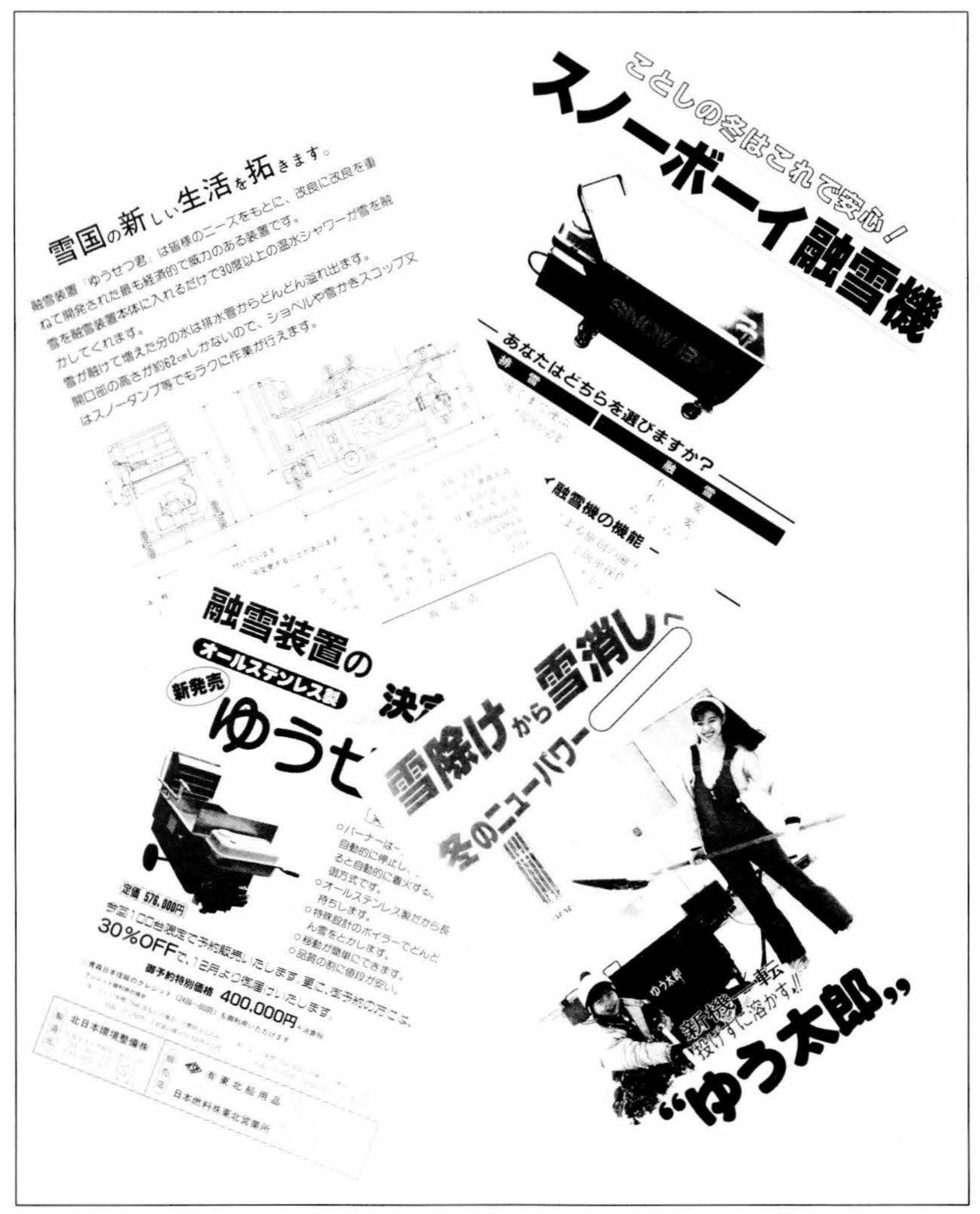

Figure 23. Fliers advertising small snow melters. 
ing, snow accumulated on the barrier grows into a dense, top-heavy structure that can fall onto the trafficable surface, endangering the general traffic. Abe (1985 [H12]) reported the development of new equipment and procedures for removing this snow without disrupting traffic.

To keep a city functioning during a snowstorm, overall city planning is essential. Seki (1982 [H13]) discussed a system that uses snow discharge drains to dispose of snow from both roads and roofs. The drain can also be used to melt snow. Sekimoto (1970 [H14]) described a test to recycle warmed water for transporting discharged snow and melt. After the oil crisis, methods of using heated water to melt snow quickly were mostly abandoned, but slow melting of snow by using warm groundwater or low-grade heat sources is widely accepted. Okuma (1985 [H15]) described such a method, and he tested paint on concrete discharge drains to improve snow transportation through a lowslope snow drain.

In a recent visit to Japan this author observed a reintroduction of snow melters. There are about a halfdozen kerosene or electric snow melters offered for home and small-business use. Apparently soaring labor costs and an aging population require an easier method of snow disposal, and the cost of energy is of less concern. Figure 23 shows several fliers advertising these snow melters.

\section{Operational and administrative approaches}

General planning. Procedures and operations for snow removal are described in the New Road SnowRemoval Handbook (Japan Const. Mech. Assn. 1981 [B1]). Information more specific to localities is provided by Tanaka (1971 [H16]), for the Meishin Throughway, Miyazaki (1974 [H17]), for the Hokuriku region, and Yamashita (1983 [H18]), for the Kanetsu Expressway. Ichihara (1970 [H19]) discussed general problems of construction and maintenance in deep-snow areas.

Addressing more specific problems, Sato and Murakuni (1982 [H20]) discussed the stabilization of snow on open cut slopes, and Tonoand Nakanishi (1985 [H21]) described snow-removal procedures on two-way roads.

Snow control on railroads. Some of Japan's famous "bullet" trains connect deep-snow areas to the warm snow-free regions in just a few hours. Such temperature changes in a short time cause interesting problems. The biggest problem is that snow on the ground is blown up by the strong wind the train generates and adheres to the equipment mounted under the carriage. The high-speed impact of snow particles causes a build-up of heavy, solid chunks of ice. Coming into warmer areas, the heavy chunks of adhered ice fall off, knocking out railroad ballast and causing damage to the train itself and to nearby structures (Saito 1971 [H22]). Shoda (1971 [H23]) obtained the critical water content above which little snow is blown up. Based on this result, a water-spraying system was installed (Ishibashi 1971 [H24]). Tohoku Shinkansen is one of the bullet train lines, operating mostly in the cold snowy Tohoku region. The design of the track and other measures for operating in cold regions are described by Tamura and Shioda (1982 [H25]).

\section{CLOSING REMARKS}

Because Japan is a small country, the total amount of funds used for highways, and in particular for snow and ice control, is relatively small. However, investment per unit length seems considerable.Traveling Japan's highway system, especially on hilly winding roads, one observes extensive constructions and structures for preventing land slides and avalanches, and noise-retaining walls. In the flat land, houses and stores are aligned side by side along the road. Where there is more space between the houses, rice paddies are intermingled with bushes and plowed fields. Along the 40 -mile route between Narita International Airport, where most foreign visitors land, and Tokyo, about $20 \%$ of the highway is raised and up to half of it has been enclosed by noiseretaining walls (Fig. 24). A visitor, eager for a first glimpse of the country, finds the view severely limited.

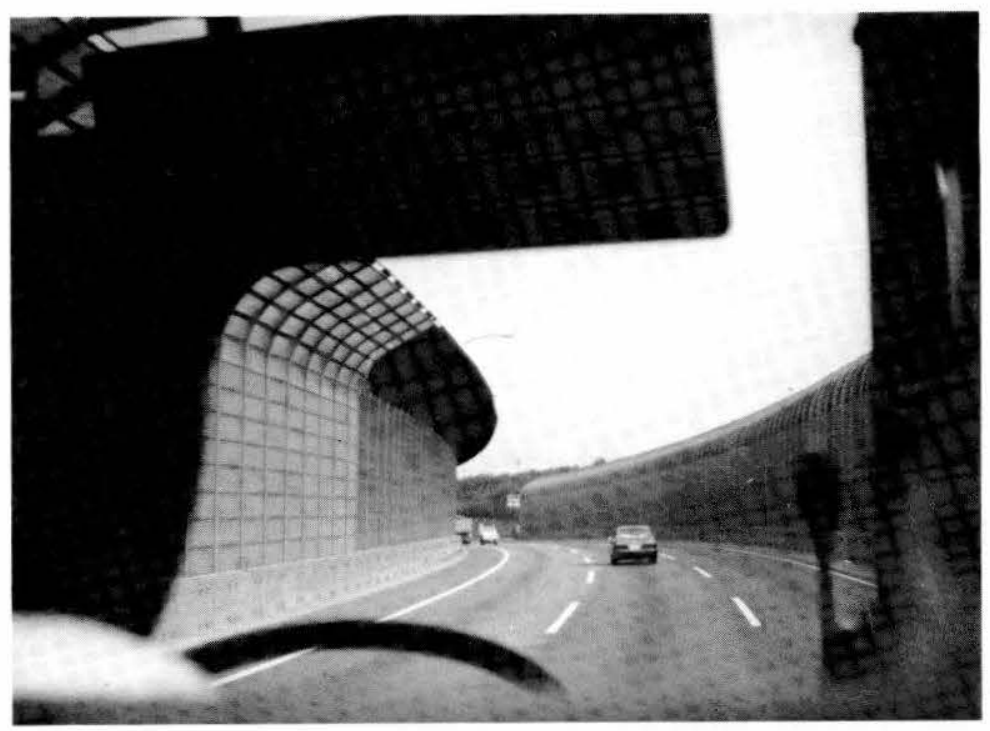

Figure 24. Noise barriers along the highway near Tokyo. 
Japan's climate is generally mild and humid, but winter precipitation along the Japan Sea coast of Honshu is mostly wet, dense snow and the amount is extensive. A population half the size of that of the U.S. lives in an island country the size of California; more than $5 \%$ of the population lives in snow country. Snowcontrol methods and equipment have been developed to fit Japanese conditions. Some of the techniques, such as melting snow by water spray, are very appropriate to Japan, though they may not be suitable to the colder and dryer areas of the United States. However, some Japanese snow-control methods, such as computer-controlled snow-removal equipment, snow fences, and information systems for road snow conditions may be found to be useful and readily applicable to North American needs.

\section{LITERATURE CITED.}

Abe, T. (1985) Development of snow removal equipment and removal procedures for median strips. Snow and Road, no. 5: 77.

Ahiko, M. and T. Tobiyama (1982) No-water spray road snow melting at Konida-cho, Yamagata City. Preprint of the Japanese Society of Snow and Ice 1982 meeting, p. 239.

Ahiko, H., K. Akiba, and K. Katsuragi (1981) Basic considerations for a waterpipe heating system. Preprint of the Japanese Society of Snow and Ice 1981 meeting, p. 61.

Aizawa, K. (1984) Snow slush conveyer. Tohoku District Construction Bureau, Internal Report.

Akiba, K., H. Ahiko, and K. Yoshida (1981) Waterpipe road heating without water spray. Preprint of the Japanese Society of Snow and Ice 1981 meeting, p. 60. Anno, T. (1981) Snow melting by geothermally stored heat. Preprint of the Japanese Society of Snow and Ice 1981 meeting, p. 12.

Anno, T. (1982a) Road snow melting and frost prevention by using water warmer than groundwater. Preprint of the Japanese Society of Snow and Ice 1982 meeting, p. 236.

Anno, T. (1982b) Road snow melting and frost prevention by using water colder than groundwater. Preprint of the Japanese Society of Snow and Ice 1982 meeting, p. 237.

Anno, T. (1985) Saving road-heating energy. Preprint of the Japanese Society of Snow and Ice 1985 meeting, p. 138.

Anno, Y. (1984a) Requirements for modeling of a snowdrift. ColdRegions Science and Technology, 8:241 (in English).

Anno, Y. (1984b) Application of Anno's modeling conditions to outdoor modeling of snow drifts. Cold
Regions Science and Technology, 9: 179 (in English). Fukuzawa, K., M. Takeuchi, K. Ishimoto, and I. Nohara (1982) Comparison of snow fence. Preprint of the Japanese Society of Snow and Ice 1982 meeting, p. 172. Goto, I. (1974) Snow melting system on the Joetsu bullet train. Journal of the Japanese Society of Snow and Ice, 36(4): 9.

Haga, S. (1984) Side-sliding rotary blower. Hokuriku District Construction Bureau, Internal Report.

Hokkaido Development Bureau (1982) Evolution of snow-removal equipment. Construction Equipment Development and Maintenance Office, Editor and Publisher.

Horino, Y., K. Katsuragi, and H. Ahiko (1982) No water spraying road snow melting by using a solar collector at Asahikawa City. Preprint of the Japanese Society of Snow and Ice 1982 meeting, p. 242.

Ichihara, K. (1970) Problems of snow and ice in highway construction and maintenance. Journal of the Japanese Society of Snow and Ice, 32(4): 94.

Ichihara, K. (1971) Highway design in deep snow areas. Journal of the Japanese Society of Snow and Ice, 33(4): 17.

Igarashi, T. (1982) Vane shear strength of snow pack. Preprint of the Japanese Society of Snow and Ice 1982 meeting, p. 146.

Inoue, H. (1984) A one-pass snowbank cutter-blower. Tohoku District Construction Bureau, Internal Report. Inoue, M. and Y. Takada (1971) Forecast system for road surface freezing. Journal of the Japanese Society of Snow and Ice, 33(4): 35.

Ishibashi, T.(1971) Blown snow control system for the Tokaido bullet train. Journal of the Japanese Society of Snow and Ice, 33(3): 89.

Ishihara, K. (1971a) Statistical snowfall forecast. Journal of the Japanese Society of Snow and Ice, 33(3): 31.

Ishihara, K. (1971b) Estimation of snow depth away from observatory. Journal of the Japanese Society of Snow and Ice, 33(3): 26.

Isobe, K., S. Kobayashi, T. Aoki, and H. Miyamura (1981) Studies of compacted snow on road surfaces. Preprint of the Japanese Society of Snow and Ice 1981 meeting, p. 9.

Iwamoto, T. and H. Inoue (1985) Development of high snowbank removal equipment. Snow and Road, No. 5: 54.

Iwamoto, T. and K. Isobe (1985) Continuous snow transportation. Preprint of the Japanese Society of Snow and Ice 1985 meeting, p. 108.

Izumi, K. and E. Akitaya (1982) The hardness of wet snow. Preprint of the Japanese Society of Snow and Ice 1982 meeting, p. 150.

Japan Construction Mechanization Association (Ed.) 
(1981) New Road Snow-Removal Handbook.

Kadoyama, Y., Y. Hagino, and T. Otuska (1985) Longitudinal skid resistance of winter tires. Snow and Road, No. 5: 50.

Kaneda, S. (1981) Starting slippage of tire chains. Preprint of the Japanese Society of Snow and Ice 1981 meeting, p. 13.

Kaneda, Y., T. Uematsu, O. Katayama, and T. Saito (1982) Outdoor model studies of drifting snow. Preprint of the Japanese Society of Snow and Ice 1982 meeting, p. 175.

Katsuragi, K., H. Yoshida, and H. Ahiko (1982) A nospray road water-heating system. Preprint of the Japanese Society of Snow and Ice 1982 meeting, p. 238.

Kawada, K., H. Narita, and E. Akitaya (1980) Snow impact force. Preprint of the Japanese Society of Snow and Ice 1980 meeting, p. 21.

Kimura, T. (1973) Snow surface detection by laser beam. Journal of the Japanese Society of Snow and Ice, 35(3): 13.

Kinosita, S. (1955) Breakdown of snow by impulsive force. I. Low-Temperature Science, A(14): 95.

Kinosita, S. (1956) Breakdown of snow by impulsive force. II. Low-Temperature Science, A(15): 149.

Kinosita, S. (1957a) Breakdown of snow by impulsive force. III. Low-Temperature Science, A(16): 119.

Kinosita, S. (1957b) The relation between the deformation velocity of snow and two types of its deformation (plastic and destructive). I. Low-Temperature Science, $\mathbf{A}(16)$ : 139.

Kinosita, S. (1958) Deformation rate and deformation type of snow. II. Low-Temperature Science, A(17): 11. Kinosita, S. (1960a) Deformation rate and deformation type of snow. III. Low-Temperature Science, A(19): 135. Kinosita, S. (1960b) The hardness of snow. I. LowTemperature Science, A(19): 119.

Kinosita, S. (1965) Intrusion of a rigid cone into snow. Low-Temperature Science, A(23): 17.

Kinosita, S. and E. Akitaya (1969) Snow and ice on roads. I. Low-Temperature Science, A(27): 163.

Kinosita, S., E. Akitaya and K. Tanuma (1970) Snow and ice on roads. II. Low-Temperature Science, $\mathbf{A}(28)$ : 311.

Kobayashi, B. (1982) Effectiveness of tip bending of snow-drift guide net. Preprint of the Japanese Society of Snow and Ice 1982 meeting, p. 174.

Kuriyama, H. (1980) Rolling resistance on packed snow. Preprint of the Japanese Society of Snow and Ice 1980 meeting, p. 96.

Kuriyama, H. (1982) Shear strength of snow and vertical stress. Preprint of the Japanese Society of Snow and Ice 1982 meeting, p. 145.

Kuriyama, H. (1984) Vane shear strength of snow. I. Effect of vane angular velocity. Journal of the Japanese
Society of Snow and Ice, 46(3): 101.

Kuriyama, H. and M. Shibuya (1978) On the power required for driving the blower of a rotary-type snowremoval machine. Journal of the Japanese Society of Snow and Ice, 40(4): 16.

Kuriyama, H., I. Nohara, and S. Kobayashi (1980) Snow cutting resistance of rotary snow remover auger. Preprint of the Japanese Society of Snow and Ice 1980 meeting, p. 95.

Kuriyama, H., I. Nohara, and S. Kobayashi (1981) Vane shear strength and rotary cutting strength of snow. Preprint of the Japanese Society of Snow and Ice 1981 meeting, p. 197.

Maeda, H. and R. Egawa (1982) Estimation of urban road snow volume to be removed during heavy snowstorms. Preprint of the Japanese Society of Snow and Ice 1982 meeting, p. 246.

Miyairi, M., J. Ohkushii and S. Ozawa (1966) Drag of bodies moving through snow with high speed.Journal of the Japanese Society of Snow and Ice, 28(1): 23.

Miyazaki, S. (1974) Highway snow control in Hokuriku. Journal of the Japanese Society of Snow and Ice, 36(4): 13.

Murakuni, M. (1982) Melting roadside snowbanks by water spray. Preprint of the Japanese Society of Snow and Ice 1982 meeting, p. 243.

Murakuni, M. (1985) Current highway road-heating facilities and problems. Snow and Road, No. 5: 27.

Muro, T. (1978) Compaction properties of wet snow. Journal of the Japanese Society of Snow and Ice, 40(3): 8.

Nakamata, S. (1982) City planning in deep snow areas. Journal of the Japanese Society of Snow and Ice, 44(1): 34.

Nakamura, H. (1981) Measurement of snow removal width. Preprint of the Japanese Society of Snow and Ice, 1981 meeting, p. 73.

Nakatao, T. (1982) Introduction of disaster index for manual snow-removal in Hokuriku, Japan. Journal of the Japanese Society of Snow and Ice, 44(4): 211.

Nakatao, T. (1985) Analysis of traffic reduction by snowfall, accumulated snow and days after the snowfall. Preprint of the Japanese Society of Snow and Ice 1985 meeting, p. 133.

Nakatao, T. and M. Mizukoshi (1982) An empirical representation of snow-control cost as a function of snow disaster index, population, and regional snow conditions. Journal of the Japanese Society of Snow and Ice, 44(4): 205.

Naruse, Y. (1982) Snow drift around snow fences and wind speed distribution. Preprint of the Japanese Society of Snow and Ice 1982 meeting, p. 173.

Nohara, I. (1983) Operational characteristics of a snow blower adapter for farm tractors. National Center for 
Disaster Prevention, Internal Report.

Nohara, I. (1985) Warm-water snow melting of asphalt paved surface using nylon piping. Preprint of the Japanese Society of Snow and Ice 1985 meeting, p. 136.

Nohara, I., H. Kuriyama, and S. Kobayashi (1982) Auger resistance and dynamic properties of snow. Preprint of the Japanese Society of Snow and Ice 1982 meeting, p. 144.

Ohshima, M. (1978) A cost evaluation of snow removal by a heating system in a city in Japan. Iournal of the Japanese Society of Snow and Ice, 40(4): 24.

Oizumi, Y. (1982) Automatic water spray snow melter control. Preprint of the Japanese Society of Snow and Ice 1982 meeting, p. 305.

Okuma, T. (1985) Snow discharge drain and snowmelting drain. Snow and Road, No. 5: 21.

Okuyama, T. (1974) Snow melting at Nagaoka City. Journal of the Japanese Society of Snow and Ice, 36(4): 7.

Road Maintenance Department, Yamagata Perfecture (1985) Waterpipe road heating. Snow andRoad, No. 5: 40 .

Sakai, K., S. Takahashi and K. Mizusawa (1982) Snow blower adapter for farm tractors. Hokuriku District Construction Bureau, Internal Report.

Sakai, K. and S. Takahashi (1983) Elevating and sidesliding operator cab. Hokuriku District Construction Bureau, Internal Report.

Sakai, K., S. Takahashi, M. Hokari and S. Haga (1982) Groove cutter for compacted snow to improve traction. Hokuriku District Construction Bureau, Internal Report.

Saito, H. (1970) Economic efficiency of snow melting. Journal of the Japanese Society of Snow and Ice, 32(4): 105.

Saito, M. (1971) Tokaido bullet train snow and ice control. Journal of the Japanese Society of Snow and Ice, 33(3): 61.

Saito, S. (1981) Snowdrift protection forest for Highway 40 near Wakkanai City. Journal of the Japanese Society of Snow and Ice, 43(2): 101.

Sakurada, R. and I. Goto (1982) Basic snow endurance capacity of cities. Preprint of the Japanese Society of Snow and Ice 1982 meeting, p. 222.

Sato, A. and G. Wakahama (1976) Plastic wave in snow. Low-Temperature Science, A. 34, p. 59.

Sato, A. and G. Wakahama (1980a) High-speed compression of snow pack. V. Preprint of the Japanese Society of Snow and Ice 1980 meeting, p. 8.

Sato, A.and G. Wakahama (1980b) Measurements of the velocity of crack propagation in ice. Low-Temperature Science, 39: 193.

Sato, K. (1982) Sidewalk snow melting by a combination of heat pump and heat pipe. Preprint of the Japanese
Society of Snow and Ice 1982 meeting, p. 240.

Sato, K. and M. Murakuni(1982) Stabilization of snow on cutout slopes in deep snow areas. Preprint of the Japanese Society of Snow and Ice 1982 meeting, p. 225. Sato, K., T. Kabashima, and K. Ikura (1981) Effect of snow-control chemicals. Preprint of the Japanese Society of Snow and Ice 1981 meeting, p. 10.

Seki, K. (1982) Area snow removal system in a densely populated area..Journal of the.Japanese Society of Snow and Ice, 44(1): 40.

Sekimoto, Y.(1970) Snow discharge drain combined with snow melter. Journal of the Japanese Society of Snow and Ice, 32(4): 108.

Shimoda, S. and K. Sato (1969) Study of rotary snowremoval machines for highways. Journal of the Japanese Society of Snow and Ice, 31(4): 85.

Shimoda, S., T. Ishibashi, and M. Oshima (1981) Car noise test on snow-covered roads. Journal of the Japanese Society of Snow and Ice, 43(3): 163.

Shimomura, C. and Y. Sakai (1985) Slip friction of tires on frozen and compressed snow surfaces. Preprint of the Japanese Society of Snow and Ice 1985 meeting, p. 135.

Shimomura, C., S. Ishihira, and T. Matsuno (1982) Snow accretion properties of road signs. Preprint of the Japanese Society of Snow and Ice 1982 meeting, p. 228. Shinojima, K., T. Fujii, and K. Ebisawa (1985) Icicle control by heat pipes in tunnels. Preprint of the Japanese Society of Snow and Ice 1985 meeting, p. 137.

Shirakashi, M., I. Kawakami, S. Sato, and S. Wakiya (1982) On hydraulic conveying of snow. I. Pressure losses in straight pipse. Iournal of the Japanese Society of Snow and Ice, 45(1): 33-39.

Shirakashi, M., K. Sato, S. Sato, A. Koshio, T. Umemura, and S. Wakiya (1984a) Hydraulic conveying of snow. IV. Flow pattern of snow-water mixture in straight pipes. Iournal of the Japanese Society of Snow and Ice, 46(4): 163-170.

Shirakashi, M.,S.Sato, A. Koshio, T. Umemura, and S. Wakiya (1984b) Hydraulic conveying of snow. V. The influence of several factors on the pressure drop of a snow-water mixture flowing in a straight pipe.Journal of the Japanese Society of Snow and Ice, 46(4): 171-178. Shirakashi, M., S. Sato, A. Koshio, Y. Tokunaga, T. Umemura, and S. Wakiya (1985) Hydraulic conveying of snow. VI. Pressure drop of snow-water mixture at an elbow. Journal of the Japanese Society of Snow and Ice, 47(3): 105-110.

Shirakashi, M., A. Koshio, Y. Tokunaga, T. Hashimoto, and S. Wakiya (1986) Hydraulic conveying of snow. VII. Energy loss of snow-water mixture flow combining at a $\mathrm{T}$-junction of pipes. Journal of the Japanese Society of Snow and Ice, , 48(2): 75-82. Shoda, M. (1971) Control of blown snow for high- 
speed trains. Journal of the Japanese Society of Snow and Ice, 33(3): 79.

Suzuki, K. (1981) Groundwater-restoration-type snow melting. Preprint of the Japanese Society of Snow and Ice 1981 meeting, p. 62.

Takahashi, K. (1969) Building a packed-snow parking lot. Journal of the Japanese Society of Snow and Ice, 31(5): 136.

Takahashi, K. and M. Shindo (1982) Development of road snow and ice forecast. Preprint of the Japanese Society of Snow and Ice 1982 meeting, p. 226.

Takahashi, Y.,S.Ito. and M.Takeuchi (1985) Curved blow-off type snow fence. Preprint of the Japanese Society of Snow and Ice 1985 meeting, p. 141.

Takamatsu, M. and M. Toida (1970) Width of snow removal. Journal of the Japanese Society of Snow and Ice, 32(4): 97.

Takeda, K., K. Yasuda and M. Takeuchi (1985) Wind tunnel test of vertically branching blow-off snow fence. Preprint of the Japanese Society of Snow and Ice 1985 meeting, p. 140.

Takeuchi, M. (1978) Snow accretion on traffic-control signs and its prevention. Journal of the Japanese Society of Snow and Ice, 40(3): 15.

Takeuchi, M. (1982) Traffic control during snowstorms. Preprint of the Japanese Society of Snow and Ice 1982 meeting, p. 224.

Takeuchi, M. and Y. Fukuzawa (1985) Visibility in blizzards and vehicle speed. Preprint of the Japanese Society of Snow and Ice 1985 meeting, p. 139.

Takeuchi, M. and S. Kamada (1973) Shear experiment on ice adhered to road surface. Journal of the Japanese Society of Snow and Ice, 35(3): 21.

Takeuchi, M. and T. Nohara (1985) Snow accretion control of snow pole. Preprint of the Japanese Society of Snow and Ice 1985 meeting, p. 142.

Tamura, A. and Y. Shioda (1982) Snow control for the Tohoku bullet train. Journal of the Japanese Society of Snow and Ice, 44(3): 153.

Tanaka, T. (1971) Snow and ice control on Meishin Throughway. Journal of the Japanese Society of Snow and Ice, 33(4): 14.

Tohoku District Construction Bureau (1982) Snowplow blade attachment for sidewalk plowing. Internal Report.

Tokunaga, Y., T. Hashimoto, K. Mizuguchi and M. Shirakashi (1987) Hydraulic conveying of snow. IX. Development of techniques for high snow concentration Journal of the Japanese Society of Snow and Ice, 49(2): 59-66.
Tono, A. and A. Nakanishi (1985) Snow removal on two-lane highways. Snow and Road, No. 5: 67.

Tsubata, I. and Y. Sorimachi (1981) Simple snowfall detector employing reflection of infrared rays. Journal of the Japanese Society of Snow and Ice, 43(2): 77.

Tsuchiyama, M., N. Suemune, Y. Fujihara, Y. Takada, K. Sasaki, and M. Inoue (1985) A method to predict road surface freezing. Preprint of the Japanese Society of Snow and Ice 1985 meeting, p. 134.

Umemura, T.,S. Ohura, T. Toruhiro, I. Hattori, and A. Okada (1984a) Hydraulic conveying of snow. II. Snow feeder to pipelines. Journal of the Japanese Society of Snow and Ice, 46(2): 51-58.

Umemura, T., T. Koyanagi, and A. Okada (1984b) Hydraulic conveying of snow. III. Separation of foreign solids from snow/water mixture by cyclone. Journal of the Japanese Society of Snow and Ice, 46(3): 121-128. Umemura, T., M. Nakayama, A. Uchiyama, Y. Tokunaga, and M. Shirakashi (1986) Hydraulic conveying of snow. VIII. Blocking of snow-water mixture flow and criterion of stagnation of snow at a pipe orifice. Journal of the Japanese Society of Snow and Ice, 48(4): 207-214.

Watanabe, Z. (1981) Strength of wet snow, a model study. Preprint of the Japanese Society of Snow and Ice 1981 meeting, p. 106.

Watanabe, Z., S. Abe, and S. Nakamata (1982) Snow depth condition after heavy snowstorm in an urban area. Journal of the Japanese Society of Snow and Ice, 44(1): 37.

Yamagami, S.(1971) Highway shoulders for deep snow areas. Journal of the Japanese Society of Snow and Ice, 33(4): 23.

Yamanaka, Y. (1985) New standard for studded tires. Snow and Road, No. 5: 87.

Yamashita,M.(1983) Snow removal operation in heavy snow areas of the Kan-etsu Expressway. Journal of the Japanese Society of Snow and Ice, 45(3): 151.

Yokomori,M.(1975) Stability of motorcycles on packed snow with special reference to tirecharacteristics. Journal of the Japanese Society of Snow and Ice, 37(1): 21. Yorioka, Y. and Y. Iwasaki (1983) Sidewalk snowremoval equipment evaluation. Chugoku District Construction Bureau, Internal Report.

Yosida, Z. (1974) Theoretical studies of snow removal by a plow. I, II. Low-Temperature Science, A(32): 39, 55.

Yosida, Z. (1975) Theoretical studies on snow removal by plows. III, IV, V. Low-Temperature Science, A(33): $39,57,75$. 


\section{USING THIS REPORT}

More than 100 reports, preprints, and reviews pertinent to highway snow control have been collected and included in this report. All but a couple of the reports are in Japanese. Appendix A gives the detailed source information, compiled and arranged in the order the articles are discussed in the text. The in-text citations include a code number (for example, [D5]) that keys them to the information in Appendix A.

Appendix B contains an alphabetical list of applicable keywords.

Appendix $C$ includes English summaries of some of the reports; these are marked with an asterisk (*) both in citations in the main text and in Appendix A. These summaries have been edited for inclusion in this report.

Appendix D presents detailed information about various snow-removal equipment that has been and is currently in use in Japan. 


\title{
APPENDIX A: DETAILED REFERENCE INFORMATION
}

\author{
Entries marked with an asterisk (*) are summarized in Appendix C, English Summaries
}

\section{BASIC STUDIES}

A1*. S. Kinosita and E. Akitaya (1969) Snow and ice on roads. I. Low-Temperature Science, Ser. A(27): 163.

A2*. S. Kinosita, E. Akitaya and K. Tanuma (1970) Snow and ice on roads. II. Low-Temperature Science, Ser. A(28): 311.

A3*. S. Kinosita (1955) Breakdown of snow by impulsive force. I. Low-Temperature Science, Ser. A(14): 95.

A4\%. S. Kinosita (1956) Breakdown of snow by impulsive force. II. Low-Temperature Science, Ser. A(15): 149 .

A5*. S. Kinosita (1957) Breakdown of snow by impulsive force. III. Low-Temperature Science, Ser. A(16): 119.

A6\%. S. Kinosita (1957) The relation between the deformation velocity of snow and two types of its deformation (plastic and destructive). I. Low-

Temperature Science, Ser. A(16): 139.

A7*. S. Kinosita (1958) Deformation rate and deformation type of snow. II. Low-Temperature Science, Ser. A(17): 11.

A8*. S. Kinosita (1960) Deformation rate and deformation type of snow. III. Low-Temperature Science, Ser. A(19): 135.

A9*. S. Kinosita (1960) The hardness of snow. I. Low-Temperature Science, Ser. A(19): 119.

A10*. S. Kinosita (1965) Intrusion of a rigid cone into snow. Low-Temperature Science, Ser. A(23): 17.

A11\%. M. Miyairi, J. Ohkushi and S. Ozawa (1966) Drag of bodies moving through snow with high speed. Journal of the Japanese Society of Snow and Ice, 28(1): 23.

A12*. A. Sato and G. Wakahama (1976) Plastic wave in snow. Low-Temperature Science, Ser. A(34): 59.

A13*. T. Muro (1978) Compaction properties of wet snow. Journal of the Japanese Society of Snow and Ice, 40(3): 8.

A14. A. Sato and G. Wakahama (1980) High-speed compression of snow pack. V. Preprint of the Japanese Society of Snow and Ice 1980 meeting, p. 8 .
A15. K. Kawada, H. Narita, and E. Akitaya (1980) Snow impact force. Preprint of the Japanese Society of Snow and Ice 1980 meeting, p. 21.

A16. Z. Watanabe (1981) Strength of wet snow, a model study. Preprint of the Japanese Society of Snow and Ice 1981 meeting, p. 106.

A17. K. Izumi and E. Akitaya (1982) The hardness of wet snow. Preprint of the Japanese Society of Snow and Ice 1982 meeting, p. 150.

A18*. Z. Yosida (1974) Theoretical studies of snow removal by a plow. I, II. Low-Temperature Science, Ser. A(32): 39, 55.

A19. Z. Yosida (1975) Theoretical studies on snow removal by a plow. III, IV, V.Low-Temperature Science, Ser. A(33): 39, 57, 75.

A20. H.Kuriyama, I. Nohara, and S. Kobayashi(1981) Vane shear strength and rotary cutting strength of snow. Preprint of the Japanese Society of Snow and Ice 1981 meeting, p. 107.

A21. H. Kuriyama (1982) Shear strength of snow and vertical stress. Preprint of the Japanese Society of Snow and Ice 1982 meeting, p. 145.

A22. T. Igarashi (1982) Vane shear strength of snow pack. Preprint of the Japanese Society of Snow and Ice 1982 meeting, p. 146.

A23\%. S. Shimoda and K. Sato (1969) Study of rotary snow-removal machines for highways. Journal of the Japanese Society of Snow and Ice, 31(4): 85.

A24*. H. Kuriyama and M. Shibuya (1978) On the power required for driving the blower of a rotary-type snow-removal machine. Journal of the Japanese Society of Snow and Ice, 40(4): 16.

A25. H.Kuriyama, I. Nohara, and S. Kobayashi (1980) Snow cutting resistance of rotary snow-removal auger. Preprint of the Japanese Society of Snow and Ice 1980 meeting, p. 95.

A26. I.Nohara, H. Kuriyama, and S. Kobayashi (1982) Auger resistance and dynamic properties of snow. reprint of the Japanese Society of Snow and Ice 1982 meeting, p. 144.

A27\%. H. Kuriyama (1984) Vane shear strength of snow.I. Effect of vane angular velocity..Journal of the Japanese Society of Snow and Ice, 46(3): 101.

A28*. M. Takeuchi and S. Kamada (1973) Shear ex- 
periment on ice adhered to a road surface.Journal of the Japanese Society of Snow and Ice, 35(3): 21.

A29. H.Kuriyama(1980) Rolling resistance on packed snow. Preprint of the Japanese Society of Snow and Ice 1980 meeting, p. 96.

A30. A. Sato and G. Wakahama (1980) Measurements of the velocity of crack propagation in ice. Low-Temperature Science, 39: 193.

A31. K. Isobe, S. Kobayashi, T. Aoki, and H. Miyamura (1981) Studies of compacted snow on road surfaces. Preprint of the Japanese Society of Snow and Ice 1981 meeting, p. 9.

\section{SNOW-REMOVAL EQUIPMENT}

B1. Japan Construction Mechanization Association (1981) New Road Snow-Removal Handbook.

B2. Hokkaido Development Bureau (1982) Evolution of snow-removal equipment. Construction Equipment Development and Maintenance Office (Ed.).

B3. K. Sakai, S. Takahashi and K. Mizusawa (1982) Snow blower adapter for farm tractors. Hokuriku District Construction Bureau, Internal Report.

B4. I. Nohara (1983) Operational characteristics of a snowblower adapter for farm tractors. National Center for Disaster Prevention, Internal Report.

B5. K. Sakai and S. Takahashi (1983) Elevating and side-sliding operator cab. Hokuriku District Construction Bureau, Internal Report.

B6. S. Haga (1984) Side-sliding rotary blower. Hokuriku District Construction Bureau, Internal Report.

B7. Tohoku District Construction Bureau (1982) Snowplow blade attachment for sidewalk plowing. Internal Report.

B8. Y. Yorioka and Y. Iwasaki (1983) Sidewalk snow-removal equipment evaluation. Chugoku District Construction Bureau, Internal Report.

B9. K. Sakai, S. Takahashi, M. Hokari and S. Haga (1982) Groove cutter for compacted snow to improve traction. Hokuriku District Construction Bureau, Internal Report.

B10. H. Inoue (1984) A one-pass snowbank cutterblower. Tohoku District Construction Bureau, Internal Report.

B11. T. Iwamoto and H. Inoue (1985) Development of high snowbank removal equipment. Snow and Road, (5): 54 .

\section{ROAD HEATING}

B12. T. Okuyama (1974) Snow melting at Nagaoka City. Journal of the Japanese Society of Snow and Ice, 36(4): 7.

B13. K. Akiba, H. Ahiko, and K. Yoshida (1981) Waterpipe road heating without water spray. Preprint of the Japanese Society of Snow and Ice 1981 meeting, p. 60.

B14. H. Ahiko, K. Akiba, and K. Katsuragi (1981) Basic considerations for a waterpipe heating system. Preprint of the Japanese Society of Snow and Ice 1981 meeting, p. 61.

B15. K. Suzuki(1981)Groundwater-restoration-type snow melting. Preprint of the Japanese Society of Snow and Ice 1981 meeting, p. 62.

B16. K. Katsuragi, H. Yoshida, and H. Ahiko (1982) A no-spray road water-heating system. Preprint of the Japanese Society of Snow and Ice 1982 meeting, p. 238.

B17. M. Ahiko and T. Tobiyama (1982) No-waterspray road snow melting at Konida-cho, Yamagata City. Preprint of the Japanese Society of Snow and Ice 1982 meeting, p. 239.

B18. T. Anno (1982a) Road snow melting and frost prevention by using water warmer than groundwater. Preprint of the Japanese Society of Snow and Ice 1982 meeting, p. 236.

B19. T. Anno (1982b) Road snow melting and frost prevention by using water colder than groundwater. Preprint of the Japanese Society of Snow and Ice 1982 meeting, p. 237.

B20. Road Maintenance Department, Yamagata Perfecture (1985) Waterpipe road heating. Snow and Road, No. 5, p. 40.

B21. I. Nohara (1985) Warm-water snow melting of asphalt paved surface using nylon piping. Preprint of the Japanese Society of Snow and Ice 1985 meeting, p. 136.

B22. T. Anno (1981) Snow melting by geothermally stored heat. Preprint of the Japanese Society of Snow and Ice 1981 meeting, p. 12.

B23. Y. Horino, K. Katsuragi, and H. Ahiko (1982) No water spraying road snow melting by using a solar collector at Asahikawa City. Preprint of the Japanese Society of Snow and Ice 1982 meeting, p. 242.

B24. K. Sato (1982) Sidewalk snow melting by a combination of heat pump and heat pipe. Preprint of the Japanese Society of Snow and Ice 1982 meeting, p. 240.

B25. Y. Oizumi (1982) Automatic water spray snow melter control. Preprint of the Japanese Society of Snow and Ice 1982 meeting, p. 305. 
B26. M. Murakuni (1982) Melting roadside snowbanks by water spray. Preprint of the Japanese Society of Snow and Ice 1982 meeting, p. 243.

B27. T. Anno (1985) Saving road-heating energy. Preprint of the Japanese Society of Snow and Ice 1985 meeting, p. 138.

B28. M. Murakuni (1985) Current highway roadheating facilities and problems. Snow and Road, (5): 27 .

B29. I. Goto (1974) Snow melting system on the Joetsu bullet train. Journal of the Japanese Society of Snow and Ice, 36(4): 9.

B30. K. Shinojima, T. Fujii, and K. Ebisawa (1985) Icicle control by heat pipes in tunnels. Preprint of the Japanese Society of Snow and Ice 1985 meeting, p. 137.

B31*. M. Shirakashi, I. Kawakami, S. Sato, and S. Wakiya(1982) On hydraulic conveying of snow. I. Pressure losses in straight pipes. Journal of the Japanese Society of Snow and Ice, 45(1): 3339.

B32*. T. Umemura, S. Ohura, T. Toruhiro, I. Hattori, and A. Okada (1984) Hydraulic conveying of snow. II. Snow feeder to pipelines. Journal of the Japanese Society of Snow and Ice, 46(2): 5158.

B33*. T. Umemura, T. Koyanagi, and A. Okada(1984) Hydraulic conveying of snow. III. Separation of foreign solids from snow/water mixture by cyclone. Journal of the Japanese Society of Snow and Ice, 46(3): 121-128.

B34*. M. Shirakashi, K. Sato, S. Sato, A. Koshio, T. Umemura, and S. Wakiya (1984) Hydraulic conveying of snow. IV. Flow pattern of snowwater mixture in straight pipes. Journal of the Japanese Society of Snow and Ice, 46(4): 163170.

B35*. M.Shirakashi, S. Sato, A. Koshio, T. Umemura, and S. Wakiya (1984) Hydraulic conveying of snow. V. The influence of several factors on the pressure drop of a snow-water mixture flowing in a straight pipe. Journal of the Japanese Society of Snow and Ice, 46(4): 171-178.

B36*. M. Shirakashi, S. Sato, A Koshio, Y. Tokunaga, T. Umemura, and S. Wakiya (1985) Hydraulic conveying of snow. VI. Pressure drop of snow/ water mixture at an elbow. Journal of the Japanese Society of Snow and Ice, 47(3): 105-110.

B37*. M. Shirakashi, A. Koshio, Y. Tokunaga, T. Hashimoto, and S. Wakiya (1986) Hydraulic conveying of snow. VII. Energy loss of snowwater mixture flow combining at a T-junction of pipes. Journal of the Japanese Society of Snow and Ice, 48(2): 75-82.
B38*. T. Umemura, M. Nakayama, A. Uchiyama, Y. Tokunaga, and M. Shirakashi. (1986) Hydraulic conveying of snow. VIII. Blocking of snow/ water mixture flow and criterion of stagnation of snow at a pipe orifice. Journal of the Japanese Society of Snow and Ice, 48(4): 207-214.

B39*. Y. Tokunaga, T. Hashimoto, K. Mizuguchi and M. Shirakashi (1987) Hydraulic conveying of snow. IX. Development of techniques for high snow concentration Journal of the Japanese Society of Snow and Ice, 49(2): 59-66.

B40. K. Aizawa (1984) Snow slush conveyer. Tohoku District Construction Bureau, Internal Report.

B41. T. Iwamoto and K. Isobe (1985) Continuous snow transportation. Preprint of the Japanese Society of Snow and Ice 1985 meeting, p. 108.

B42. S. Kobayashi and M. Kumagai (1988) Air transportation of snow. II. Prepring of the Japanese Society of Snow and Ice 1988 meeting, p. 100.

\section{CHEMICAL SNOW MELTING}

C1. K. Sato, T. Kabashima, and K. Ikura (1981) Effect of snow-control chemicals. Preprint of the Japanese Society of Snow and Ice 1981 meeting, p. 10.

\section{SNOW PROTECTION FACILITIES}

D1. Y.Anno (1984a) Requirements for modeling of a snowdrift. Cold Regions Science and Technology, 8: 241. (In English.)

D2. Y.Anno (1984b) Application of Anno's modeling conditions to outdoor modeling of snow drifts. ColdRegions Science and Technology,9: 179. (In English.)

D3. K. Takeda, K. Yasuda, and M. Takeuchi (1985) Wind-tunnel test of vertically branching blowoff snow fence. Preprint of the Japanese Society of Snow and Ice 1985 meeting, p. 140.

D4. Y. Kaneda, T. Uematsu, O. Katayama, and T. Saito (1982) Outdoor model studies of drifting snow. Preprint of the Japanese Society of Snow and Ice 1982 meeting, p. 175.

D5. K. Fukuzawa, M. Takeuchi, K. Ishimoto, and I. Nohara (1982) Comparison of snow fence. Preprint of the Japanese Society of Snow and Ice 1982 meeting, p. 172.

D6. Y.Naruse (1982) Snow drift around snow fences and wind speed distribution. Preprint of the Japanese Society of Snow and Ice 1982 meeting, p. 173.

D7. B. Kobayashi (1982) Effectiveness of tip bend- 
ing of snow-drift guide net. Preprint of the Japanese Society of Snow and Ice 1982 meeting, p. 174.

D8. Y. Takahashi, S. Ito. and M. Takeuchi (1985) Curved blow-off type snow fence. Preprint of the Japanese Society of Snow and Ice 1985 meeting, p. 141.

D9. S. Saito (1981) Snowdrift protection forest for Highway 40 near Wakkanai City. Journal of the Japanese Society of Snow and Ice, 43(2): 101.

\section{TRAFFICABILITY, FRICTION, AND ADHESION}

E1. T. Nakatao (1985) Analysis of traffic reduction by snowfall, accumulated snow and days after the snowfall. Preprint of the Japanese Society of Snow and Ice 1985 meeting, p. 133.

E2. M. Takeuchi (1982) Traffic control during snowstorms. Preprint of the Japanese Society of Snow and Ice 1982 meeting, p. 224.

E3. M. Takeuchi and Y.Fukuzawa (1985) Visibility in blizzards and vehicle speed. Preprint of the Japanese Society of Snow and Ice 1985 meeting, p. 139.

E4*. M. Takeuchi (1978) Snow accretion on trafficcontrol signs and its prevention. Journal of the Japanese Society of Snow and Ice, 40(3): 15.

E5. C. Shimomura, S. Ishihira, and T. Matsuno (1982) Snow accretion properties of road signs. Preprint of the Japanese Society of Snow and Ice 1982 meeting, p. 228.

E6. M. Takeuchi and T. Nohara (1985) Snow accretion control of snow pole. Preprint of the Japanese Society of Snow and Ice 1985 meeting, p. 142.

E7. S. Kaneda (1981) Starting slippage of tire chains. Preprint of the Japanese Society of Snow and Ice, 1981 meeting, p. 13.

E8. Y.Kadoyama, Y. Hagino, and T. Otuska(1985) Longitudinal skid resistance of winter tires. Snow and Road, (5): 50.

E9. C. Shimomura and Y.Sakai (1985) Slip friction of tires on frozen and compressed snow surfaces. Preprint of the Japanese Society of Snow and Ice 1985 meeting, p. 135.

E10. M. Takamatsu and M. Toida (1970) Width of snow removal. Journal of the Japanese Society of Snow and Ice, 32(4): 97.

E11. H. Nakamura (1981) Measurement of snowremoval width. Preprint of the Japanese Society of Snow and Ice, 1981 meeting, p. 73.

E12*. M. Yokomori (1975) Stability of motorcycles on packed snow with special reference to tire characteristics. Journal of the Japanese Society of Snow and Ice, 37(1): 21

\section{SOCIAL AND ECONOMIC IMPACT}

F1*. T. Nakatao (1982) Introduction of disaster index for manual snow-removal in Hokuriku, Japan. Journal of the Japanese Society of Snow and Ice, 44(4): 211.

F2*. T.Nakatao and M. Mizukoshi (1982) An empirical representation of snow-control cost as a function of snow disaster index, population, and regional snow conditions. Journal of the Japanese Society of Snow and Ice, 44(4): 205.

F3. R. Sakurada and I. Goto (1982) Basic snow endurance capacity of cities. Preprint of the Japanese Society of Snow and Ice 1982 meeting, p. 222.

F4. Z. Watanabe, S. Abe, and S. Nakamata (1982) Snow depth condition after heavy snowstorm in an urban area. Journal of the Japanese Society of Snow and Ice, 44(1): 37.

F5. H. Saito (1970) Economic efficiency of snow melting. Journal of the Japanese Society of Snow and Ice, 32(4): 05.

F6*. M. Ohshima (1978) A cost evaluation of snow removal by a heating system in a city in Japan. Journal of the Japanese Society of Snow and Ice, 40(4): 24.

F7. K. Takahashi (1969) Building a packed-snow parking lot. Journal of the Japanese Society of Snow and Ice, 31(5): 136.

\section{STATUTORY MEASURES AND REGULATIONS}

G1. Y. Yamanaka (1985) New standard for studded tires. Snow and Road, (5): 87.

G2*. S. Shimoda, T. Ishibashi, and M. Oshima (1981) Car noise test on snow-covered roads. Journal of the Japanese Society of Snow and Ice, 43(3): 163.

\section{COLLECTIVE MEASURES}

H1*. T. Kimura (1973) Snow surface detection by laser beam. Journal of the Japanese Society of Snow and Ice, 35(3): 13.

H2*. I. Tsubata and Y. Sorimachi (1981) Simple snowfall detector employing reflection of infrared rays. Journal of the Japanese Society of Snow and Ice, 43(2): 77.

H3. H. Maeda and R. Egawa (1982) Estimation of urban road snow volume to be removed during 
heavy snowstorms. Preprint of the Japanese Society of Snow and Ice 1982 meeting, p. 246.

H4. S. Nakamata (1982) City planning in deep snow areas. Journal of the Japanese Society of Snow and Ice, 44(1): 34.

H5. K. Ishihara (1971) Statistical snowfall forecast. Journal of the Japanese Society of Snow and Ice, 33(3): 31 .

H6. K. Ishihara (1971) Estimation of snow depth away from observatory. Journal of the Japanese Society of Snow and Ice, 33(3): 26.

H7. M. Inoue and Y. Takada (1971) Forecast system for road surface freezing. Journal of the Japanese Society of Snow and Ice, 33(4): 35.

H8. K. Takahashi and M. Shindo (1982) Development of road snow and ice forecast. Preprint of the Japanese Society of Snow and Ice 1982 meeting, p. 226.

H9. M. Tsuchiyama, N. Suemune, Y. Fujihara, Y. Takada K. Sasaki, and M. Inoue (1985) A method to predict road surface freezing. Preprint of the Japanese Society of Snow and Ice 1985 meeting, p. 134.

H10. K. Ichihara (1971) Highway design in deep snow areas. Journal of the Japanese Society of Snow and Ice, 33(4): 17.

H11. S. Yamagami (1971) Highway shoulders for deep snow areas. Journal of the Japanese Society of Snow and Ice, 33(4): 23.

H12. T. Abe (1985) Development of snow-removal equipment and removal procedures for median strips. Snow and Road, (5): 77.

H13. K. Seki (1982) Area snow-removal system in a densely populated area.Journal of the Japanese Society of Snow and Ice, 44(1): 40.

H14. Y.Sekimoto (1970) Snow discharge drain combined with snow melter. Journal of the Japan- ese Society of Snow and Ice, 32(4): 108.

H15. T. Okuma (1985) Snow discharge drain and snow-melting drain. Snow and Road, (5): 21.

H16. T. Tanaka (1971) Snow and ice control on Meishin Throughway. Journal of the Japanese Society of Snow and Ice, 33(4): 14.

H17. S. Miyazaki (1974) Highway snow control in Hokuriku. Journal of the Japanese Society of Snow and Ice, 36(4): 13.

H18. M. Yamashita (1983) Snow-removal operation in heavy snow areas of the Kan-etsu Expressway. Journal of the Japanese Society of Snow and Ice, 45(3): 151.

H19. K. Ichihara (1970) Problems of snow and ice in highway construction and maintenance..Journal of the Japanese Society of Snow and Ice, 32(4): 94.

H20. K. Sato and M. Murakuni (1982) Stabilization of snow on cutout slopes in deep snow areas. Preprint of the Japanese Society of Snow and Ice 1982 meeting, p. 225.

H21. A. Tono and A. Nakanishi (1985) Snow removal on two-lane highways. Snow and Road, (5): 67.

H22. M. Saito (1971) Tokaido bullet train snow and ice control. Journal of the Japanese Society of Snow and Ice, 33(3): 61.

H23. M. Shoda (1971) Control of blown snow for high-speed trains. Journal of the Japanese Society of Snow and Ice, 33(3): 79.

H24. T. Ishibashi (1971) Blown snow control system for the Tokaido bullet train. Journal of the Japanese Society of Snow and Ice, 33(3): 89.

H25. A. Tamura and Y. Shioda (1982) Snow control for the Tohoku bullet train. Journal of the Japanese Society of Snow and Ice, 44(3): 153. 


\section{APPENDIX B: LIST OF KEYWORDS}

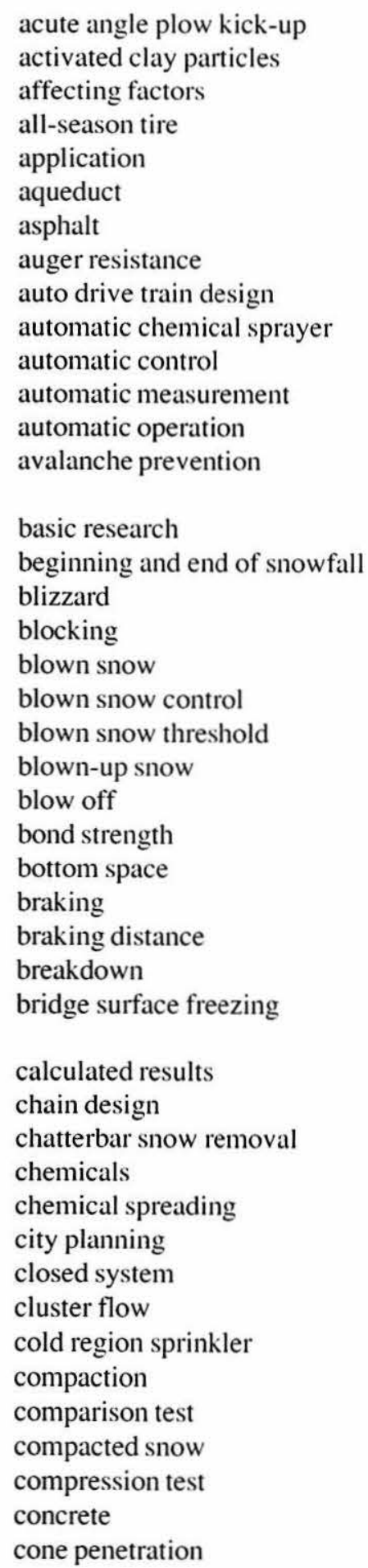

A19
D1,D2
E1
E8
B28
B26
A28
A20,A26
A29
H17
B33
H1
B40
H20

\section{A9}

H8

E3

B38

D8,E4

H23, H24

$\mathrm{H} 23$

H22

D3,D8

A16

D5

G1,H19

E2

A3-A5

H9

H15

E7

H21

$\mathrm{C} 1, \mathrm{H} 10$

B1

H4

$\mathrm{H} 13$

B34

H24

A13

B 10,E7

A31,B9,E9

A 14

A28

A10 connector standardization

continuous measurement

continuous snow conveyer

continuous traffic

control

control logic

cornice cutter

cost

cost analysis

crack velocity

critical strength

cumulative snowfall

cumulative snow discharge

curves

curved fence

cutout slope

cyclone

daily mean melting

deceleration

deflector

deformation

deformation rate

deformation type

density

design base

design base in deep snow areas

design criteria

disaster index

discharge well

downwind drift

drift guide net

drifting snow

economic impact

economic

economics

efficiency

effectiveness of chemicals

effect of woods

elbow

energy loss

energy saving

energy supply

environmental effects
B3

$\mathrm{H} 1$

B40,B41

$\mathrm{H} 12$

H16

B25

$\mathrm{H} 12$

$\mathrm{H} 18$

F6

A30

A27

H3

F4

H19

D8

H20

B33

H3

A11

E4

A12

A6-A8

A6-A8

A 17,A31

B32,H5,H6,H10,

H11,H14

H5,H6

H11

Fl

B14

D6

D7

D4

F1,F2

$\mathrm{H} 12$

F5

B39

C1

D4

B36

B37

B 13,B25

B27

H17 


\begin{tabular}{|c|c|c|c|}
\hline equilibrium & D5 & highway road-heating design & B28 \\
\hline equipment & $\mathrm{B} 11, \mathrm{H} 18$ & highway snow control & $\mathrm{H} 17$ \\
\hline equipment evaluation & B8 & highway snow removal & B26 \\
\hline experimental results & $\mathrm{H} 15$ & highway traffic capacity & E11 \\
\hline \multirow[t]{2}{*}{ experiments } & A26,H15 & high wind area & D9 \\
\hline & & hill climbing & G1 \\
\hline facility & $\mathrm{H} 18$ & Hokuriku & H5 \\
\hline fall back & B7 & homogeneous flow & B34 \\
\hline farm tractor adapter & B3,B4 & horizontal scale & E11 \\
\hline field measurements & A22 & & \\
\hline field observation & $\mathrm{A} 1, \mathrm{~A} 2$ & ice & $\mathrm{H} 7, \mathrm{H} 10, \mathrm{H} 16$ \\
\hline field study & D7,D8 & ice adhesion & A28 \\
\hline flexible hose & B40,B41 & ice forecast & $\mathrm{H} 7$ \\
\hline flow pattern & B34 & ice mechanics & $\mathrm{A} 30$ \\
\hline flow-type kick-up & A18,A19 & ice sheet & E9 \\
\hline flow velocity & B36 & icicle control & B30 \\
\hline flying debris & $\mathrm{H} 22$ & impact & A3-A5 \\
\hline forecast system & $\mathrm{H} 7, \mathrm{H} 8$ & impact force & A11,A15 \\
\hline foreign objects separation & B33 & impact process & A15 \\
\hline forest & D9 & impulse loading & A 15 \\
\hline friction & H10,H19 & indentation & A10 \\
\hline \multirow[t]{2}{*}{ frictional force } & B35 & infrared snow sensor & $\mathrm{B} 25, \mathrm{H} 2$ \\
\hline & & infrared ray scattering & $\mathrm{H} 2$ \\
\hline general & B1 & installed snow-melting system & B12 \\
\hline geothermal heat & B30 & & \\
\hline geothermal road-heating & B20 & junction & B37 \\
\hline geothermal snow-melting & B13-B15,B22 & & \\
\hline grader attachment & B9 & Kinosita hardness & A17 \\
\hline groundwater & $\begin{array}{l}\text { B13,B17,B22,B29, } \\
\text { B30,H17 }\end{array}$ & Kuroda shear strength & A22 \\
\hline groundwater level & B15,B20 & labor requirement & $\mathrm{F} 1$ \\
\hline \multirow[t]{2}{*}{ groundwater restoration } & B15, B20 & laboratory measurement & A27 \\
\hline & & laser beam & $\mathrm{Hl}$ \\
\hline hardness & $\mathrm{A} 9, \mathrm{~A} 17$ & laws and regulations & B1 \\
\hline hardship caused by snow & E1 & lee side & D6 \\
\hline heat balance & B30 & liquid water content & A17 \\
\hline heat control & B22,B28,B29, & load effect & E9 \\
\hline heat flow & B21,B27 & local meteorology & E5 \\
\hline heat pipe application & B30 & lukewarm water & B18 \\
\hline heat pipes & B24,B30,B32 & & \\
\hline heat pump & B24 & machinery section & B7 \\
\hline heat storage & B14,B15,B22 & maintenance & $\mathrm{H} 16$ \\
\hline heat supply & B14 & mechanical ice control & $\mathrm{A} 30$ \\
\hline heated water & B29 & mechanical ice removal & A28 \\
\hline heating cost & B20 & mechanical snow-removal basics & $\mathrm{A} 17, \mathrm{~A} 21, \mathrm{~A} 22$ \\
\hline heating pipe & B17,B22 & median snowbank control & H12 \\
\hline high concentration & B39 & metamorphosis & $\mathrm{H} 23$ \\
\hline high speed & $\mathrm{A} 11, \mathrm{~A} 12, \mathrm{~A} 14, \mathrm{H} 23$ & meteorological data & E3 \\
\hline high-speed photography & A15 & meteorological forecast & H9 \\
\hline high-speed plowing & A18 & meteorological factors & H5,H6 \\
\hline highway & $\mathrm{H} 7, \mathrm{H} 11, \mathrm{H} 16$ & meteorology & H6 \\
\hline highway design & D5,H10,H11,H20 & microscopic observation & A 31 \\
\hline highway design\& maintenance & H19 & mixing & B32 \\
\hline highway maintenance & D5,H16 & mixture & \\
\hline
\end{tabular}


B33,B34,B35,B39

mixture flow

mobile sprayer

mobile snow melter

model study

motorcycle stability

movable snow drain

moving melter

multiple-level use

multiple truck formation

multiple regression

\section{Nagaoka city}

narrow-road snow removal

natural conditions

natural snow

Niigata $\mathrm{Nr} 652 \mathrm{~S}$

noise pollution

noise spectrum

nonmetal chain

no-spray water heating

nylon tubing

on-off control

on-site testing

one-pass operation

operation procedure

operational safety

operating cost

orifice

packed snow

packed snow trafficability

paint

parking

particulate pollution

passable width

performance

photography

piping system

planning of snow-melting

plastic wave

plowing

power consumption

power efficiency

power loss

power requirement

power requirement analysis

pressure distribution

pressure drop

projectile

pump-up well
B38

B13

F5

D1,D2,D4

E12

$\mathrm{H} 13$

F5

B18

$\mathrm{H} 12$

H5

H4

B40,B41,H21

F2

A27

A24

G2

G2

E7

B16

B21

$\mathrm{H} 2$

B11

$\mathrm{B} 6, \mathrm{~B} 10$

$\mathrm{H} 18$

B5

B23

B38

E12,F7,G2

E12

A28

F7

G1

E10

B4

E11

B13

F5

A12,A14

A3-A9,E10

B16,B18,B19,

$\mathrm{B} 32$

A24,A25

B39

A23,A25,B28

A24

B37

B35,B36,B41,

B42

A11

B14 pushover method

$\mathrm{H} 12$

quantitative indexing

F2

questionnaire

$\mathrm{B} 5, \mathrm{~F} 4$

radiative heating E5

railroad

$\mathrm{H} 22, \mathrm{H} 25$

railroad snow control $\quad \mathrm{H} 22$

$\begin{array}{ll}\text { railroad snow-melting system } & \text { B29 }\end{array}$

reactive force

A29

recirculation

reflection of crack

regional snow-control funding

regression analysis

regulation

re-injection

residential area

resistance

resistance on ice

return well

reversible pipe heating

riding snowblower

rigid wheel

road aberration

road cross-section

road cut

road design

road freezing prevention

road heating

road ice scraper

road sign

B21

A30

F2

H8

G1

B17

$\mathrm{H} 4$

A11,A14,B31

G1

B18,B 15

B18,B 19

$\mathrm{B} 8$

A29

G1

E10

D4

$\mathrm{H} 4$

B23

$\mathrm{B} 13, \mathrm{~B} 16, \mathrm{~B} 18$, $\mathrm{B} 21, \mathrm{~B} 23, \mathrm{~B} 24$,

$\mathrm{B} 28, \mathrm{H} 17$

B2

H18

E5

road snow and ice classification A31

road snow and ice forecast $\mathrm{H} 8$

road snow melting B16,B21

road snow melting $\quad$ B13,F5,F6

road surface freezing forecast $\quad \mathrm{H} 9$

$\begin{array}{ll}\text { road surface temperature } & \text { B20, } \mathrm{H} 9\end{array}$

road temperature forecast $\quad \mathrm{H} 9$

roller packing

rolling resistance

F7

A29

roof snow $\mathrm{H} 13$

rotary cutting strength

A20

rotary snowblower

A23,A26,B2,

E10

$\mathrm{B} 3, \mathrm{~B} 4$

$\mathrm{B} 6, \mathrm{~B} 11$

B6

$\begin{array}{ll}\text { rubber-bottomed plow } & \text { B12 }\end{array}$

saw blade test

B10

saw-toothed cutter

B10,B11 
scattering of data

semi-empirical analysis

service level

shear adhesive strength

shear strength

shoulder

side-sliding blower

side-sliding cab

sidewalk

sintering

site preparation

skid resistance

slippage

slush pump

snow

snow accretion

snow and ice

snow and ice forecast

snowbank

snowbank cut adapter

snowbank removal

snowblower basics

snowblower design

snow classification

snow compressibility

snow compression blade

snow condition

snow control

snow control basics

snow control cost analysis

snow control plan

snow control planning

snow control in deep snow areas

snow conveyer

snow density

snow depth

snow depth distribution

snow depth guage

snow detector

snow disaster index

snow discharge volume

snow disposal

snow drag

snow drain

snow drain design basics

snow drain gutter

snowdrift

snowdrift control
A22

A24

E10

A28

A21,A22

H11

B6

B5

B3,B32

A21

D9

E8

E7

B31,B32,B40,B41

A3,A5,A10,A20

A22,D5,D6,H10,

H11,H16

E4,E5,E6

A1,A2,H19

$\mathrm{H} 7$

B5,B26

$\mathrm{H} 12$

B6,B10,B11

A20,A24-A27

A23

$\mathrm{A} 1, \mathrm{~A} 2, \mathrm{~A} 10$,

A31

A27

B7

C1

$\mathrm{C} 1, \mathrm{H} 21, \mathrm{H} 22$,

$\mathrm{H} 25$

B42,F4

F6

H4

$\mathrm{H} 3$

$\mathrm{H} 18$

B42

A13,B4

E1,F1,F4,H1,H6

D4

H1

H1

F1,F2

F4

B31,H14

A11

B27,H13-H15

A1,A2,B31-B39,

H15

B31

D1,D3,D5,D7,

E2

D9 snowdrift modeling

snow endurance capacity

snowfall

snowfall forecast

snowfall intensity

snow fence

snow groove cutter

snow hardness

snow melter control

snow melting

D1,D2

F3

E1,F3

H8

B27

D1,D3,D5-D8

B9

A25,A31,B9

$\mathrm{B} 25, \mathrm{H} 2$

$\mathrm{B} 1, \mathrm{~B} 15, \mathrm{~B} 17, \mathrm{~B} 23$,

B24,B26,F5,H14,

$\mathrm{H} 15, \mathrm{H} 17$

snow melting and ice prevention B18,B19

snow melting by groundwater $\quad \mathrm{B} 17$

snow melting capacity

H15

B27

A18

snow movement

A12,A14

snow pack

B2,B8

snowplow

snowplow accessory

B7

snowplow design basics

snow pole

A3-A12,A14-A16,

A18,A19

E6

snow removal and road design

snow-removal capacity

E10

F3

snow-removal equipment

$\mathrm{B} 1, \mathrm{~B} 2$

$\mathrm{H} 21$

B1

snow-removal planning

snow-removal system design

H13

H3

B40,B41

snow separator

D1

$\mathrm{H} 20$

E2

E8,E12

A13

H13-H15

B42

F1,F2

B19,B24

B23

B27

B1

D9

H23

B25

B25

A18,A19

B29

E12

B27

E7,H19

F5

E1,F2 


$\begin{array}{ll}\text { statistics } & \text { H5-H7,H25 } \\ \text { step width } & \text { H20 } \\ \text { stored heat } & \mathrm{B} 14 \\ \text { stream line } & \mathrm{D} 6 \\ \text { strength } & \mathrm{A} 10, \mathrm{~A} 16 \\ \text { studded tire } & \mathrm{E} 8, \mathrm{G} 2 \\ \text { studding design } & \mathrm{E} 8 \\ \text { studless tire } & \mathrm{E} 8 \\ \text { supporting strength } & \mathrm{A} 13 \\ \text { surface detection } & \mathrm{H} 1 \\ \text { surface treatment } & \mathrm{E} 4 \\ \text { system design } & \mathrm{F} 6 \\ & \\ \text { tee } & \mathrm{B} 37 \\ \text { temperature drop } & \mathrm{B} 16 \\ \text { temperature effect } & \mathrm{E} 9 \\ \text { test results } & \mathrm{A} 24, \mathrm{~B} 9 \\ \text { theory } & \mathrm{A} 16, \mathrm{H} 15 \\ \text { three-track formation } & \mathrm{H} 12 \\ \text { threshold speed } & \mathrm{H} 23 \\ \text { throw accuracy } & \mathrm{B} 5 \\ \text { throw distance } & \mathrm{A} 23 \\ \text { throw target } & \mathrm{B} 5 \\ \text { tire chains } & \mathrm{E} 7, \mathrm{E} 12, \mathrm{G} 2 \\ \text { tire friction } & \mathrm{E} 9 \\ \text { tire size effect } & \mathrm{E} 9 \\ \text { toll booth area } & \mathrm{B} 29 \\ \text { topography } & \mathrm{H} 6 \\ \text { traction } & \mathrm{B} 9, \mathrm{E} 9, \mathrm{G} 1, \mathrm{H} 19 \\ \text { traffic } & \mathrm{B} 13, \mathrm{C} 1 \\ \text { traffic control } & \mathrm{E} 2, \mathrm{E} 3 \\ \text { traffic management } & \mathrm{E} 2 \\ \text { traffic planning } & \mathrm{H} 4 \\ \text { traffic reduction } & \mathrm{E} 1 \\ \text { traffic safety } & \mathrm{E} 3 \\ \text { traffic sign } & \mathrm{E} 4, \mathrm{E} 6 \\ \text { trafficability } & \mathrm{E} 12 \\ \text { trafficable width } & \mathrm{E} 10, \mathrm{E} 11, \mathrm{~F} 4 \\ \text { transportation } & \mathrm{A} 1, \mathrm{~A} 2 \\ \text { tunnel } & \mathrm{B} 30, \mathrm{H} 25 \\ \text { tunnel entrance } & \mathrm{B} 28, \mathrm{H} 21 \\ \text { two-track formation } & \mathrm{H} 12 \\ \end{array}$

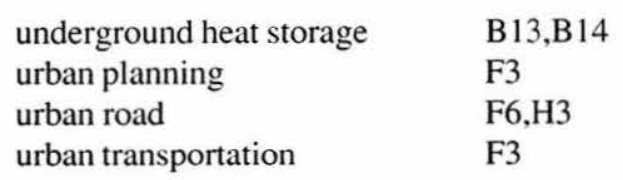

B13,B14

F3

F6, H3

F3

A28

A20-A22,A26

A17

E3

A27

A30

D3

A21

D7,E2-E4

A31

A16

B35,B36

B8

B21

F6

B14

B31,B32,H23

A16

B26

B13,B17,B19,H17

B15,B16,B17,B21,

B22,B24,B29,B30,

H13,H14

H14

B26,B29,H22,H24

B13

B16

E1

A13,A16,A17

E6

E5

D6,D7

D7

B 10,B11,D3

F7

E8 


\section{APPENDIX C: ENGLISH SUMMARIES}

These English-language summaries of the Japanese snow-removal literature have been edited for this report to improve their readability. Any figure references refer to illustrations included in the original Japanese reports and articles.

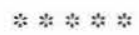

A1 Seiiti Kinosita and Eizi Akitaya (1969) Snow and ice on roads. I. Low-Temperature Science, Ser. A(27): 163.

The characteristics of snow on roads change continuously with the action of traffic, snow removal, weather conditions, etc., and appear in many different forms. Attention must be given to classification of the snow forms when studying snow removal, ice control operations, and winter driving.

Measurements of density, hardness, temperature, and soil content and micrographic observations were carried out in the winter of 1968-1969 on thin snow layers covering urban arterial roads in Hokkaido.

The following classification of snow types is proposed on the basis of these results:

New snow-Composed of snowflakes, immediately after a snowfall on roads; density $\rho \approx 0.1$ $\mathrm{g} / \mathrm{cm}^{3}$.

Powdery snow-Composed of loose grains 0.05 to $0.3 \mathrm{~mm}$ in diameter; blown up by passing cars; $\rho=0.27$ to $0.41 \mathrm{~g} / \mathrm{cm}^{3}$.

Grainy snow-Composed of loose grains $0.3 \mathrm{~mm}$ or larger in diameter; never blown up; formed by thermal metamorphosis, mechanical mixing, and chemical treatment; $\rho=0.28$ to $0.50 \mathrm{~g} /$ $\mathrm{cm}^{3}$.

Packed snow-A network texture of grains 0.05 to $0.3 \mathrm{~mm}$ in diameter; $\rho=0.45$ to $0.75 \mathrm{~g} / \mathrm{cm}^{3}$, hardness $H=20$ to $170 \mathrm{~kg} / \mathrm{cm}^{2}$.

Ice crust-Polycrystalline ice with air bubbles 0.1 to $0.5 \mathrm{~mm}$ in diameter; formed by freezing of wet packed snow; $\rho>0.75 \mathrm{~g} / \mathrm{cm}^{3}, H=90$ to $300 \mathrm{~kg} / \mathrm{cm}^{2}$.

Ice film-Polycrystalline ice with tiny air bubbles 0.01 to $0.1 \mathrm{~mm}$ in diameter; formed by freezing of meltwater film.

Slush-Formed by melting snow.

Snow on roads is sometimes composed of two or three layers; figures included in the article show packed snow, ice crust. powdery snow, and the ice film appearing in the slip trace of a car.

A2 Seiiti Kinosita, Eizi Akitaya, and Kunio Tanuma (1970) Snow and ice on roads. II. Low-Temperature Science, Ser. A(28): 311.

Where traffic is heavy, the snow layers that cover winter roads are very thin; their thickness is ordinarily less than several centimeters. The snow is changed continuously by the action of traffic, snow removal efforts, and the weather. Thus it is important to clarify the characteristics of the various types of snow on the road surface

Snow and ice were observed on urban arterial roads in Hokkaido, Japan, in the winters of 1968-1969 and 1969-1970. The density, hardness, temperature, and free water content were measured, and micrographic observations were carried out on the textures. Based on the results, it was proposed that snow and ice on roads should be divided into seven types: new snow, powdery snow, grainy snow, packed snow, ice crust, ice film, and slush.

At times one of the above exists as a single layer on roads, and at other times a combination of two or more types may exist in layers. Changes from one type to another occur frequently. The changes are caused by mechanical mixing, chemical treatment, or heat absorption. The heat is applied by warm air, solar radiation, or car tires rotating at high speed. The temperatures of tires at various speeds were measured. When a car runs at a high speed, the temperature of its tires frequently rises above $0^{\circ} \mathrm{C}$. 
Snow or ice renders the road surface very slippery. The slippery condition depends on the type of snow. Measurements were also made on the static and sliding friction of tires on the surface.

A3 Seiiti Kinosita (1955) The breakdown of snow by impulsive force. I. Low-Temperature Science, Ser. A(14): 95.

When a massive body is dropped onto a snow surface, the body experiences an intricate series of resistance forces from the snow before it is stopped, having sunk some distance into the snow. By putting a block of snow on a metal plate provided with a force-recording device and dropping a solid brass cylinder on it, Yosida, Kuroiwa, and the present author registered in previous experiments the resistance force transmitted through the snow to a force-recording device. In this experiment, the author attached the force-recording device to the falling cylinder itself, so the resistance force was registered more accurately than before.

A hollow cylinder made of thin iron plate $(6.6 \mathrm{~cm}$ diameter) with a closed bottom was fitted to the lower part of a solid lead cylinder (mass $=5 \mathrm{~kg}$ ); between the two a ring-formed steel spring was inserted. Very thin wires of an alloy with high electrical resistance were stretched along the surfaces of the spring. When the whole system was dropped onto the snow surface from a height of 0 to $6 \mathrm{~cm}$ above its surface, the resistance force exerted by the snow on the bottom of the hollow cylinder compressed the ring-formed spring. The thin wires on its outer and inner surfaces were elongated or shortened by the extension and contraction of each of the surfaces of the spring, with the result that their electrical resistance changed in proportion to the magnitude of the resistance force. This change in the electric resistance of the wires was recorded by an electromagnetic oscillograph.

Although not all experiments made under the same conditions yielded the same results, the mode of change in the resistance force during the time interval (less than $0.2 \mathrm{~s}$ ) needed for the falling body to be stopped in the snow after it first touches the snow surface can be classified into the following five types:

Type A-The resistance force increases step by step, forming two or three stages before it reaches the final value. Compact snow usually showed this type.

Type B-A large resistance force lasting about $0.01 \mathrm{~s}$ appears at the very first and is then followed by a long-lasting constant resistance force. This type was found generally on uniform soft compact snow. Even non-uniform compact snow composed of several snow layers tended to belong to this type when the metal cylinder was dropped parallel to the direction of the layers. [Ed. note: The block of snow was set on its side.]

Type C - The resistance force fluctuates widely and an oscillogram of the resistance force looks like a series of many steep peaks. Wet granular snow showed this type of resistance force. Compact snow tended also to belong to this type when it was composed of several snow layers of strikingly different nature.

Type D-The resistance force increases gradually from nothing to a maximum value showing no steps, unlike type A. Soft fresh snow showed this type. When the flat bottom of the falling cylinder was replaced by a conical bottom with its apex downwards, this type of resistance force was also found in compact snow. Granular snow showed a type intermediate between $\mathrm{A}$ and $\mathrm{D}$.

Type BC-A middle type between B and C. Firm compact snow and granular snow often showed this type.

The energy absorbed by the snow when the metal cylinder is dropped on it is equal to $w=\{M g(h+D)\} / S$ $\mathrm{kg}-\mathrm{wt}-\mathrm{cm} / \mathrm{cm}^{2}$ per horizontal unit area, where $M g, S, h$, and $D$ are the weight of the metal cylinder, the area of its bottom, the height above the snow surface from which it is dropped, and the subsidence depth at which it is stopped, respectively. This energy $w$ is supposed to be in intimate relation to the mass of snow compressed by the falling metal cylinder, that is, $a=D \rho \mathrm{g} / \mathrm{cm}^{2}$, where $\rho$ is the density of snow before it is compressed. Indeed, it was found that $w$ increased in proportion to the increase in $a$ in the case of compact snow, while the rate of increase in $a$ was gradually diminished with the increase in $w$ in the case of granular snow. The ratio $w / a$ could be used to represent the hardness of snow. The value of its inverse, $a / w$, was found to lie in the range from 0.5 to 1.5 in the case of compact snow. In illustrations that accompany the article, $a / w$ is shown in relation to the density of snow and to the time average value of the resistance force. 
When a mass of compact snow was sprinkled with water, the value of $a / w$ increased, showing that the snow became softer when it was wetted. The same result was observed when compact snow was crushed to pieces and gathered again. Breakdown of the ice bridges that had connected the ice grains composing the initial snow would be the cause of the increase in softness in this case. When the flat bottom of the falling cylinder was replaced by a conical one, $a / w$ usually tended to show a smaller value, that is, the snow appeared to be harder. The cause of this decrease in $a / w$ seems to be that the conical bottom compresses the snow sideways, while the flat bottom compresses it only in the downward direction.

A4 Seiiti Kinosita (1956) Breakdown of snow by impulsive force. II. Low-Temperature Science, Ser. A(15): 49.

The intricately changing resistance force that a body encounters while falling into snow was registered by an electromagnetic oscillograph. The resistance force showed large slow changes with superimposed rapid changes. The large changes seemed to arise from the difference in the strength of each of the snow layers comprising the snow, which were broken down one after another as the falling body sank into the snow. To study the relation between the large changes in the resistance force and the layered construction of the snow body, falling-body experiments were made on snow for which the load-supporting strength $W$ had previously been measured for each of its layers. It was found that each of the layers acted on the falling body with a resistance force of almost the same magnitude as its own load-supporting strength $W$.

The rapid changes that are superimposed on the larger slow ones seem to be due to the intermittent breakdowns that take place in each of the snow layers. One snow layer is of uniform structure, but it does not give way all at once; it undergoes several intermittent breakdowns. The impulses corresponding to each breakdown were calculated from the registered curve of the resisting force.

The snow at the bottom of the hole made by the falling body showed a large load-supporting strength, much greater than the load-supporting strength $W$ of the snow layer down to which the region of compressed snow had developed. Such a large increase in load-supporting strength was explained by the existence of a shearing force acting on the side surface of the region of the compressed snow.

Shearing strength was measured on many snow samples of different temperatures and different water contents. At $0^{\circ} \mathrm{C}$ it decreased with increasing water content; below $0^{\circ} \mathrm{C}$ it increased with decreasing temperature.

When the mass of snow compressed by the falling body and the energy absorbed by the snow are denoted by $a$ and $w$ respectively, the ratio $a / w$ can be considered to be a measure of the softness of the snow. The author found the values of this ratio to be in the range 0.5 to 2 for ordinary settled snow. The snow of winter 19551956, having been subjected to an intense sublimation metamorphosis, was very fragile and showed large values of the ratio, within the range 5 to 10 .

A5 Seiiti Kinosita (1957) Breakdown of snow by impulsive force. III. Low-Temperature Science, Ser. A(126): 119.

A body dropped onto snow is acted upon by the resistance force $R$ of the snow while the body is descending into it. This resistance force was registered by an electromagnetic oscillograph. The mode of the change in these resistance forces could be classified into five types. These types and the sorts of snow that each type exhibited are:

Type A-Uniform soft compact snow and a block of snow placed sideways so that the snow layers composing it stood upright.

Type B-Wet granular snow.

Type C-Compact snow.

Type D-Soft fresh snow. When the flat bottom of the falling body was replaced by a conical one with its apex downwards, this type was found also in the case of compact snow.

Type AB-A middle type between A and B. Firm compact snow and granular snow.

The resistance force $R$ arises from two different causes: pressure resistance $P$, which acts on the base of 
the region of compressed snow that developed underneath the falling body, and shearing force $Q$, which acts on its boundary side surface. This was confirmed by a specially devised experiment where $P$ increased gradually from a small value to a large one during the fall of the body within the snow while $Q$ appeared with a large value at the very first and declined suddenly to a small value. On the basis of such characteristics of $P$ and $Q$, some discussion was presented on the appearance of the five types of manifestation of the resistance force listed above.

When the snow was composed of several layers of different character, the resistance force showed a few peaks in its curve. It was confirmed experimentally that the peaks appeared at the instant when especially strong layers present in the snow were broken down. On the basis of this correspondence between the peaks and the strong layers it could be determined which part of the resistance force was caused by which of the snow layers.

The statistical strength of the bottom of the hole made by the falling body was found to be much greater than that of the deepest snow layer reached by the region of compressed snow. The resistance force commenced with a very steep large peak at the second fall of the body onto the bottom of the hole.

The mean value of the resistance force of snow $R$ may be used as a measure of its mechanical strength. The mean value $\bar{R}_{\mathrm{t}}$ is equal to $M g\left(T^{\prime}+T\right) / T$, where $M g, T^{\prime}$, and $T$ denote the weight of the falling body, the time intervals from the beginning of its fall to the instant of its first contact with the snow surface, and from then to the instant of its arrest by the snow, respectively. Space mean value $\bar{R}_{\mathrm{x}}$ is given by $M g(h+D) / D$, where $h$ and $D$ denote the height above the snow surface from which the falling body is dropped and the depth at which it is stopped, respectively. $\bar{R}_{\mathrm{t}}$ was found to be almost equal to $\bar{R}_{\mathrm{x}}$ in the case of a falling body with a flat bottom, while for one with a conical bottom the time mean value $\bar{R}_{\mathrm{t}}$ was without exception larger than the space mean value $\overline{R_{\mathrm{x}}}$.

The relation between the mechanical strength of snow $\bar{R}_{\mathrm{x}} / S$ (where $S$ is the area of the bottom of the falling body), and snow density $\rho$ is illustrated in the text with different marks for different kinds of snow. In the case of compact snow the greater the density, the stronger it becomes; the following relation between $\bar{R}_{\mathrm{x}} / S\left(\mathrm{~kg} / \mathrm{cm}^{2}\right)$ and $\rho\left(\mathrm{g} / \mathrm{cm}^{3}\right)$ is found:

$$
3.5(\rho-0.14)>\bar{R}_{\mathrm{x}} / S>1.3(\rho-0.14) .
$$

A6 Seiiti Kinosita (1957) The relation between the deformation velocity of snow and types of its deformation (plastic and destructive). I. Low-Temperature Science, Ser. A(16): 139.

The resistance force of snow against the compression to which it is subjected to was registered electrically by experimental apparatus. The speed of compression $v$ was chosen within the range of 1 to $40 \mathrm{~mm} / \mathrm{min}$. It was found that the snow deformed in two different ways according to whether $v$ lies above or below a value $v^{*}$ in the above-mentioned range. When $v>v^{*}$, the snow was deformed destructively, being fractured intermittently on the surface through which the compressive force was applied. The curve of resisting force $p$ had a sawtoothed appearance; sudden depressions of the curve at the right end of each "tooth" correspond to the intermittent fractures. When $v$ was gradually lowered, the teeth on the curve became broader and their height increased slowly until, finally, when $v$ became smaller than $v^{*}$ the teeth became so broad and flat that no depression representing the fracture occurred. In the latter case the snow was continuously deformed in a plastic manner. The deformation for $v>v^{*}$ and for $v<v^{*}$ are called "destructive" and "plastic," respectively.

\section{Plastic Type}

A series of photographs shows the plastic deformation of a snow column (snow density $\rho=0.38$, temperature $T=-3^{\circ} \mathrm{C}, v=4.8 \mathrm{~mm} / \mathrm{min}$ ); the resistance force $p$ continued to rise, at first rapidly and then slowly, without any discontinuous depression. It reached as high as $4 \mathrm{~kg} / \mathrm{cm}^{2}$ in the last stage of the experiment. The displacements of each mark put on the surface of the column showed that it shortened almost uniformly over its whole length.

When a rigid disk was pushed into a block of snow at low speed, the disk sank into it, making a conical depression on its surface. An illustration shows the vertical section of such a deformed block sprayed with colored water $\left(\rho=0.26, T=-2.3^{\circ} \mathrm{C}, v=2.6 \mathrm{~mm} / \mathrm{min}\right)$. The snow was most deeply tinted below the bottom of the depression; the tint diffused outwards, showing no distinct boundary of the tinted region. The resistance 
force $p$ of the snow block was continuous in the same manner as for the snow column described above.

\section{Destructive Type}

Another series of photographs shows the destructive deformation of a snow column during its compression ( $\rho=0.38$, temperature $T=-3^{\circ} \mathrm{C}, v=24.5 \mathrm{~mm} / \mathrm{min}$ ). The bottom of the snow column was destroyed and the snow squeezed out to pile up around the foot of the column. The relative positions of the marks on the surface of the undestroyed part of the snow column did not change, showing that the remaining part was not shortened. The resistance force appeared as saw-toothed waves. Its maximum value-that is, the value at the crests of the teeth-was $1 \mathrm{~kg} / \mathrm{cm}^{2}$, a strikingly small value when compared to that found in the case of plastic deformation.

The tinted cross section of a snow block into which a rigid disk was pushed at a speed of $5.2 \mathrm{~mm} / \mathrm{min}$ is illustrated. The disk made a hole with vertical side walls. A sharply stained region, the region of compressed snow, appeared below the bottom of the hole; this is in contrast to the diffusely stained region in the case of plastic deformation. In the case of the column, the destroyed snow that was extruded collected below the disk to form the region of compressed snow. The resistance force was saw-toothed; its maximum value was much smaller than that found in another case illustrated in the report.

To cause destructive deformation of wet snow required a larger compression speed than for dry snow. The curve of the resistance force was still saw-toothed, but it largely lost its regularity. In the case of the wet snow column, the destroyed snow was squeezed out in a tongue shape.

\section{Resistance Force $\mathrm{p}$ vs Compression Speed $\mathrm{v}$}

Since $p$ seemed to increase indefinitely over time, in the case of plastic deformation it was impossible to assign a definite value of $p$ for a given value of $v$. However, $p$ tended always to take a larger value as $v$ increased. In the case of destructive deformation, $p$ changed up and down between the maximum $p^{*}$ and the minimum $p_{*}$; the mean values of $p^{*}$ and $p_{*}$ became smaller as $v$ increased. The boundary velocity $v^{*}$ at which plastic deformation passes over to destructive deformation is 3 to $8 \mathrm{~mm} / \mathrm{min}$ in the case of soft snow ( $\rho=0.2$ to 0.3 ) and 7 to $12 \mathrm{~mm} / \mathrm{min}$ in the case of hard snow ( $\rho=0.35$ to 0.43 ).

The time interval $t^{*}$ between two successive ruptures - that is, the breadth of one sawtooth of the curve of resistance force-multiplied by $v$ gives the displacement $x^{*}$ of the compressing plate during that interval. $x^{*}$ is almost equal to or a few times larger than the size of the ice particles composing the snow.

The relation between $v$ and the elastic coefficient $E$ of the snow computed from the slope of the rising part of each sawtooth are illustrated. The values of $E$ are almost equal to those obtained by other researchers by the static method.

The characteristic quantities $t^{*}, x^{*}, p^{*}, p^{*}-p_{*}, p_{*}$, and $E$ of the teeth on the curve of the resistance force are not the same for each of the teeth; the frequencies with which values of the characteristic quantities appear are graphed in illustrations.

For plastic deformation of snow, viscosity coefficient $\eta$ is computed by the formula

$$
\eta=p_{1} \dot{\varepsilon}
$$

where $p_{1}$ and $\dot{\varepsilon}$ are the stress and the increasing rate of the strain of snow at the last stage of the experiment, respectively. The value of $\eta$ here is very small when compared with that found in the case of compression due to the natural weight of the snow cover.

The main features of these results, such as the appearance of the saw-toothed curve of resistance force for destructive deformation and its passing over to plastic deformation with decreasing compressing velocity, were explained by representing the snow by Maxwellian models. In that explanation the Maxwellian models were assumed to be destroyed when the stress produced in them reached a certain magnitude.

A7 Seiiti Kinosita (1958) The relation between the deformation velocity of snow and types of its deformation. II. Low-Temperature Science, Ser. A(17): 11.

In the previous paper [reference A6], the author reported the results of experiments in which snow samples in the form of a column or a large block were compressed at constant speeds $v$ of different magnitudes ranging 
from 1 to $40 \mathrm{~mm} / \mathrm{min}$. In the case of snow blocks the compression plate was pushed into them. The snow was found to deform in two different manners-plastic and destructive-according to whether $v$ lay below or above a critical speed $v^{*}$. The former type of deformation was called "plastic" and the latter "destructive." The resistance $R$ exhibited by snow against compression increased continuously in the case of plastic deformation while it oscillated like a saw-toothed wave between a maximum $R^{*}$ and a minimum $R_{*}$ in the case of destructive deformation.

This paper describes the continuation of the experiments reported in reference A6. Another type of destructive deformation was found, which the author named "destructive deformation of the second kind." This type of deformation occurs when the speed of compression exceeds another critical speed $v^{* *}$, which is larger than $v^{*}$. In this case the curve of resistance $R$ loses the saw-toothed feature characteristic of destructive deformation and becomes continuous, showing only small fluctuations. In addition to this change in $R$, under destructive deformation of the second kind, the ice fragments that were ejected in pieces from the destroyed part of the snow columnduring destructive deformation unite into a thin sheet of ice.

The critical speeds $v^{*}$ and $v^{* *}$ that divide these three types of contraction depend upon the snow temperature $T$. In the article, the three types are represented for snow with a density of 0.37 to 0.40 by different marks on the $T-v$ plane. Each of the three regions divided by the thick broken line and the dotted line on the plane contains the marks of only one type of contraction. The dividing lines show the relationships between $T, v^{*}$, and $v^{* * *}$. They can respectively be represented by

$$
\begin{aligned}
& v^{*}=11+0.4 T \mathrm{~mm} / \mathrm{min} \text {, and } \\
& v^{* * *}=17 \times 10^{-0.154 T} \mathrm{~mm} / \mathrm{min} .
\end{aligned}
$$

The critical speeds $v^{*}$ and $v^{* *}$ also depend upon snow density $\rho$. Similar to the above, the three types of deformation are plotted by different marks on the $v-\rho$ plane for the restricted temperature range of $0^{\circ}$ to $-5^{\circ} \mathrm{C}$. The plane is divided into three parts and the dividing lines show the dependence of $v^{*}$ and $v^{* *}$ upon $\rho . v^{*}$ can be formulated by

$$
v^{*}=30 \rho \mathrm{mm} / \mathrm{min} \text {. }
$$

The division between the regions of destructive deformation and destructive deformation of the second kind is not very clear. The author can do nothing more than to represent $v * *$ in a rather vague way as

$55 \mathrm{~mm} / \mathrm{min}>v^{* * *}>35 \mathrm{~mm} / \mathrm{min}$,

independently of $\rho$.

The types of contraction are represented on the $p-\rho$ plane where $p$ is the resistance $R$ taken for a unit area, that is, $p$ is $R$ divided by the area $A$ of compression. The marks indicate the value of $p$ at $5 \%$ contraction for plastic deformation and $p^{*}=R^{*} / A$ for destructive deformation. For destructive deformation of the second kind, the mean value of $p$ is adopted. Then the lines dividing the plane into regions of different types of deformation indicate the values of $p$ corresponding to the critical speeds $v^{*}$ and $v^{* *}$ in relation to density $\rho$. Let these values of $p$ be represented by $p_{1}$ and $p_{2}$. Then the relationships between $p_{1}, p_{2}$, and $\rho$ are given by

$$
\begin{aligned}
& p_{1}=21.4 \rho^{3} \mathrm{~kg} / \mathrm{cm}^{2} \text { and } \\
& p_{2}=12.6 \rho^{3} \mathrm{~kg} / \mathrm{cm}^{2} .
\end{aligned}
$$

The values of $p$ and $v$ observed on the snow columns of densities 0.37 to 0.40 at different temperatures are plotted. The difference in temperature is indicated by the different shapes of the marks. It can be seen that the change of $p$ with $v$ can be represented schematically by the curve $a p_{1} p_{2} b . p$ tends to increase slowly with the 
increase of $v$ in the region of plastic deformation to reach $p_{1}$ at $v=v^{*}$. Beyond this point, in the region of destructive deformation, $p$ decreases with increasing $v$ and still continues to decrease at a somewhat reduced rate after having crossed the second critical point $p_{2}$ at $v=v^{* *}$. How the resistance $p$ of snow depends on compression speed $v$ and snow density $\rho$ is indicated by figures accompanying the text.

Plastic contraction does not damage snow but makes it stronger. When snow columns once subjected to plastic deformation are compressed destructively, $p *$ is found to have been increased by the plastic deformation, and critical speed $v^{*}$ has also been shifted toward a larger value.

All the results of this experiment were obtained by compressing snow samples parallel to their stratification so as to keep the nature of the snow unchanged in the direction of compression. The destruction of snow columns undergoing destructive deformation occurred only at their end planes. When the destructive deformation occurs perpendicular to the stratification, however, the plane of destruction ceases to be confined to the end planes of the snow column: many planes within the body of the snow column become by turns planes of destruction. A series of photographs shows the destructive deformation of a snow column cut from the snowcover perpendicular to its stratification. Arrows indicate the position of destruction generated within the body of the column.

A8 Seiiti Kinosita (1960) The relation between the deformation velocity of snow and its types of deformation. III. Low-Temperature Science, Ser. A(19): 135.

For the last several years, Kinosita has been studying plastic and destructive deformation of snow by compressing columns of snow at constant speeds $v$ of different magnitudes. The results of the experiments have been reported in his previous papers [references A6, A7]. He found that the columns of snow were subjected to destructive deformation when $v$ was above a certain critical speed $v^{*}$, while they underwent plastic compression when $v$ was below $v^{*}$.

1) The stress $p$ induced within the snow by compression changes with time $t$. In the case of destructive deformation, the stress $p$ shows saw-toothed oscillations between a maximum $p^{*}$ and a minimum $p_{*}$, while in the case of plastic deformation $p$ shows a rapid rise at first, followed by a prolonged gentle rise. The elastic coefficient $E$ of the snow can be determined from slope $d p / d t$ of the rising portions of the sawteeth and of the initially rapidly rising part $A B$ of the curve:

$$
E=(d p / d t) /(v / l),
$$

where $l$ is the height of the snow column. In the case of plastic deformation, another physical constant, viscosity coefficient $\eta$, is introduced, which concerns the slowly increasing part $B C D$ of the curve. Viscosity coefficient $\eta$ is defined as $\eta=p / \varepsilon$, where $\varepsilon=v / l$ is the strain rate. Actually, $\eta$ is not a constant because $p$ changes with time. For the sake of comparison, the magnitude of $\eta$ is represented by its value at the strain $\varepsilon$ of $5 \%$.

The relationships of $E$ and $\eta$ to snow temperature $T$, snow density $\rho$, and strain rate $\dot{\varepsilon}$ are illustrated. Elastic coefficient $E$ is independent of $T$ but increases with increasing $\rho$ and $\dot{\varepsilon}$. Viscosity coefficient $\eta$ increases rapidly with decreasing $T$. An increase in $\rho$ or a decrease in $\dot{\varepsilon}$ causes $\eta$ to increase. These relationships can be represented by the equations

$$
\begin{aligned}
& \log _{10} E=5.9 \rho+0.24 \log _{10} \dot{\varepsilon}+6.4 \\
& \log _{10} \eta=-0.04 T+4.6 \rho-0.87 \log _{10} \dot{\varepsilon}+4.55
\end{aligned}
$$

where $E, \eta, T, \rho$, and $\dot{\varepsilon}$ are in units of dyne $/ \mathrm{cm}^{2}$, dyne $\bullet \mathrm{sec} / \mathrm{cm}^{2},{ }^{\circ} \mathrm{C}, \mathrm{g} / \mathrm{cm}^{3}$, and $1 / \mathrm{s}$, respectively. Eq A8-2 is available within the ranges of $-30<T<0,0.1<\rho<0.5$, and $10^{-6}<\dot{\varepsilon}<10^{-1}$, while eq A8-3 is within $-30<$ $T<0,0.1<\rho<0.5$, and $10^{-7}<\dot{\varepsilon}<\dot{\varepsilon}^{*}$. Here $\dot{\varepsilon}^{*}=v^{*} / l$ is the critical strain rate.

2) With plastic deformation, the strain $\varepsilon_{\mathrm{B}}$ at point $B$, where the slope of the stress curve becomes gentle, is almost constant $(0.01-0.02)$, irrespective of the values of $T, \rho$, and $\dot{\varepsilon}$. Maximum stress $p^{*}$ of the destructive deformation increases with decreasing $v$ but never exceeds the $p$ that the snow exhibits at strain $\varepsilon_{\mathrm{B}}$ when it is subjected to plastic deformation at the critical speed $v^{*}$. Those facts, together with the results described above, 
permit the general feature of $p-\varepsilon, \varepsilon$ curves to be schematically represented. In the figure the numerals 1 to 6 attached to the lines indicate their increasing order to strain rate $\dot{\varepsilon}$.

3) When the compression of snow is stopped after the snow has been strained to some extent $\dot{\varepsilon}_{\mathrm{D}}$, the stress $p$ begins to decrease rapidly, with no change occurring in the strain. This is the phenomenon of stress relaxation. Let the rate of relaxation be represented by the ratio $\lambda=p_{1} / p_{\mathrm{D}}$, where $p_{\mathrm{D}}$ and $p_{1}$ are the values of $p$ at the moment of and 1 minute after cessation of the compression, respectively. The dependence of $\lambda$ upon $\rho$ and $T$ is very weak as compared to its dependence upon $\dot{\varepsilon}$.

4) When snow gets wet, the critical speed $v^{*}$ increases. For instance, wet snow with a density of 0.28 and a free water content of $2.6 \%$ could be compressed plastically even at such a great speed as $60 \mathrm{~mm} / \mathrm{min}$, while the same snow, when dry at $0^{\circ} \mathrm{C}$, began destructive deformation at the speed of $11.5 \mathrm{~mm} / \mathrm{min}$. The tendency of $\eta$ to decrease with increasing $\dot{\varepsilon}$ is the same in wet snow as in dry, but the value of $\eta$ is, for the same $\dot{\varepsilon}$, much smaller in wet than in dry snow.

A9 Seiiti Kinosita (1960) The hardness of snow. I. Low-Temperature Science, Ser. A(19): 119.

Hard snow is thousands of times harder than soft snow. Kinosita devised an instrument for accurately measuring the hardness of snow over a wide range. A thin circular metal plate $\mathrm{C}$ ( $\operatorname{area}=S \mathrm{~cm}^{2}$ ) is put on the snow surface. Rod A with a small cylinder B at its bottom end (weight $=M \mathrm{~kg}$ ) is stood on plate $\mathrm{C}$. A brass cylinder $\mathrm{m}$ (weight $=m \mathrm{~kg}$ ) with a hole through the center is held $h \mathrm{~cm}$ above the upper surface of B with rod A passed through its center. When brass cylinder $m$ is released, it collides with cylinder $B$, pushing the whole appliance some distance $d \mathrm{~cm}$ into the snow. The resistance force of the snow averaged over distance $d$ is equal to $\bar{F}(\mathrm{~kg})=m[1+(h / d)]+M$. The harder the snow, the larger the value of $F$. The author defines the hardness $H$ of snow as $F$ divided by area $S$ of plate $\mathrm{C}$, that is, $H=\overline{F / S ~ k g} / \mathrm{cm}^{2}$. The wide range of hardness from about $1 \mathrm{~g} / \mathrm{cm}^{2}$ (new soft snow) to about $20 \mathrm{~kg} / \mathrm{cm}^{2}$ (old compact snow) can be covered by changing the values of $S$, $m$, and $h$. Diameter $D$ of plate $C$, the weight of $\mathrm{m}$, and height $h$, which should be most suitably chosen for different kinds of snow, are given.

The change in hardness of a snowcover in relation to the distance above the ground is shown. The hardness was determined by three different hardness meters: H-Kinosita's, $\mathrm{K}-$ Kuroda's, and R-Rammsonde's. Kinosita's appears to give the most reasonable hardness profile.

Hardness $H$ is plotted against snow density $\rho$. An illustration uses triangles to show the values obtained on wet snow; all other marks are for dry snows at temperatures from $0^{\circ}$ to approximately $-9^{\circ} \mathrm{C}$. With dry snows, the relationship between $H$ and $\rho$ is represented by $H=100 \rho^{4}$.

In snow, feet make holes and skis make tracks or grooves. The energy needed to make a hole and a groove was determinedusing thepresent hardness meter. Making a hole was found to require three times as much energy as making a groove. Once a hole is made, its bottom becomes five times harder than the natural snow surface.

The snow compressed by the present hardness meter creates a distinctly bordered region of compacted snow beneath the bottom of the hole. A thin section for microscopic observation was cut vertically through the snow below the center of the hole. In a portion of a thin section taken just below the border of the compressed region the ice grains are joined firmly with one another. In this compressed region, the ice grains lie like sand grains with no joints between them.

A10 Seiiti Kinosita (1964) Intrusion of a rigid cone into snow. Low-Temperature Science, Ser. A(23): 17.

A rigid cone was intruded into snow at constant speeds of from 1 to $30 \mathrm{~mm} / \mathrm{min}$. The apex angles of the cones were $6,30,60,90,120$, and $150^{\circ}$. With the exception of the $6^{\circ}$ cone, above a certain critical speed, the snow deformed destructively and below it plastically. With destructive deformation, breakdown occurred intermittently along the grain boundaries of the ice grains composing the snow. The broken ice grains were packed into the compressed region beside or under the cone. The amount of resistance increased rapidly, presenting a sawtoothed curve. With plastic deformation, the horizontal layers of the snow lengthened and bent, and most of the ice grains in the snow near the cone underwent basal slip. The amount of resistance increased without any discontinuity. 
When the $6^{\circ}$ cone was pressed into the snow, the amount of resistance increased with occasional sharp peaks. In a photograph of a thin section, the ice grains look as if they had been cut off with a sharp-edged razor. Microscopic observations indicated that, as the apex of the cone touched each ice grain, the resistance force increased sharply. Recrystallization originated from this contact point, and then the ice grains contacted the cone by basal slip.

From these results, the following relationships between the force $F \mathrm{~kg}$, the vertical angle of the cone $\theta$, snow density $\rho \mathrm{g} / \mathrm{cm}^{3}$, and the subsiding distance of the apex of the cone under the snow surface $Z \mathrm{~cm}$ were obtained:

$$
\begin{array}{ll}
\text { For destructive deformation } & F=7 \theta^{1.67} \rho^{3} Z^{2} \\
\text { For plastic deformation } & F=14 \theta^{1.67} \rho^{3} Z^{2} .
\end{array}
$$

A11 M. Miyairi, J. Ohkushi, and S. Ozawa (1966) The drag of bodies moving through snow at high speeds. Journal of the Japanese Society of Snow and Ice, 28(1): 23.

The drag of bodies moving through snow at high speeds $(15-40 \mathrm{~m} / \mathrm{s})$ was studied. Shells (as high-speed moving bodies) were shot into a pile of snow by an air gun, and the output from a built-in acceleration meter was recorded on an oscillogram. The impulsive acceleration of the shells when they hit the snow surface was measured, and the relation between the drag and the speed of the shell was obtained by integrating the curve on the oscillogram. In the speed range studied, the drag of a body can be expressed as a sum of a term proportional to the square of the velocity and a constant term.

A12 Atsushi Sato and Gorow Wakahama (1976) Plastic wave in snow. Low-Temperature Science, Ser. A(34): 59.

When snow is pushed very fast by a moving body, a plastic wave is generated at the head of the body. If the velocity of the moving body nears that of the plastic wave, the snow may exert a great resistive force against the body, as described by Yosida. It is therefore important to study the dynamic behavior of snow at a high rate of deformation, which takes place when a snowplow is used on the highway, a train runs on a railroad covered with snow, or an avalanche occurs.

The detailed processes of high-speed deformation of snow were studied through laboratory experiments on the impulsive compression of snow.

Rectangular parallelepiped blocks of snow, $20 \mathrm{~cm}$ in high with an upper surface area of $10 \times 10 \mathrm{~cm}^{2}$, were cut from the homogeneous snow layers of a snow pack. The density of the snow ranged from 0.17 to $0.49 \mathrm{~g} /$ $\mathrm{cm}^{3}$. Guided by thin metal wires, a cylindrical 1-kg metal weight was dropped from a height of $2 \mathrm{~m}$ above the surface of the snow block. The strike generated not only elastic waves but also a plastic wave in the snow. Fracturing of the snow often took place when the snow density exceeded $0.3 \mathrm{~g} / \mathrm{cm}^{3}$. Though an elastic wave is invisible, a plastic wave advancing through the snow can be directly observed by the successive displacement of dark lines marked at 2-cm intervals on the front surface. The propagation of a plastic wave through the snow block was observed with $16-\mathrm{mm}$ slow-motion film taken at approximately 42,000 frames per second. The velocity of the front of the plastic wave was obtained by analyzing the film. Together with direct observation of the plastic wave, the pressure accompanying the front of this wave was detected and its velocity was obtained by a pressure-detecting device embedded beforehand in the snow block, which was connected to an oscilloscope. The plastic wave velocity was obtained from the slow-motion films; it was confirmed that these two agreed fairly well with each other.

\section{Dependence of Snow Density on Plastic Wave Velocity}

The travel-time curve of a plastic wave propagating through a fine-grained snow of $0.81 \mathrm{~g} / \mathrm{cm}^{3}$ in density is represented by a thick solid line running through solid squares. The gradient of this curve gives the front velocity, $U$, of the plastic wave in the snow; the value of $U$ in this case is $6.2 \mathrm{~cm} / \mathrm{s}$ for the impact speed of 4.3 $\mathrm{m} / \mathrm{s}$. The dark lines on the snow surface move downwards, as shown by the solid thin curves originating from 
the solid squares. The gradient of each thin curve gives the particle velocity $u$ of snow immediately after the passing of the plastic wave. For the same impact speed, the value of $u$ ranges from $4.3 \mathrm{~m} / \mathrm{s}$ at the upper portion of the snow block - the same as the impact speed-to $3.8 \mathrm{~m} / \mathrm{s}$ at depths of $8-10 \mathrm{~cm}$ below the top surface.

Plastic wave velocities obtained for various kinds of dry snow are plotted with open circles against the snow density. Though these plots are widely scattered, it can be seen from the figure that the plastic wave velocity $U$ for dry snow increases with increase of the density $\rho_{0}$, of snow: $U$ is $6.5 \mathrm{~m} / \mathrm{s}$ for $\rho_{0}=0.2 \mathrm{~g} / \mathrm{cm}^{3}$ and $12 \pm 2$ $\mathrm{m} / \mathrm{s}$ for $\rho_{0}=0.4 \mathrm{~g} / \mathrm{cm}^{3}$.

\section{Dependence of Free Water Content of Snow on Plastic Wave Velocity}

Using wet snow samples cut from fine-grained snow layers of a melting snow pack whose density ranged from 0.43 to $0.44 \mathrm{~g} / \mathrm{cm}^{3}$, plastic wave velocity $U$ was measured for wet snow with a free water content $w$ that ranged from 2.6 to $17.7 \%$. The velocity $U$ was plotted against the free water content $w$, and against the snow density $\rho_{0}$ with solid circles. There is no distinct correlation between $U$ and $w$, but $U$ is in general smaller than for dry snow of the same density.

\section{Changes in Density and Structure of Snow Caused by Impaction}

Thin sections $1 \mathrm{~cm}$ thick were cut from a snow block after each impact so changes in the snow's structure caused by the impact could be examined. It was observed under a transmitted light that the snow immediately below the indented weight was heavily compacted by the impact. The structure of the underlying snow appeared to remain unchanged; this was verified by a microscopic examination of its texture.

Immediately after the impact, snow density was measured at $1-\mathrm{cm}$ intervals throughout the snow sample, which had an original density of $0.30 \mathrm{~g} / \mathrm{cm}^{3}$. The density of the heavily compacted portion was found to be much greater than that of the original snow, but it decreased from $0.61 \mathrm{~g} / \mathrm{cm}^{3}$ at the top down to $0.49 \mathrm{~g} / \mathrm{cm}^{3}$ at the bottom. The density of snow in the underlying portion $\mathrm{B}$, however, remained the same as the original density.

\section{Comparison of Observed Density of Heavily Compacted Portion}

\section{to That Predicted by Plastic Wave Theory}

When a plastic wave propagates through snow, the density of the snow should increase abruptly along the wave front. Since the pressure $P$ in the snow and the particle velocity $u$ of the snow are both zero before the arrival of the wave front, the following equations can be derived from the conservation of mass and momentum of snow (Rankine-Hugoniot relations):

$$
\begin{aligned}
& \rho_{1}=\rho_{0} /(1-u / U) \\
& P_{1}=\rho \cdot U \cdot u=\rho_{0}\left(1-\rho_{0} / \rho_{1}\right) \cdot U^{2}
\end{aligned}
$$

where $\rho_{0}$ and $\rho_{1}$ are the density of snow before and immediately after the passage of the plastic wave front respectively, $U$ is the velocity of the plastic wave front, and $u$ is the particle velocity of snow.

The density $\rho_{1}$ of snow at the wave front was calculated by using eq 1 for various snow samples with different densities. For instance, $\rho_{1}=0.50 \pm 0.05 \mathrm{~g} / \mathrm{cm}^{3}$ for snow of $\rho_{0}=0.18 \mathrm{~g} / \mathrm{cm}^{3}$, and $\rho_{1}=0.55 \pm 0.03 \mathrm{~g} / \mathrm{cm}^{3}$ for $\rho_{0}$ $=0.24 \mathrm{~g} / \mathrm{cm}^{3}$. For a higher density of snow $\left(\rho_{0}=0.3 \mathrm{~g} / \mathrm{cm}^{3}\right)$, the calculated value of $\rho_{1}$ generally exceeds 0.8 $\mathrm{g} / \mathrm{cm}^{3}$ or even becomes $0.917 \mathrm{~g} / \mathrm{cm}^{3}$, that is, the density of ice. It is, however, most unlikely that this will occur in snow. It is known that the density of the closest packed snow grains is $0.60 \mathrm{~g} / \mathrm{cm}^{3}$. To attain a higher density of snow than $0.6 \mathrm{~g} / \mathrm{cm}^{3}$, the snow must be compressed to allow plastic deformation of the snow grains. This implies that the density associated with the plastic wave front cannot exceed the density of snow at the closest packing: $\rho_{1}=0.6 \mathrm{~g} / \mathrm{cm}^{3}$. When the value of $\rho_{1}$ exceeds $0.6 \mathrm{~g} / \mathrm{cm}^{3}$, macroscopic fracturing would occur at the wave front. Such macroscopic fracturing was actually observed fairly frequently at the time of impact running through the entire snow block, whose density was greater than $0.3 \mathrm{~g} / \mathrm{cm}^{3}$.

Equation A12-1 can be rewritten as follows: 


$$
U=u /\left(1-\rho_{0} / \rho_{1}\right)
$$

This equation shows that the plastic velocity becomes larger when impact velocity $u$ is larger or initial snow density $\rho_{0}$ approaches $\rho_{1}$, the density of snow at the closest packing. If $\rho_{0}=\rho_{1}$, then $U$ becomes infinite. In the experiments, impact velocity $u$ was taken as $4.3 \pm 0.2 \mathrm{~m} / \mathrm{s}$, so the plastic wave velocity $U$ is a unique function of the initial snow density $\rho_{0}$, provided that $\rho_{1}$ is fixed at a constant value such as $0.6 \mathrm{~g} / \mathrm{cm}^{3}$. The curve in the dashed line in figure 5 of the text indicates the relation between $U$ and $\rho_{0}$ when $\rho_{1}=0.6 \mathrm{~g} / \mathrm{cm}^{3}$. Though the observed values are widely dispersed, it may be said that they tend to fit the predicted curve.

\section{Pressure}

The pressure $P_{1}$ associated with the plastic wave can be estimated from eq A12-2 by substituting the observed values of $U$ and $u$, together with the initial density of snow $\rho_{0}$. The values of $P_{1}$ thus obtained range from 0.03 to 0.29 bars. These pressure values were compared with those obtained from direct measurements. The observed values of $P_{1}$ ranged mostly from 0.1 to 0.4 bars. Though the observed values are slightly larger than those estimated from the theoretical formulas, the order of magnitude of $P_{1}$ was found to be 0.1 to 0.3 bars. Since the compressive strength of the snow is 0.1 to 0.3 bars, breaking of ice bonds between snow grains or microscopic fracturing of snow could occur at the arrival of the plastic wave front.

A13 Tatsuro Muro (1978) Compaction properties of wet snow.Journal of the Japanese Society of Snow and Ice, 40(3): 8 .

The mechanical properties of artificially compacted wet snow in Fukui City were studied to provide basic data for the trafficability of oversnow vehicles. The bulk density of wet snow compacted under constant energy increased steadily with the increase of water content, while the dry bulk density remained constant. These phenomena are different from those of soil materials. The cone resistance of wet snow compacted under constant energy varies with water content and snow density, giving maximum values at $8 \%$ water content and at $0.62 \mathrm{~g} / \mathrm{cm}^{3}$ wet density. The maximum value decreases mainly with the increase of the grain size of snow particles. The cone resistance of wet snow with a constant water content and grain size increases exponentially with the snow density.

A18a Zyungo Yosida (1974) Theoretical studies of snow removal by a plow. I. Flow-type kick-up of snow caused by a plow moving at high speeds. Low-Temperature Science, Ser. A(32): 39.

The first thing a snow plow does is kick up snow with its front edge. The main purpose of this paper and the following one [reference $\mathrm{A} 18 \mathrm{~b}$ ] is to derive equations for velocity $v$ or $v_{\mathrm{c}}$, the velocity of the snow immediately after the kick-up. As plow shapes vary, the motion of the snow that is caused by the plow may conveniently be determined by using the value of $v$ or $v_{c}$ as an initial condition for movement of the snow on the sloping surface of the plow blade. Use is made of coordinates moving together with the plow. The following assumptions were made:

1) The snow to be removed by a plow is homogeneous in nature, of density $\rho_{0}$, of thickness $h^{3}$ and lies on flat ground; 2) the plow runs at constant speed $V$ along a straight line; 3 ) the front edge of the plow is perpendicular to this straight line; 4) the snow undergoes uniaxial compression, with the axis always in the direction of its instant motion, not only when it is nearing the plow but alsoduring the very short interval in which it is being kicked up; 5) uniaxial stress $p$ of the snow increases in proportion to any increase in its uniaxial strain $\varepsilon$, that is, the relation $p=k \varepsilon$ holds during a loading process, while $p$ decreases with no change in $\varepsilon$ during an unloading process: the uniaxial compression of the snow is completely plastic; 6) the snow is pulverized when $p$ reaches a critical value $p_{\mathrm{c}}$, which will be called the "stress of pulverization."

A weak plastic deformation is propagated within the snow at the speed given by $c=\sqrt{k / \rho_{0}}$. Let $\gamma$ be defined by

$$
\gamma=(V / c)^{2}=\rho_{0} V^{2} / k
$$


If $\gamma>1$, that is if $V>c$, it is shown that the snow undergoes no compression before it reaches the edge of the plow. In this paper and the next one [reference $\mathrm{Al} 18 \mathrm{~b}$ ], the term "high-speed" means $V$ is greater than $c$; the studies are limited to snow kicked up by a plow moving at "high speeds."

There are two types of kick-up: flow and spray. In the flow type, the kicked-up snow flows up the sloping surface of the plow, maintaining its own consistency and staying in contact with the surface. In the case of the spray type, the snow is pulverized by the kick-up and flies off in a direction that deviates from the horizontal by more than the scooping angle a of the plow. The two types of kick-up are studied separately in this paper and the next one [reference A18b]. Velocities $v$ and $v_{c}$ mentioned above are those of the snow just after flow- and spray-type kick-up, respectively.

As uniaxial stress $p$ in the snow flowing up the sloping surface of the plow will be small, let it be assumed to be zero. Then the law of energy gives

$$
1-(v / V)^{2}=p_{\mathrm{A}}{ }^{2} / k \rho_{0} V^{2}
$$

where $p_{\mathrm{A}}$ is the maximum value that $p$ attains during flow-type kick-up. The value of $p_{\mathrm{A}}$ is estimated in the following way. Forces $f$ are distributed over a small area at the edge of the plow to kick up the snow. $\boldsymbol{F}$ represents the resultant of $f$. If the plow were fictitiously removed and the snow went straight beyond the position of the edge of the plow with horizontal components $f_{\mathrm{x}} \mathrm{s}$ of $f \mathrm{~s}$ acting on it, the stress in the snow would increase to attain a maximum value given by

$$
p_{\mathrm{A}}^{\prime}=-F_{\mathrm{x}} /(\gamma-1) h_{0},
$$

where $F_{\mathrm{x}}$ is the horizontal component of $\boldsymbol{F}$. It is assumed that $p_{\mathrm{A}}^{\prime}$ gives the value of $p_{\mathrm{A}}$. The law of momentum gives

$$
-F_{\mathrm{x}} / h_{0}=\rho_{0} V^{2}\{1-(v / V) \cos \alpha\} .
$$

From eq A18a-2, -3 , and $-4, v / V$ is obtained as a function of $\gamma$ with $\alpha$ as a parameter:

$$
v / V=\left[\gamma \cos \mathrm{a}+(\gamma-1) \sqrt{(1-1)^{2}-\gamma \sin ^{2} a}\right] /\left[\gamma \cos ^{2} \mathrm{a}+(\gamma-1)^{2}\right] .
$$

Running resistance of the plow due to flow-type kick-up is equal to $-F_{\mathrm{x}}$.If $-F_{\mathrm{x}}$ is written in the form $C_{1} h_{0} \rho_{0} V^{2}$, the coefficient of running resistance $C_{1}$ is given by

$$
C_{1}=1-(v / V) \cos \alpha
$$

Curves of $v / V$ and $C_{1}$ are drawn against $\gamma$ for three different values of $\alpha\left(30^{\circ}, 45^{\circ}\right.$, and $\left.60^{\circ}\right)$. Flow kick-up does not occur in the regions of $\gamma$ ranging from 1 to $\gamma_{0}$ s, which are values of $\gamma$ corresponding to the cross marks located at the left extreme of each curve. It is shown in reference $\mathrm{A} 18 \mathrm{~b}$ that in these regions the snow kick-up is realized in spray form.

A18b Zyungo Yosida (1974) Theoretical studies on snow removal by a plow. II. Spray-type kick-up of snow caused by a plow moving at high speeds. Low-Temperature Science, Ser. A(32): 55.

In this paper, the spray type of kicked up snow caused by a plow moving at high speeds is studied theoretically on the same assumptions made in reference A18a, which dealt with the flow type of kick-up. As mentioned in reference A18a, velocity $V$ of the plow is considered high speed when it exceeds the propagation velocity $c$ of the plastic wave in the snow to be removed by the plow. Photographs accompanying the text show snow being kicked up by a plow attached to a diesel locomotive running at a speed of about $80 \mathrm{~km} / \mathrm{hr}$. Three of the photos are taken from a kinematographic film depicting the process of the flow type of kick-up. The plow was $V$-shaped with a narrow horizontal ledge along its upper margin. The number 33 had been written on the surface of snow. 
When the plow kicked up the snow, the numerical figure rose without being crushed. This shows that the kickup was of the flow type. The snow flew sideways horizontally after it had flowed up the sloping surface of the plow and struck the ledge. When the snow was kicked up by the front edge of the plow, it was pulverized and sprayed in a direction inclined forward so that it flew high without hindrance from the ledge.

It was assumed in reference A18a that snow is pulverized when its uniaxial stress reaches stress of pulverization $p_{c}$. Let the angle that the direction of motion of the snow makes against the horizontal at any instant in the very short interval of flow kick-up be denoted by $\theta$. Stress $p$, which the snow has at that instant, will be a function of $\theta$ and $\gamma$, that is, $p=f(\theta, \gamma)$. As $\theta$ increases, $p$ increases, and when $\theta$ reaches a critical value $\alpha_{c}$, it will attain the value of $p_{\mathrm{c}}$ to pulverize the snow. This relation between $p_{\mathrm{c}}$ and $\alpha_{\mathrm{c}}$, namely $p_{\mathrm{c}}=f\left(\alpha_{\mathrm{c}}, \gamma\right)$, may be put equal to the relation between $p_{\mathrm{A}}^{\prime}$ and $\alpha$ expressed by eq A18a-3 in the summary of reference A18a. This equalization results in

$$
\varepsilon_{\mathrm{c}}=\gamma\left[1-\left(v_{\mathrm{c}} / V\right) \cos \alpha_{\mathrm{c}}\right] /(\gamma-1) .
$$

Here $\varepsilon_{\mathrm{c}}$ is the strain of pulverization given by $p_{\mathrm{A}} / k$. Velocity $v_{\mathrm{c}}$ is the velocity of the snow at the instant of pulverization and can be determined by replacing $v$ and $p_{\mathrm{A}}$ with $v_{\mathrm{c}}$ and $p_{\mathrm{c}}$ in energy eq A 18a-2 of reference A18a:

$$
1-\left(v_{\mathrm{c}} / V\right)^{2}=p_{\mathrm{c}}^{2} / k \rho_{0} V^{2}
$$

By eliminating $v_{\mathrm{c}} / V$ from eq A18b-1 and A18b-2, the following function relating $\alpha_{\mathrm{c}}$ with $\gamma$ and $\varepsilon_{\mathrm{c}}$ is obtained:

$$
\left.\cos \alpha_{\mathrm{c}}=\left[\varepsilon_{\mathrm{c}}+\left(1-\varepsilon_{\mathrm{c}}\right) \gamma\right] / \sqrt{\gamma\left(\gamma-\varepsilon_{\mathrm{c}}^{2}\right.}\right) \text {. }
$$

In the text, $\alpha_{c}$ is plotted against $\gamma$ for three different values of $\varepsilon_{c}$. For the snow to be pulverized, $\alpha_{c}$ must be less than $\alpha ; \alpha_{c}$ is an increasing function of $\gamma$, so pulverization of the snow can occur only when $\gamma$ is small enough to keep $\alpha_{c}$ less than $\alpha$. The pulverized snow flies with velocity $v_{c}$ in a direction deviating by $\alpha_{c}$ from the horizontal to reflect on the surface of the plow. The direction in which the reflected snow is sprayed makes the angle $\alpha_{s}=2 \alpha-\alpha_{c}$ with the horizontal.

The above is a description of how flow kick-up is transformed into spray kick-up. Coefficient $C_{2}$ of the plow's running resistance due to spray kick-up is given by

$$
C_{2}=1-\left(v_{\mathrm{c}} / V\right) \cos \alpha_{\mathrm{s}} .
$$

The value of $v_{\mathrm{c}} / V$ is plotted against $\gamma$. Curves of $C_{2}$ versus $\gamma$, together with those of coefficient $C_{1}$ of running resistance due to flow kick-up, are drawn. The scooping angle $\alpha$ of the plow is the only parameter for $C_{1}$, while $\varepsilon_{\mathrm{c}}$ makes another parameter for $C_{2}$ in addition to $\alpha$. The smaller $\gamma$ and $\varepsilon_{\mathrm{c}}$ are and the greater $\alpha$ is, the more likely it is that flow kick-up will be transformed into spray. In three illustrations, dotted curves marked $C_{1}$ give the coefficient of running resistance due to virtual flow kick-up that fails to occur because of the transformation.

If force $F_{v}$ with which the snow pushes down the front edge of the plow is expressed in the form of $D \rho_{0} h_{0} V^{2}$, coefficient $D$ is given as a function of $\gamma$ with parameter $\alpha$ when the kick-up is of the flow type, and as a function of $\gamma$ with parameters $\alpha$ and $\varepsilon_{c}$ when the kick-up is of the spray type. In the text, $D$ is plotted against $\gamma$ for particular values of the parameters. Suffixes 1 and 2 attached to $D$ refer to flow and spray kick-up, respectively.

A23 Shigeru Shimoda and Kenkichi Sato (1969) Study of rotary type snow-removal machines for highways. Journal of the Japanese Society of Snow and Ice, 31(4): 85.

This paper deals with experiments on the basic performance of a typical group of rotary-type snow-removal machines, consisting of a one-stage blower, a two-stage blower, and a cutter. The results obtained were as follows:

1) Integrating the test results, semi-empirical formulas of the engine power required for snow-collecting work were obtained. These formulas enable us to calculate the engine power required within a wide scope 
of various conditions, such as snow depth, snow density, working speed, and number of blower revolutions.

2) The empirical formulas of engine power required for base-machine traction were given as well as simple function formulas referring to working speed.

3) Ranges of snow-throw under various conditions were measured, and the characteristics of the three different types of machines were discussed.

A24 Hiroshi Kuriyama and Mitsuru Shibuya (1978) On the power required for driving the blower of a rotary type snow-removal machine. Journal of the Japanese Society of Snow and Ice, 40(4): 16.

A semitheoretical formula of the power required to drive the blower of a rotary-type snow-removal machine is deduced from the vortex model of snow, when the thickness of the snow on the blower-casing is represented in a vortex curve. It is proved that the calculated values agree approximately with the experimental values, comparing the calculated values of the power required for driving the blower from the semitheoretical formula with the experimental values of a Niigata-652S rotary-type snow-removal machine. The blower's effective throwing power for snow was 30 to $45 \%$ of the power required to drive the blower.

A27 Hiroshi Kuriyama (1984) Vane shear strength of snow. I. Effect of vane angular velocity. Journal of the Japanese Society of Snow and Ice, 46(3): 101.

The effects of both vane angular velocities and snow densities were studied in vane shear tests for dry deposited snow with densities from 0.068 to $0.296 \mathrm{~g} / \mathrm{cm}^{3}$. Two similar types of vanes 4 and $5 \mathrm{~cm}$ wide and 6 and $7.5 \mathrm{~cm}$ high were used in the angular velocity range from 0.05 to $5.0 \mathrm{rad} / \mathrm{s}$. The results indicate that there was no effect due to difference of vane size. The vane shear strength depends strongly on vane angular velocity in the range from 0.05 to $0.25 \mathrm{rad} / \mathrm{s}$, and weakly when it exceeds $0.25 \mathrm{rad} / \mathrm{s}$. In addition, it was found that the vane shear strength can be expressed as a power function of the snow density.

A28 Masao Takeuchi and Shin-etsu Kamada (1973) Shear experiment on ice adhered to road surface. Journal of the Japanese Society of Snow and Ice, 35(3): 21.

The shear strength of ice adhered to road surface material and painted asphalt was measured in the laboratory. The shear strength of the bond between ice and asphalt exceeds the strength of the ice, so failure occurs in the ice rather than at the interface. In the case of lining tape and painted asphalt, the failure occurs at the interface. The shear strength of ice adhered to asphalt is about seven times as great as that of ice adhered to painted asphalt.

B33 Masataka Shirakashi, Ikuo Kawakami, Shinji Sato, and Shoichi Wakiya (1982) On hydraulic conveying of snow. I. Pressure losses in straight circular pipes. Journal of the Japanese Society of Snow and Ice, 45(1): 33-39.

The frictional pressure loss of a snow-water mixture in circular straight pipes was investigated experimentally. The pressure losses in both a vertical and a horizontal pipe with an inner diameter of $40 \mathrm{~mm}$, as well as the flow rate and the mixing ratio of snow in the discharge, were measured. The flow patterns were observed at transparent sections of the pipe. The results were compared with those for a mixture of water and plastic beads whose size and density difference from the water were nearly equal to those of the snow used in this experiment.

Snow particles usually adhered to each other to make a large cluster whose dimension was nearly $50-80 \%$ of the pipe diameter, and the flow pattern did not change much with the flow rate of the mixing ratio of snow. The position of the pipe, that is whether it was horizontal or vertical, did not affect these flow patterns a clearly as it did in the case of the plastic bead mixture. At Reynolds numbers $(\mathrm{Rm})$ below $5 \times 10^{4}$ the coefficient of pipe friction was larger than that for water, and it increased with the mixing ratio of snow. At $R m$ above $5 \times 10^{4}$ (or a velocity greater than $2 \mathrm{~m} / \mathrm{s}$ ) it was nearly equal to that for water independent of the mixing ratio of snow or the inclination of the pipe. 
B34 Teruyoshi Umemura, Shigeaki Ohura, Takashi Tokuhiro, Ichiro Hattori and Akira Okada (1984) Hydraulic conveying of snow. II. Snow feeder to pipelines. Journal of the Japanese Society of Snow and Ice, 46(2): 51-58.

A swirl-mixing type of snow feeder was studied to develop a hydraulic snow-conveying system for urban use. The device consisted of a mixing tank equipped with a turbine impeller and a centrifugal feed pump commonly used for conveying slurry. The performance was evaluated in terms of critical snow fraction (maximum fraction of snow attainable at a given mixing condition), power consumption for mixing, and snow fraction difference between the tank and the pipe. The effects of the dimensions of the feeder and operating conditions were also investigated. The optimum diameter ratio of the impeller to the tank was found to be about 2.5. The optimum slurry volume for a given impeller diameter was found, for example $0.1 \mathrm{~m}^{2}$ for a 200-mmdiameter impeller. The optimum rotation rate of the impeller was $600 \mathrm{rpm}$ for all the experiments. The performance of the pump was also studied; the pumping head and efficiency decreased about $15 \%$ with a $20 \%$ increase of the snow fraction in the pipe. It was found that common slurry pumps can be used for snow feeding.

B35 Teruyoshi Umemura, Tomoyoshi Koyanagi and Akira Okada (1984) Hydraulic conveying of snow. III. Separation of foreign solids from snow-water mixture by cyclone. Journal of the Japanese Society of Snow and Ice, 46(3): 121-128.

This paper presents experimental studies on the separation of foreign solids from snow-conveying pipeline water by a cyclone. Either water or a snow-water mixture was introduced into a cyclone together with plastic beads $\left(1.04 \mathrm{~g} / \mathrm{cm}^{3}\right)$ or fine gravel $\left(1.45 \mathrm{~g} / \mathrm{cm}^{3}\right)$. The collection efficiency and pressure drop were measured. The effects of dimensions were also investigated. There is a critical flow rate under which the snow accumulates in the cyclone, which then loses its function. When the flow rate exceeded the critical, the collection efficiency and pressure drop of the snow-water mixture were almost the same or slightly better than those for water alone. The effects of the dimensions of the cyclone were almost the same as those already known for a common cyclone. Separation of sand and gravel by the use of a cyclone seemed to be effective, but in the case of plastic beads the separation behavior did not follow the known theory concerning the dependence of collection efficiency upon flow rate.

B36 Masataka Shirakashi, Ken-ichi Sato, Seiji Sato, Atsushi Koshio, Teruyoshi Umemura, and Shoichi Wakiya (1984) Hydraulic conveyance of snow. IV. Flow pattern of snow-water mixture in straight pipes. Journal of the Japanese Society of Snow and Ice, 46(4): 163-170.

The flow of snow-water mixtures in straight pipes of circular cross section (inner diameters $D=40 \mathrm{~mm}$ and $77 \mathrm{~mm}$ ) was observed in the velocity range of $0.5-1.9 \mathrm{~m} / \mathrm{s}$ and snow fractions of $3-30 \%$. The samples were granulated snow and fresh snow. The flow pattern of a snow-water mixture could be classified into four types: 1) cluster flow, 2) flow with snow clusters in a homogeneous snow-water mixture, 3) homogeneous flow, and 4) cylindrical flow.

The cluster flow, shown at low values of velocity and snow fraction, and the cylindrical flow at high snow fraction were characteristic patterns for a snow-water mixture. In the horizontal pipe the snow clusters were slightly longer in the axial direction than in the vertical pipes and moved near the upper wall of the pipe. However, for the cylindrical and the homogeneous flows, little difference in flow pattern between horizontal and vertical pipes could be discerned.

Since fresh snow was slightly more difficult to mix with water than granulated snow, the cylindrical flow was attained at a lower snow fraction and the homogeneous flow was not observed for fresh snow. Generally speaking, the inclination of the pipe and the properties of snow had only a slight influence on the flow, and the outline of the flow pattern of the snow-water mixture in a pipe was shown to be decided by the snow fraction and the Froude number.

B37 Masataka Shirakashi,Seiji Sato, Atsushi Koshio, Teruyoshi Umemura, and Shoichi Wakiya(1984) 
Hydraulic conveying of snow. V. The influence of several factors on the pressure drop of a snow-water mixture flowing in a straight pipe. Journal of the Japanese Society of Snow and Ice, 46(4): 171-178.

The pressure drop of a snow-water mixture in smooth-walled, straight pipes with circular cross section (inner diameter $D=40 \mathrm{~mm}$ and $77 \mathrm{~mm}$ ), the flow rate and the snow volume fraction $C$ at discharge were measured for both fresh and granulated snow in the range of $0<C<0.3$ and $3<F_{\mathrm{r}}<210$, where Froude number $F_{\mathrm{r}}=U_{\mathrm{m}}{ }^{2} /$ $(11-s \mid g D)$ and $s$ is the density ratio of ice to pure water. An increase of the frictional force at the pipe wall due to snow mixing increased the pressure drop in a horizontal pipe. This pressure drop increased with $C$ when flow velocity $U_{\mathrm{m}}$ was low, but approached that measured for pure water with increasing $U_{\mathrm{m}}$. In a vertical pipe the pressure drop decreased with $C$ for an ascending flow and increased for a descending flow due to gravity coupled with a reduction of the mean density of the mixture. In a horizontal pipe, fresh snow gave a slightly higher value to hydraulic gradient $i$ than granulated snow at intermediate values of $C$ and $F_{\mathrm{r}}$. The additional pressure drop coefficient defined by $\phi=\left(i-i_{w}\right) /\left(C i_{w}\right)$, where $i_{w}$ is the hydraulic gradient for water, can be expressed as a function of $F_{\mathrm{r}}$, irrespective of $D, C$, and $U_{\mathrm{m}}$. Equations for the additional pressure drop coefficient for horizontal and vertical flows are also presented as determined from experimental results.

B38 Masataka Shirakashi, Seiji Sato, Atsushi Koshio, Yasushi Tokunaga, Teruyoshi Umemura, and Shoichi Wakiya (1985) Hydraulic conveying of snow. VI. Pressure drop of snow-water mixture in an elbow. Journal of the .Japanese Society of Snow and Ice, 47(3): 105-110.

The pressure drop of a snow-water mixture in commercial elbows ( $90^{\circ}$ bend pipe with sharp curvature) connecting two straight pipes of circular cross section was measured and the influences of the pipe diameter $D(40 \mathrm{~mm}$ and $77 \mathrm{~mm})$, the setting direction of the elbow, flow velocity $U_{\mathrm{m}}{ }^{2}$, snow volume fraction $C$ at discharge, and the properties of the snow were investigated.

From the experimental results for granulated snow and fresh snow in the regions $U_{\mathrm{m}}=0.3$ to $2.5 \mathrm{~m} / \mathrm{s}, C=$ 0 to $30 \%$, and $F_{\mathrm{r}}=3$ to $200\left(=U_{\mathrm{m}}{ }^{2} /(11-s \mid g D)(s\right.$ is the density ratio of ice to pure water, $g$ is the acceleration of gravity) the following conclusions were obtained.

When the pressure drop between two points upstream and downstream of an elbow was expressed as the sum of the pressure loss $h_{\mathrm{e}}$ due to change of flow direction and the friction loss $h_{\mathrm{s}}$ in the straight pipe, $h_{\mathrm{e}}$ was usually far greater than $h_{\mathrm{s}}$. Mixing of snow increased $h_{\mathrm{e}}$ at a low value of $F_{\mathrm{r}}$, although the increase in pressure loss was less than for the flow in a straight pipe. The increment of $h_{\mathrm{e}}$ due to snow mixing decreased with increasing $U_{\mathrm{m}}$ and when $F_{\mathrm{r}} \geq 100 h_{\mathrm{e}}$ it was virtually equal to that for water irrespective of $C$. In this case the equivalent length of the bend loss $h_{\mathrm{e}}$ was 40 to 50 times the pipe diameter. The influences of the setting direction of the elbow and the snow properties were found to be negligible.

Throughout the experimental runs no choking was observed at the elbows, which, together with the above results on the pressure drop, confirmed that a bend in a pipeline is not a cause of difficulty for the hydraulic conveyance of snow.

B39 Masataka Shirakashi, Atsushi Koshio, Yasushi Tokunaga, Tsuyoshi Hashimoto, and Shoichi Wakiya (1985) Hydraulic conveying of snow. VII. Energy loss of snow-water mixture flow combining at a T-junction of pipes. Journal of the Japanese Society of Snow and Ice, 48(2): 75-82.

When the hydraulic conveyance technique is used to remove snow from an urban area, a branching pipeline system is considered to be effective. In this study, the energy loss of a granulated-snow-water mixture flow combining at a $\mathrm{T}$-junction of pipes with circular cross section (the simplest geometry of connecting elements used in a pipeline) was investigated experimentally.

A branch pipe met a straight main pipe (both $77 \mathrm{~mm}$ in diameter) at a $90^{\circ}$ angle. The granulated-snow-water mixtures with equal snow fractions were combined at the junction. The flow rates in the main pipe upstream from the junction, $Q_{1}$, and in the branch pipe, $Q_{2}$, were measured by electromagnetic flow meters. The pressure distribution along the pipes and the volume of snow fraction in the discharge were measured for variable flow rate $Q_{2} / Q_{3}$ under the condition of constant $Q_{3}$, the flow rate in the main pipe downstream from the junction. Beads of ABS resin were used as the solid sample for comparison.

Power losses due to the confluence were obtained by subtracting frictional losses in straight pipes from the 
total losses at the junction. The confluence loss coefficient $\zeta_{\mathrm{c}}$ for the bead-water mixture increased with an increasing solid fraction, and the relation between $\zeta_{\mathrm{c}}$ and $Q_{2} / Q_{3}$ for the snow/water mixture was nearly equal to that for water, irrespective of the snow fraction. In conclusion, the power loss due to the confluence for the granulated-snow-water mixture is well estimated from $\zeta_{\mathrm{c}}$ data for water.

B40 Teruyoshi Umemura, Mikio Nakayama, Akira Uchiyama, Yasushi Tokunaga, and Masataka Shirakashi (1986) Hydraulic conveying of snow. VIII. Blocking of snow-water mixture flow and criterion of stagnation of snow at pipe orifice. Journal of the Japanese Society of Snow and Ice, 48(4): 207-214.

Based on observations of flows, an outline of the blocking phenomenon of snow/water mixture flow in closed channels is given. It was confirmed that a characteristic blocking occurred due to the property of snow in the mixture flow, i.e., a tendency of snow blocks to adhere to each other and to form a densified plug in the channel, compressed by the water pressure. Since the blocking was revealed to originate from the stagnation of the snow cluster, the criterion at an orifice in a horizontal pipe was investigated experimentally. With pipe diameter $D$ $=47-90 \mathrm{~mm}$ and an areal contraction ratio $K=0.068 \sim 0.27$, the dependence of the critical flow velocity $V_{\mathrm{st}}$ (below which snow clusters were arrested at the orifice) on $D$, on $K$, on snow volume fraction $C$ in the discharge, and on the property of snow was clarified:

1) When $C<C^{*}$, where $C^{*}$ is 0.15 and 0.12 for granulated snow and fresh snow respectively, $V_{\mathrm{st}}$ is inversely proportional to $D$ and independent of $C$. When $C>C^{*}$, snow clusters almost fill the pipe and $V_{\mathrm{st}}$ is inversely proportional to $D$ and proportional to $C$. Meanwhile, the influence of $K$ on $V_{\mathrm{st}}$ is not significant over the whole experimental range of $C$.

2) Fresh snow is apt to stagnate, and the critical values of $D V_{\mathrm{st}}$ with $C<C^{*}$ and $D V_{\mathrm{st}} / C$ with $C>C^{*}$ for fresh snow are 1.4 and 2 times the corresponding ones for granulated snow.

3) Blocking can be avoided by applying the critical values of $D V_{\mathrm{st}}$ or $D V_{\mathrm{st}} / C$ obtained in this work as the criterion of stagnation.

B41 Yasushi Tokunaga, Tsuyoshi Hashimoto, Kazunari Mizuguchi, and Masataka Shirakashi (1986) Hydraulic conveying of snow. IX. Development of techniques for high snow concentration. Journal of the Japanese Socicty of Snow and Ice, 49(2): 59-66.

To improve the efficiency of hydraulic conveying of snow by a pump and pipeline system, techniques to measure and control the in-situ concentration of a snow/water mixture flowing through a pipe were developed. The optimum condition is discussed on the basis of high-concentration data obtained by applying these techniques.

The volume snow fraction in the pipe, $C$, was determined by the in-situ concentration meter devised here in the range of $C=0$ to $30 \%$ within $3 \%$ error. Using the devised water separator, an instrument for extracting water from the mixture flowing in a pipe, a high-concentration flow up to $C=35 \%$ was attained. This upper limit of $C$ was reached when the water separator was choked by a densified snow cluster.

When $C$ was greater than critical value $C_{\mathrm{cr}}$, the pressure loss in a horizontal pipe increased rapidly with $C$, deviating from the value predicted by the current method. Although $C_{\mathrm{cr}}$ depends slightly on the flow velocity, roughly speaking, $C_{\mathrm{cr}} \geq 25 \%$ for granulated snow and $\mathrm{C}_{\mathrm{cr}} \geq 22 \%$ for the fresh snow.

It was concluded that the power loss was minimized when $C=C_{\mathrm{cr}}$ under the condition that the mass flow-rate of snow and the conveying distance were given.

E4 Masao Takeuchi (1978) Snow accretion on traffic-control signs and its prevention. Journal of the Japanese Society of Snow and Ice, 40(3): 15.

Visual observations of snow accretion on signs and continuous measure-ments of the wind velocity and air temperature have been made in blowing snow on the Ishikari plain in Hokkaido. The flow and velocity distribution of wind around and on the surfaces of signs was measured.

The results show that snow accretion develops around the wind stagnation point of the sign, that at a wind velocity exceeding 4 to $5 \mathrm{~m} / \mathrm{s}$ the sign is covered even with dry snow that does not contain liquid water, and that 
this dry snow accretion can occur more easily with increasing wind velocity, with ascending air temperature, and with decreasing sign area.

The dry snow accretion is classified into three types. The most frequently observed is caused by the strong collision of snow against the sign. This type of snow accretion is explained in terms of snow melting at its points of contact with the sign due to the collision, which transforms the snow's kinetic energy into its internal energy: the melted snow adheres to sign.

Experiments for preventing snow accretion were carried out by three methods: 1) utilization of the wind's force, 2) surface treatment of the sign, and 3) alteration of the wind flow around the sign. Of these, the last method-altering the wind flow - shifts the wind stagnation point, causing snow to collide with the sign at an acute angle so that accretion becomes more difficult.

Thus, the last method is effective for practical use.

E12 Motomu Yokomori (1974) Stability of motorcycles on packed snow-with special reference to characteristics of tired wheels. Journal of the Japanese Society of Snow and lce, 37(1): 21.

Several kinds of motorcycle tires were selected to test the stability and safety of driving on snow-covered roads. As a measure of the stability felt by the riders, the deflective angle of the handlebars was adopted. The stability of "snow tires" is much improved when the air pressure in the tire is lower than the specified pressure; if the pressure was lowered only in the rear tire, stability was reduced. With wide tires, the stability is much improved when the weight, output, and other mechanical characteristics of the motorcycle are nearly the same. If a chain is used only on the rear tire, stability improves, especially as speed increases. Stability is improved by using a rope instead of a tire chain; the rope is more effective and is also handier.

F1 Tesuro Nakatao (1982) Introduction of a disaster index for manual snow-removal in Hokuriku, Japan. Journal of the Japanese Society of Snow and Ice, 44(4): 211.

This paper reviews several indices proposed by its author (Nakatao 1968, 1976) for describing the intensity of a snow disaster: the three fundamental indices $P_{\theta}$ for the air temperature, $P_{\mathrm{W}}$ for the precipitation, and $P_{\mathrm{H}}$ for the maximum snow cover depth, and applied these indices to snow-removal operations. This paper also introduces a new disaster index $U$, which corresponds to the personal labor in energy $E$ when a civilian manually removes the snowcover from the road. Manual labor $E$ in the Hokuriku district is expressed in terms of new snowfall depth $h$, snowcover depth $H$, road width, and so on. In the expression obtained, introducing an equivalent depth of snow removal by $\lambda \mathrm{H}$, where $\lambda$ depends on the road and snow conditions, its value is about 1.7. Rewriting $h$ and $H$ in the expression for $E$ in terms of $P_{\mathrm{W}}$ and $P_{\mathrm{H}}$, the manual snow-removal labor index $U=k \lambda P_{\mathrm{W}} P_{\mathrm{H}} B$ is obtained where $k$ is a certain constant and $B$ is the area of road to be manually cleared. The index gives the local difference of daily or annual labor in different districts along the Japan Sea.

F2 Tetsuro Nakatao and Mitsuharu Mizukoshi (1982) An empirical representation of snow-control cost as a function of snow-disaster index, population, and regional snow conditions. Journal of the Japanese Society of Snow and Ice, 44(4): 205.

The severity of a snow disaster in Japan depends on the conditions of the natural environment and on human activities. This paper first describes the authors' past research: Nakatao $(1968,1976)$ proposed a snow-disaster index $T$ based on climate and snow-removal conditions; Nakatao and Mizukoshi (1978) gave an empirical expression for prefectural snow-control $\operatorname{cost} M=\gamma N T$, where $N$ is the population reflecting an index of social and economic conditions (the constant $\gamma$ for each prefecture had a mean error of $\pm 47 \%$ ); and Nakatao and Mizukoshi (1979) introduced the distance $x$ from the seacoast to the weather station in the most populous city (usually the capital of the prefecture) into an improved empirical expression where the mean error of $\gamma$ was $33 \%$. The rest of the paper analyzes the relation between the population distribution in each prefecture and snowcontrol costs. A new empirical formula for $M$ is introduced for sparsely populated prefectures. Combining the two formulas for densely populated and sparsely populated prefectures, the snow-control $\operatorname{cost} M$ is given, and 
the constant $\gamma$ is within an error of $22 \%$, except for Yamaguchi Prefecture.

F6 Mamoru Ohshima (1978) A cost evaluation study of snow removal by heating-system in a city in Japan. Journal of the Japanese Society of Snow and Ice, 40(4): 24.

The feasibility of snow removal through heat energy by two types of systems was studied. One is a pipeline subsystem that carries warm water to the surface of the city roads and a power plant that supplies warm water to the pipeline system as well as electricity to the citizens.

The other also consists of a pipeline subsystem as above as well as a boiler plant to supply the warm water. The study was applied to the city of Nagaoka in Niigata Prefecture, which has a population of about 170,000 , where about $120 \times 10^{9} \mathrm{kcal}$ of heat is needed to melt snow through the winter in high-density residential areas. A technology assessment and cost analysis of the two systems were undertaken. In the case of using electric power plant with a power output of $250 \mathrm{MW}$, the conclusion is very hopeful: the initial cost of the system is about $¥ 47$ billion, which includes $¥ 20$ billion for the initial cost of constructing the pipeline system. On the other hand, the operating cost is $¥ 783$ million, which means that if electricity produced by the plant is bought by an electric company for the price of $9 ¥ / \mathrm{kWh}$, the running cost for $10^{3} \mathrm{kcal}$ heat load is $¥ 44$.7. This also means that if electricity is purchased for a price higher than $10 ¥ / \mathrm{kWh}$, the cost for $10^{3} \mathrm{kcal}$ heat load is nearly equal to zero $(<¥ 10)$.

G2 Shigeru Shimoda, Tatsuya Ishibashi, and Makoto Oshima (1981) Car noise test on snow-covered roads. Journal of the Japanese Society of Snow and Ice, 43(3): 163.

In snowy districts, automobiles are fitted with snow tires, studded snow tires, and tire chains to increase adhesion between tire treads and road surfaces. To obtain definitive information on car noise under such conditions, noise measurements were carried out on roads covered with packed snow and on snow-free asphalt roads. It was found that:

1) The outdoor sound levels pertaining to the tested tires and chains showed a tendency to vary according to the vehicle speed that seems to be strengthened by the pattern noise.

2) Outdoor noise tests of three different tires showed that the snow-tire characteristics, which are strongly affected by the pattern noise, has clear peaks of SPL (sound pressure level) at low-order fundamental frequencies. A more marked tendency is seen in the case of studded tires.

3) Frequency analyses of outdoor noise when various chains were used showed the SPL is very high around $1 \mathrm{kHz}$, and the frequency characteristics seem to vary according to the forms and materials of the chains.

4) On a packed-snow-covered road, the SPL of outdoor noise decreased over the entire frequency range, in comparison with outdoor noise on the snow-free road. The SPL of indoor noise shows appreciable differences on both packed-snow and snow-free roads.

H1 Tadashi Kimura (1973) Snow surface detection by laser beam. Journal of the Japanese Society of Snow and Ice, 35(3): 13.

Snow surface detection has been achieved by a new detector that consists of a light beam of a He•Ne gas laser and a small-size silicon photocell. In the detector, the $\mathrm{He} \mathrm{Ne}$ gas laser beam projected horizontally is detected by the silicon photocell, which has a small-bore hood attached to reduce sunlight, and the ascending snow surface is detected when it intercepts the laser beam.

Using the detector, an apparatus for repeated measurements at 2-cm intervals of snow depth was constructed. A reliability test of this apparatus was carried out at Yukomabetsu, Hokkaido, from 26 March to 2 April 1971 .

The relation between the snow depth change and snowfall intensity was investigated by the use of observed data. This paper gives four experimental results:

1) Snow surface detection by laser beam is not affected by most weather conditions or by changes in sunlight. 
2) During snowfall, a relative decrease of snowcover thickness near the snow surface has been noticed. This phenomenon is due to an increase in the weight of successively falling snowflakes.

3) Four observational results of the relation between the snow depth change and the snowfall intensity at Yukomabetsu agree with similar observations Kimura made at Nagaoka in 1971.

4) The apparatus for repeated measurements functions as a snowfall intensity meter. Thus, it can be used as a detector in an automatic snow-melting system such as a water sprinkler; however, measures are necessary to prevent freezing of wet snow settling on the apparatus.

H2 Ichiro Tsubata and Yoshio Sorimachi (1981) Simple snowfall detector employing infrared rays reflection. Journal of the Japanese Society of Snow and Ice, 43(2): 77.

The use of subterranean water to melt snow is indispensable for roads in Japan and has also been utilized for roofs in snow-covered areas. In addition, techniques of electrically melting snow and anti-frost systems have recently been applied to pedestrian crossings and to buildings. The effective operation of snow-melting installations has also been taken up as an important problem from the viewpoint of conservation of water and electrical energy. It is difficult to handle a snow-melting installation effectively, however, so a practical device for auto-matically detecting snowfall and controlling snow-melting installations has been much desired.

The authors produced a simple trial snowfall detector by applying the principle that infrared rays emitted by a diode are reflected diffusely by fallen snow. The theory of measurement is as follows: The infrared rays are set not to reach the photo-receiving element (photodiode) because they are reflected by the black snow-catching plate with a heater, so the detector does not operate when it is not snowing. On the other hand, when it is snowing, some of the infrared rays are diffusely reflected by snow that has fallen on the snow-catching plate and they do reach the photodiode; the detector notices that snow is falling and operates the snow-melting installation. When it stops snowing, the fallen snow on the snow-catching plate is melted by the heater, infrared rays reflected by the black snow-catching plate cannot reach the photodiode, the detector stops operating, and the snow-melting installation stops operating. The authors performed a series of experiments with the snowfall detector from 13 to 26 February 1980 that showed a detection accuracy of $80 \%$. Problems that need to be discussed in the future include the sensitivity of the detector, setting of the timer, and the relation between these items and weather conditions. 
Table D1. Seven-ton snowplows (27,000-lb GVW).

\begin{tabular}{|c|c|c|c|c|c|c|c|c|c|c|c|c|c|c|}
\hline $\begin{array}{r}\text { Base vehi } \\
\text { Year int }\end{array}$ & $\begin{array}{l}\text { cle type: } \\
\text { roduced: }\end{array}$ & $\begin{array}{l}T 730^{I} \\
1960\end{array}$ & $\begin{array}{l}\mathrm{ZHIO} 0^{2} \\
1960\end{array}$ & $\begin{array}{l}T 370^{l} \\
1967 \\
\end{array}$ & $\begin{array}{c}\mathrm{ZH} 12 \mathrm{D}^{2} \\
1967\end{array}$ & $\begin{array}{l}W 80^{l} \\
1972\end{array}$ & $\begin{array}{l}W 81^{3} \\
1972\end{array}$ & $\begin{array}{l}W 81^{3} \\
1975\end{array}$ & $\begin{array}{c}T F 30 G D^{4} \\
1975 \\
\end{array}$ & $\begin{array}{l}\mathrm{ZH110^{5 }} \\
1975\end{array}$ & $\begin{array}{c}F W 112 H^{3} \\
1978\end{array}$ & $\begin{array}{c}W D 300^{5} \\
1978\end{array}$ & $\begin{array}{c}C F 30 G D^{4} \\
1978 \\
\end{array}$ & \\
\hline \multicolumn{14}{|c|}{ Vehicle Performance } & \\
\hline Maximum speed & $(\mathrm{km} / \mathrm{hr})$ & 69 & 69 & 102 & 82 & 100 & 80 & 80 & 80 & 80 & 95 & 85 & 80 & \\
\hline Fuel consumption & $(\mathrm{km} / \mathrm{L})$ & & & 4.3 & & 4.3 & 4.0 & 4.0 & 4.3 & 4.0 & 4.0 & 4.0 & 4.3 & t7 \\
\hline Turning radius & (m) & 9.5 & 9.7 & 9.5 & 9.7 & 9.5 & 8.7 & 8.7 & 9.3 & 9.0 & 8.7 & 8.7 & 9.4 & Z \\
\hline \multicolumn{14}{|l|}{ Dimensions } & 至 \\
\hline Length & $(\mathrm{cm})$ & 1,043 & 1,030 & 960 & 955 & 890 & 1,025 & 1,025 & 1,038 & 1,058 & 1,048 & 1,055 & 1,078 & $\theta$ \\
\hline Width & $(\mathrm{cm})$ & 292 & 292 & 309 & 309 & 295 & 295 & 295 & 295 & 295 & 310 & 310 & 310 & 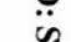 \\
\hline Height & $(\mathrm{cm})$ & 270 & 270 & 293 & 295 & 300 & 307 & 317 & 306 & 310.5 & 340 & 339.5 & 344 & 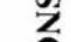 \\
\hline Wheelbase & $(\mathrm{cm})$ & 430 & 425 & 430 & 425 & 430 & 430 & 430 & 428 & 435 & 430 & 430 & 428 & \\
\hline \multicolumn{14}{|l|}{ Weight Distribution } & \\
\hline Total & $(\mathrm{kg})$ & 10,530 & 10,400 & 14,070 & 13,435 & 12,115 & 11,075 & 11,575 & 11,615 & 12,090 & 13,750 & 13,540 & 13,120 & 玨 \\
\hline Front & $(\mathrm{kg})$ & 5,235 & 4,955 & 5,786 & 5,777 & 5,720 & 5,691 & 5,691 & 5,615 & 5,765 & 5,800 & 5,620 & 5,690 & 3 \\
\hline Rear & (kg) & 5,295 & 5,425 & 8,284 & 7,658 & 6,395 & 5,384 & 5,884 & 6,000 & 6,325 & 7,950 & 7,925 & 7.430 & 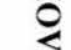 \\
\hline \multicolumn{14}{|l|}{ Engine } & \\
\hline Type & & DB31A & DS30 & 6D81 & DS50 & 6DB1 & $6 \mathrm{DC} 2$ & $6 \mathrm{DC} 2$ & PE6 & ED100 & $8 \mathrm{DC} 4$ & KE100 & DE6 & 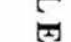 \\
\hline Displacement & (cc) & & & 8,550 & 7,982 & 8,500 & 9,955 & 9,955 & 11,670 & 11,581 & 13,273 & 13,267 & 11,670 & \\
\hline Maximum output & (hp/rpm) & $155 / 2200$ & $150 / 2400$ & $165 / 2300$ & $160 / 2400$ & $165 / 2300$ & $200 / 2500$ & $200 / 2500$ & $220 / 2300$ & $260 / 2300$ & $265 / 2300$ & $270 / 2300$ & $220 / 2300$ & \\
\hline Maximum torque & $(\mathrm{kgm} / \mathrm{rpm})$ & $55 / 1400$ & $50 / 1600$ & & & & $67 / 1200$ & $67 / 1200$ & $83 / 1200$ & $88 / 1600$ & $89 / 1600$ & $95 / 1400$ & $83 / 1200$ & 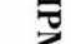 \\
\hline Generator & $(\mathrm{V}-\mathrm{kW})$ & & & $24-0.4$ & & $24-0.6$ & $24-25 \mathrm{~A}$ & $24-25 \mathrm{~A}$ & $24-25 \mathrm{~A}$ & $24-35 \mathrm{~A}$ & $24-40 \mathrm{~A}$ & $24-40 \mathrm{~A}$ & $24-35 \mathrm{~A}$ & 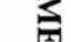 \\
\hline Starter & (V-hp) & & & 24-7 & & 24-7 & $24-6.5 \mathrm{~kW}$ & $24-6.5 \mathrm{~kW}$ & $24-6 \mathrm{~kW}$ & & $24-6 \mathrm{~kW}$ & $24-6 \mathrm{~kW}$ & $24-6 \mathrm{~kW}$ & Z \\
\hline Battery & $(\mathrm{V}-\mathrm{AH})$ & & & $12-150 \times 2$ & & $12-150 \times 2$ & $12-150$ & $12-150$ & $12-150$ & $12-150$ & $12-150$ & $12-150$ & $12-150$ & 7 \\
\hline Drive Train & & $4 \times 4$ & $4 \times 4$ & $4 \times 4$ & $4 \times 4$ & $4 \times 4$ & $4 \times 4$ & $4 \times 4$ & $4 \times 4$ & $4 \times 4$ & $4 \times 4$ & $4 \times 4$ & $4 \times 4$ & 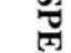 \\
\hline \multicolumn{14}{|l|}{ Plow } & \\
\hline Width & $(\mathrm{cm})$ & 292 & 292 & 309 & 309 & 295 & 295 & 285 & 285 & 285 & 285 & 285 & 285 & Ti2 \\
\hline Plow height & $(\mathrm{cm})$ & & & & & & & 25 & 25 & 25 & 25 & 25 & 25 & \\
\hline Standard speed & $(\mathrm{km} / \mathrm{hr})$ & & & & & & & 35 & 35 & 35 & 35 & 35 & 35 & 焉 \\
\hline Width & $(\mathrm{cm})$ & & & 285 & 285 & 285 & 285 & 285 & 285 & 285 & 280 & 280 & 280 & 0 \\
\hline Grader blade height & $(\mathrm{cm})$ & & & & & & & 15 & 15 & 15 & 150 & 150 & 150 & $\mathbf{z}$ \\
\hline Standard speed & $(\mathrm{km} / \mathrm{hr})$ & & & & & & & & & & $5-10$ & & & \\
\hline
\end{tabular}

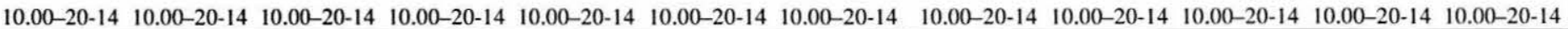

1-Mitsubishi 7-ton dump truck.

2-Hino 7-ton dump truck.

3-Mitsubishi snowplow truck.

4 -Nissan snowplow truck.

5-Hino snowplow truck. 
Table D2. Ten-ton snowplows (37,000-lb GVW).

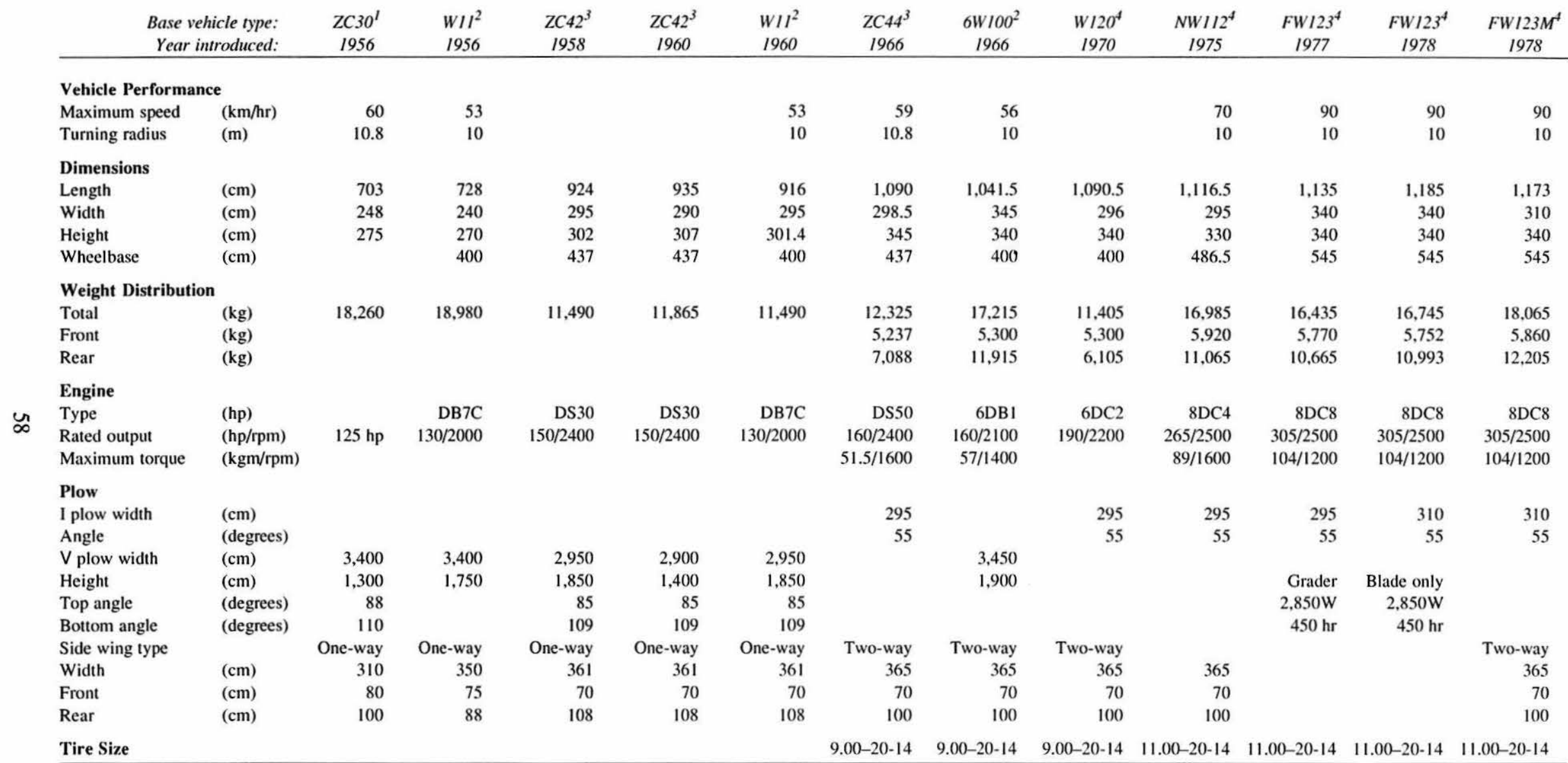

1-Hino 8-ton dump truck

2-Mitsubishi 10-ton dump truck

3-Hino 10-ton dump truck

4-Mitsubishi snowplow truck 
Table D3. Rotary snowblowers (400- to 800-hp class).

\begin{tabular}{|c|c|c|c|c|c|c|c|c|c|c|c|}
\hline $\begin{array}{r}\text { Veh } \\
\text { Year in }\end{array}$ & $\begin{array}{l}\text { le type: } \\
\text { oduced: }\end{array}$ & $\begin{array}{c}H T R-300^{\prime} \\
1966 \\
\end{array}$ & $\begin{array}{c}\text { HTR-301A } \\
1968 \\
\end{array}$ & $\begin{array}{c}H T R-301^{I} \\
1971\end{array}$ & $\begin{array}{c}R-500 B^{2} \\
1972\end{array}$ & $\begin{array}{c}R-500 B^{2} \\
1973\end{array}$ & $\begin{array}{c}\text { HTR-301Cl } \\
1975\end{array}$ & $\begin{array}{c}\text { HTR-302 } \\
1976\end{array}$ & $\begin{array}{c}\text { HTR-303A } \\
1978 \\
\end{array}$ & $\begin{array}{c}\text { HTR }-700^{\prime} \\
1969\end{array}$ & $\begin{array}{c}S R-303^{3} \\
1970\end{array}$ \\
\hline \multicolumn{12}{|l|}{ Rotary Blower } \\
\hline Removal rate & $(\mathrm{t} / \mathrm{hr})$ & 2,500 & 2,100 & 2,100 & 2,800 & 2,800 & 3,000 & 2,000 & 3,000 & 3.500 & 4,200 \\
\hline Removal width & $(\mathrm{cm})$ & 260 & 260 & 260 & 270 & 270 & 260 & 260 & 260 & 275 & 310 \\
\hline Removal height & $(\mathrm{cm})$ & 180 & 180 & 175 & 190 & 190 & 175 & 175 & 175 & 176 & 1,80 \\
\hline Throw distance & (m) & $15,30,50$ & $8,15,30$ & $8,15,30$ & $13,20,25$ & $13,20,25$ & 15,30 & 20,45 & 20,40 & 30 & 39 \\
\hline Maximum speed & $(\mathrm{km} / \mathrm{hr})$ & 34 & 34 & 34 & 34 & 34 & 41 & 40 & 40 & 50 & 51.5 \\
\hline Work speed & $(\mathrm{km} / \mathrm{hr})$ & & $0-20.5$ & & & & $0-19.5$ & $0-20$ & & $0-20$ & $0-20$ \\
\hline Turning radius & (m) & 6.8 & 7.2 & 7.2 & 6.25 & 6.25 & 8.4 & 7.35 & 6.54 & 10.8 & 10 \\
\hline \multicolumn{12}{|l|}{ Dimensions } \\
\hline Length & $(\mathrm{cm})$ & 765 & 774.5 & 774.5 & 800 & 8,9 & 773 & 848.5 & 868 & 950 & 1,164 \\
\hline Width & $(\mathrm{cm})$ & 260 & 260 & 260 & 270 & 270 & 260 & 260 & 260 & 275 & 315 \\
\hline Height & $(\mathrm{cm})$ & 345 & 345 & 345 & 350 & 355 & 345 & 349 & 349 & 348 & 348 \\
\hline \multicolumn{12}{|c|}{ Weight Distribution } \\
\hline Total & $(\mathrm{kg})$ & 12,165 & 14,035 & 14,380 & 18,900 & 19,650 & 15,110 & 13,860 & 15,050 & 24,050 & 21,860 \\
\hline Front & (kg) & 8,000 & & 8,930 & 11,590 & 11,900 & 8,900 & 8,395 & 9,150 & 16,660 & \\
\hline Rear & (kg) & 4,000 & & 5,340 & 7,310 & 7,750 & 6,100 & 5,465 & 5,900 & 7,390 & \\
\hline Steering system & & Front-wheel & Rear-wheel & Rear-wheel & Four-wheel & Rear-wheel & Rear-wheel & Rear-wheel & Articulation & Front-wheel & Front-wheel \\
\hline Wheelbase & $(\mathrm{cm})$ & 258 & & 259 & 330 & 330 & 300 & 280 & 300 & 330 & 380 \\
\hline \multicolumn{12}{|l|}{ Engine Type } \\
\hline Running & & UD4 & UD4 & UD4 & & & & & & & 120DCl0W \\
\hline Combined & & & & & 8DK20CTA & 8DK20CTA & 8DK20CT & RD10T & S6ATA & 12DK20PTA & \\
\hline Blower & & UD6 & UDV8 & UDV8 & & & & & & & $120 \mathrm{H} 20 \mathrm{CTA}$ \\
\hline \multicolumn{12}{|l|}{ Rated Output } \\
\hline Running & (hp) & 109 & 139 & 139 & & & & & & & $330 / 2200$ \\
\hline Combined & (hp/rpm) & & & & $490 / 2200$ & $490 / 2200$ & $410 / 2200$ & $350 / 2000$ & $410 / 2200$ & $700 / 1500$ & \\
\hline Blower & (hp) & 170 & 272 & 272 & & & & & & & $510 / 1800$ \\
\hline Tire Size & & $14.00-24-12$ & $14.00-24-12$ & $14.00-24-20$ & $16.00-25-24$ & $16.00-25-24$ & $14.00-24-20$ & $14.00-24-20$ & $14.00-24-20$ & $13.00-24-18$ & $16.00-25-28$ \\
\hline \multirow{2}{*}{\multicolumn{2}{|c|}{$\begin{array}{l}\text { Rotary Blower System } \\
\text { Auger type }\end{array}$}} & Two-stage & Two-stage & Two-stage & Two-stage & Two-stage & Two-stage & Two-stage & Two-stage & Two-stage & One-stage \\
\hline & & Ribbon screw & Ribbon screw & Ribbon screw & Screw rake & Screw rake $\mathrm{I}$ & Ribbon screw $\mathrm{F}$ & Ribbon screw & Ribbon screw & Ribbon screw & \\
\hline Diameter & $(\mathrm{cm})$ & 140 & 140 & 140 & 140 & 140 & 140 & 140 & 140 & 150 & \\
\hline Width & $(\mathrm{cm})$ & 236.5 & 236.5 & 236.5 & 240 & 240 & 233.5 & 236.5 & 236.5 & 240 & \\
\hline Rpm & (rpm) & $108,153,190$ & $88.5,130,174$ & $88.5,130,174$ & $146,187,237$ & $180,231,292$ & 119,168 & 128,215 & 121,204 & $132,170,214$ & \\
\hline Blower type & & One-stage & One-stage & One-stage & One-stage & One-stage & One-stage & One-stage & One-stage & One-stage & Beilhack \\
\hline Diameter & $(\mathrm{cm})$ & 130 & 130 & 129 & 1,40 & 140 & 129 & 129 & 129 & 148 & 150 \\
\hline Depth & $(\mathrm{cm})$ & 60 & 60 & 59.5 & 65 & 65 & 59.5 & 59.5 & 59.5 & 65 & 73 \\
\hline $\mathrm{Rpm}$ & (rpm) & $220,313,388$ & $172,253,339$ & $172,253,339$ & $178,230,291$ & $178,230,291$ & 233,330 & 244,406 & 230,388 & $158,192,259$ & $133,196,264$ \\
\hline Drive train & & HST & HST & HSTw & $\mathrm{N} /$ torque conv. & w/ torque conv. & HST & HST & HST & HST & Auto. trans. \\
\hline
\end{tabular}

1-Nihon Josetsuki

2-Toyo Unpanki

3-Mitsubishi 
Table D4. Rotary snowblowers (Nihon Josetsuki 200-hp class).

\begin{tabular}{|c|c|c|c|c|c|c|c|c|c|c|}
\hline $\begin{array}{r}\text { Vel } \\
\text { Year in }\end{array}$ & $\begin{array}{l}\text { hicle type: } \\
\text { troduced: }\end{array}$ & $\begin{array}{c}\text { HTR-I } \\
1960\end{array}$ & $\begin{array}{c}H T R-2 \\
1961\end{array}$ & $\begin{array}{c}\text { HTR-3 } \\
1962\end{array}$ & $\begin{array}{c}H T R-4 \\
1063\end{array}$ & $\begin{array}{c}\text { HTR-4 } \\
1966\end{array}$ & $\begin{array}{c}H T R-41 \\
1970\end{array}$ & $\begin{array}{c}\text { HTR-4I } \\
1975\end{array}$ & $\begin{array}{c}\text { HTR-200 } \\
1977 \\
\end{array}$ & $\begin{array}{c}H T R-200 \\
1978\end{array}$ \\
\hline \multicolumn{11}{|l|}{ Rotary Blower } \\
\hline Removal rate & & $4,000 \mathrm{~m}^{3} / \mathrm{hr}$ & $5,000 \mathrm{~m}^{3} / \mathrm{hr}$ & $6,000 \mathrm{~m}^{3} / \mathrm{hr}$ & $6,000 \mathrm{~m}^{3} / \mathrm{hr}$ & $6,000 \mathrm{~m}^{3} / \mathrm{hr}$ & $1.200 \mathrm{t} / \mathrm{hr}$ & $1,200 \mathrm{t} / \mathrm{hr}$ & $1,300 \mathrm{t} / \mathrm{hr}$ & $1,300 \mathrm{t} / \mathrm{hr}$ \\
\hline Removal width & $(\mathrm{cm})$ & 250 & 250 & 250 & 260 & 260 & 260 & 260 & 260 & 260 \\
\hline Removal height & $(\mathrm{cm})$ & 130 & 150 & 160 & 160 & 140 & 140 & 153 & 153 & 153 \\
\hline Throw distance & $(\mathrm{m})$ & 16.5 & 20,40 & 15,25 & 15,25 & 15,25 & 15,25 & 15,25 & 15,25 & 15,25 \\
\hline Maximum speed & $(\mathrm{km} / \mathrm{hr})$ & 25 & 25 & 30 & 35 & 32 & 30 & 30 & 40 & 40 \\
\hline Work speed & $(\mathrm{km} / \mathrm{hr})$ & $0-10$ & $0-13$ & $0-14.2$ & $0-14.5$ & $0-11.6$ & $0-11.6$ & $0-11$ & $0-22$ & $0-22$ \\
\hline Turning radius & (m) & 8.6 & 7.2 & 7.2 & 6.0 & 7.5 & 7.5 & 7.5 & 6.32 & 6.4 \\
\hline Length & $(\mathrm{cm})$ & 746.2 & 758.3 & 795 & 668 & 666 & 669.5 & 672 & 699 & 699 \\
\hline Width & $(\mathrm{cm})$ & 250 & 250 & 260 & 260 & 260 & 260 & 260 & 260 & 260 \\
\hline Height & $(\mathrm{cm})$ & 286 & 275 & 295 & 310 & 340.3 & 337 & 348 & 348 & 337 \\
\hline \multicolumn{11}{|c|}{ Weight Distribution } \\
\hline Total weight & (kg) & 11,000 & 9,625 & 10,775 & 9,800 & 10,930 & 11,205 & 11,780 & 12,165 & 11,645 \\
\hline Front & (kg) & & 6,652 & 7,447 & & 7,100 & 7,150 & 8,150 & & 7.915 \\
\hline Rear & (kg) & & 2,973 & 3,328 & & 3,665 & 4,055 & 3,630 & & 3,730 \\
\hline Steering system & & Rear-wheel & Rear-wheel & Rear-wheel & Rear-wheel & Rear-wheel & Rear-wheel & Rear-wheel & Articulation & Articulation \\
\hline Wheelbase & $(\mathrm{cm})$ & 392 & 332.5 & 332.5 & 259 & 259 & 259 & 259 & 280 & 280 \\
\hline \multicolumn{11}{|l|}{ Engine } \\
\hline Type & & DB3IC & UD6 & UD6 & UD6 & UD6 & UD6 & PD6T & PD6T & PD6T \\
\hline Rated output & (hp/rpm) & $102 / 1800$ & $170 / 1800$ & $170 / 1800$ & $170 / 1800$ & $170 / 800$ & $170 / 1800$ & $201 / 1800$ & $213 / 2000$ & $213 / 2000$ \\
\hline \multicolumn{11}{|l|}{ Tires } \\
\hline Front & & $14.00-24-10$ & $9.00-20-14$ & $9.00-20-14$ & $12.00-20-14$ & $12.00-20-14$ & $12.00-20-14$ & $12.00-20-14$ & $12.00-20-14$ & $12.00-20-14$ \\
\hline Rear & & $18.00-25-16$ & $9.00-20-14$ & $9.00-20-14$ & $12.00-20.14$ & $12.00-20-14$ & $12.00-20-14$ & $12.00-20-14$ & $12.00-20-14$ & $12.00-20-14$ \\
\hline Blower System & & Two-stage & Two-stage & Two-stage & Two-stage & Two-stage & Two-stage & Two-stage & Two-stage & Two-stage \\
\hline Auger type & & Ribbon screw & Ribbon screw & Ribbon screw & Ribbon screw & Ribbon screw & Ribbon screw & Ribbon screw & Ribbon screw & Ribbon screw \\
\hline Diameter & $(\mathrm{cm})$ & & 120 & 120 & 120 & 120 & 120 & 120 & 120 & 120 \\
\hline Width & $(\mathrm{cm})$ & & 225 & 225 & 235 & 235 & 235 & 237.6 & 237.6 & 237.6 \\
\hline Speed & $(\mathrm{rpm})$ & & 150,193 & 150,193 & 146,181 & 150,183 & 128,156 & 128,156 & 131,164 & 131,164 \\
\hline Blower type & & Rotary & Rotary & Rotary & Rotary & Rotary & Rotary & Rotary & Rotary & Rotary \\
\hline Diameter & $(\mathrm{cm})$ & & 110 & 110 & 110 & 110 & 109 & 109 & 109 & 109 \\
\hline Depth & $(\mathrm{cm})$ & & 50 & 50 & 40 & 47 & 47 & 47 & 44.5 & 44.5 \\
\hline Speed & (rpm) & 315,406 & 315.406 & 265.331 & 273.334 & 273.334 & 273.334 & 273,334 & 281.352 & 281,352 \\
\hline
\end{tabular}




\section{REPORT DOCUMENTATION PAGE}

Public reporting burden for this collection of information is estimated to average 1 hour per response, including the time for reviewing instructions, searching existing data sources, gathering and maintaining the data needed, and completing and reviewing the collection of information. Send comments regarding this burden estimate or any other aspect of this collection of information, including suggestion for reducing this burden, to Washington Headquarters Services, Directorate for Information Operations and Reports, 1215 Jefferson Davis Highway, Suite 1204, Arlington, VA 22202-4302, and to the Office of Management and Budget, Paperwork Reduction Project (0704-0188), Washington, DC 20503.

\begin{tabular}{|l|l|l|}
\hline 1. AGENCY USE ONLY (Leave blank) & 2. REPORT DATE & 3. REPORT TYPE AND DATES COVERED
\end{tabular}

September 1990

4. TITLE AND SUBTITLE

Highway Snow Control Research in Japan

PE: 4A161102AT24

TA: SS

6. AUTHORS

WU: 006

Kazuhiko Itagaki

7. PERFORMING ORGANIZATION NAME(S) AND ADDRESS(ES)

8. PERFORMING ORGANIZATION

REPORT NUMBER

U.S. Army Cold Regions Research and Engineering Laboratory

72 Lyme Road

Special Report 90-33

Hanover, New Hampshire 03755-1290

10. SPONSORING/MONITORING

9. SPONSORING/MONITORING AGENCY NAME(S) AND ADDRESS(ES) AGENCY REPORT NUMBER

Office of the Chief of Engineers

Washington, D.C. 20314-1000

11. SUPPLEMENTARY NOTES

12a. DISTRIBUTION/AVAILABILITY STATEMENT

12b. DISTRIBUTION CODE

Approved for public release; distribution is unlimited.

Available from NTIS, Springfield, Virginia 22161.

\section{ABSTRACT (Maximum 200 words)}

The wide range of Japanese efforts to control snow and ice on highways is reviewed. Many studies parallel U.S. and European research, but extensive basic studies of applications of modern high technology are noted as well.

\begin{tabular}{|c|c|c|}
\hline $\begin{array}{l}\text { 14. SUBJECT TERMS } \\
\text { Economic impact } \\
\text { Forecast } \\
\text { Highway }\end{array}$ & $\begin{array}{l}\text { Japan } \\
\text { Snow and ice control } \\
\text { Snow melting facilities }\end{array}$ & $\begin{array}{l}\text { Snow removal } \\
\text { Sociological impact } \\
\text { Trafficability }\end{array}$ \\
\hline $\begin{array}{l}\text { 17. SECURITY CLASSIFICATION } \\
\text { OF REPORT } \\
\text { UNCLASSIFIED }\end{array}$ & $\begin{array}{l}\text { 18. SECURITY CLASSIFICATION } \\
\text { OF THIS PAGE } \\
\text { UNCLASSIFIED }\end{array}$ & $\begin{array}{l}\text { 19. SECURITY CLASSIFICATION } \\
\text { OF ABSTRACT } \\
\text { UNCLASSIFIED }\end{array}$ \\
\hline
\end{tabular}

15. NUMBER OF PAGES 65

16. PRICE CODE

20. LIMITATION OF ABSTRACT

UL 